\title{
Proceso de Conceptualización del Entendimiento del Negocio para Proyectos de Explotación de Información
}

\author{
Federico Carlos Peralta ${ }^{1,2,3}$ \\ 1. Programa de Maestría en Ingeniería de Sistemas de Información. Universidad Tecnológica Nacional. FRBA \\ 2. Grupo de Investigación en Sistemas de Información. Universidad Nacional de Lanús. Argentina. \\ 3. Laboratorio de Investigación y Desarrollo en Tecnologías de Computación Gráfica y Arte Digital. Universidad Nacional de Río \\ Negro. Argentina. \\ peralta.federico@yahoo.com.ar
}

\begin{abstract}
Resumen-La disponibilidad y análisis de la información son esenciales para garantizar la correcta toma de decisiones. Debido al excesivo volumen de datos de una organización, resulta imprescindible estructurar y categorizar la masa de información que debe ser relevada para alcanzar la comprensión del negocio. Es fundamental identificar la información crítica para el negocio y obtener la misma desde el comienzo del proyecto de manera sistemática y articulada. En base a la información relevada, el responsable del proyecto podrá realizar estimaciones válidas y gestionar correctamente cada una de las tareas y actividades del proyecto. Cualquier proyecto de software puede fracasar como consecuencia de un entendimiento incorrecto del negocio, lo cual puede tener un fuerte impacto en la operación del negocio respectivo. En este contexto, se propone la construcción de un proceso de conceptualización del entendimiento del negocio para proyectos de Explotación de Información.
\end{abstract}

Palabras Clave-Explotación de Información, Entendimiento del Negocio, Modelo de Proceso, Proyecto.

\section{INTRODUCCIÓN}

En esta sección, se plantea el contexto del trabajo de investigación (sección I.A), se establecen los objetivos (sección I.B): general (sección I.B.1) y específicos (sección I.B.2), se define el alcance del proyecto (sección I.C), se especifican los fundamentos del trabajo (sección I.D), se describe la metodología de desarrollo empleada (sección I.E), y por último, se resume la estructura general del mismo (sección I.F).

\section{A. Contexto de la Investigación}

El uso adecuado de las Tecnologías de Información y Comunicación (TIC's) se ha convertido en un elemento estratégico en términos de competitividad para las distintas organizaciones dentro del proceso de la globalización [1].

Las organizaciones actuales toman sus decisiones, cada vez más, basándose en el conocimiento procedente de los datos almacenados en sus bases o almacenes de datos. Conceptos conocidos como "Explotación de Datos", "Inteligencia de Negocios" y "Gestión del Conocimiento", se están desarrollando a un ritmo muy acelerado [2].

La Explotación de Información es una disciplina que ha mostrado una gran evolución en los últimos años. Las organizaciones han comenzado a analizar y explotar grandes masas de información, residentes en sus sistemas informáticos, con el propósito de obtener nuevos conocimientos a partir de las mismas. Su principal objetivo es descubrir información oculta o implícita, que no es posible conseguir mediante la utilización de métodos estadísticos convencionales [3; 4].

Existe tanta información en una organización que es indispensable identificar cuál es la información que tiene un mayor impacto en las operaciones del negocio [5]. En tal sentido, resulta importante informar, entender y manejar el dominio de la información y los procesos específicos, para comprender el fin y llevar a cabo una correcta gestión de requerimientos basada en el entendimiento de las actividades de cualquier organización [1].

En los últimos años, la diversidad, el número y la complejidad de los proyectos de Explotación de Datos ha aumentado ligeramente, lo que hace que los procesos para el desarrollo de este tipo de proyectos tengan que estandarizarse para lograr resultados que puedan ser integrados, reutilizados e intercambiados en un futuro [6].

Se han ido desarrollando diversas metodologías que posibilitan gestionar la complejidad de proyectos de Explotación de Información de una manera uniforme. Actualmente, la comunidad científica considera ya probadas las metodologías SEMMA, CRISP-DM y $\mathrm{P}^{3} \mathrm{TQ}$ [7].

\section{B. Objetivos del Trabajo}

1) Objetivo General

- Desarrollar un modelo de proceso de conceptualización del entendimiento del negocio para proyectos de Explotación de Información.

2) Objetivos Específicos

- Identificar y contextualizar la temática objeto de estudio.

- Describir y comparar las distintas metodologías existentes que aplican a proyectos de Explotación de Información.

- Establecer los elementos teóricos que respaldan la construcción de un estado de la cuestión sobre un modelo de proceso de conceptualización del entendimiento del negocio.

- Desarrollar el nuevo modelo y definir correctamente sus fases, tareas y productos.

- Identificar las técnicas adecuadas aplicables al nuevo modelo.

- Realizar la prueba de concepto con el objeto de validar los procesos y conceptos definidos.

\section{Alcance de la Investigación}

Los alcances del trabajo se detallan a continuación: 
En primer lugar, se plantea el desarrollo de un modelo de proceso de conceptualización del entendimiento del negocio para proyectos de Explotación de Información, como base de la comprensión conceptual y de procesos de la organización, lo cual justifica la creación de un modelo para este tipo de proyectos.

Al mismo tiempo, se busca justificar el uso de un modelo de proceso de conceptualización para lograr la educción del entendimiento del negocio, indicando las ventajas que acarreará su implementación en una organización empresarial.

Se incluye también, una descripción de las principales metodologías utilizadas en proyectos de Explotación de Información, estableciendo un marco de referencia para el desarrollo del nuevo modelo.

Adicionalmente, se describe una protofase que articula un conjunto de técnicas y herramientas asociadas para lograr el entendimiento del negocio [8]. Se prevé utilizar la misma como base para la confección del nuevo modelo de proceso que contemple la definición de las fases, tareas y productos necesarios para alcanzar dicho conocimiento, y la utilización de las técnicas adecuadas aplicables al modelo en cuestión.

Finalmente, se desarrolla un modelo de proceso de conceptualización del entendimiento del negocio para proyectos de Explotación de Información y se realiza la prueba de concepto con el objeto de validar los procesos y conceptos definidos en el presente trabajo de investigación.

\section{Fundamentación}

Año tras año, las empresas pierden muchísimo dinero, su credibilidad falla, la insatisfacción de los clientes se acrecienta y todo ello como consecuencia de la mala calidad de los datos con que toman sus decisiones, o que simplemente, utilizan para llevar a cabo sus operaciones [5].

El responsable del proyecto debe disponer de la información apropiada para garantizar una correcta toma de decisiones, y consecuentemente, permita lograr el cumplimiento efectivo de los objetivos propuestos.

En tal sentido, el problema abierto que se identifica consiste en la necesidad de estructurar y categorizar la masa de información que debe ser relevada para lograr el entendimiento del negocio para proyectos de Explotación de Información que contribuya a realizar una administración exitosa en este tipo de proyectos.

Es importante dar solución al problema existente para poder hacer inferencias válidas y evitar tomar decisiones erróneas, que puedan ocasionar severas consecuencias, tales como: la cancelación del proyecto, productos finales inservibles o defectuosos, insatisfacción por parte del cliente, tensión laboral entre los distintos departamentos de la empresa y líneas de autoridad, retraso en los entregables, despidos, pérdida de credibilidad, etc.

Por tal motivo, resulta sumamente beneficioso contar con un modelo de proceso de conceptualización del entendimiento del negocio que pueda ser utilizado para proyectos de Explotación de Información y guíe al responsable del proyecto en el abordaje de dicho conocimiento, y a su vez, favorezca una organización adecuada del proyecto que permita su propia gestión y control.

\section{E. Metodología de Desarrollo}

Se siguen los siguientes pasos lógicos para alcanzar el conocimiento de forma sistemática y ordenada, como parte de la metodología para el desarrollo del proyecto planteado, contemplando distintos aspectos necesarios para el cumplimiento efectivo de los objetivos propuestos:

En primer lugar, se lleva a cabo una investigación documental acerca del conocimiento denominado "Entendimiento del Negocio" [9;8], el uso de técnicas para la educción de dicho conocimiento y las principales metodologías de Explotación de Información. La revisión bibliográfica incluye artículos de revistas especializadas y de trabajos presentados en congresos, diversos libros, investigaciones llevadas a cabo por organismos de prestigio internacional, sitios web de entidades e instituciones vinculadas con la temática objeto de estudio, etc.

En segundo lugar, se realiza la construcción de un marco teórico para avanzar en el desarrollo del modelo de proceso de conceptualización del entendimiento del negocio; con base en el estudio de lo recopilado durante el ejercicio previo y en función de la información procesada, se consolida el informe final del estado de arte del proyecto.

En tercer lugar, se plantea la problemática de investigación del presente trabajo, a partir de la complejidad que involucra la comprensión clara del dominio del negocio en proyectos de Explotación de Información.

En cuarto lugar, y considerando la información procesada previamente, se diseña el nuevo modelo de proceso y se definen las fases, las tareas y los productos respectivos. Adicionalmente, se identifican las técnicas adecuadas aplicables al nuevo modelo para alcanzar la comprensión del negocio, modelando las mismas en función de los objetivos trazados.

Luego de abordar el análisis y diseño del nuevo modelo de proceso, se documenta la solución propuesta para la problemática descripta, proporcionando información útil sobre el modelo de proceso que se ha creado.

Una vez elaborada dicha solución, se realiza la prueba de concepto respectiva, con el objeto de validar los procesos y conceptos definidos en el presente trabajo.

Por último, una vez cumplidas las etapas anteriores, se consolida toda la información y se redacta la memoria final de la investigación.

\section{F. Estructura del Trabajo}

En la sección I (Introducción), se plantea el contexto del trabajo de investigación, se establecen los objetivos generales y específicos del mismo, se define el alcance del proyecto, se especifican los fundamentos del trabajo, se describe la metodología de desarrollo empleada, y por último, se resume la estructura general del mismo.

En la sección II (Estado del Arte), se aborda el tratamiento del conocimiento denominado "Entendimiento del Negocio" [9;8] que engloba diversas cuestiones, tales como son: la etimología de la palabra negocio, la conceptualización del negocio, los procesos de negocio, el modelado de procesos de negocio, el entendimiento del negocio propiamente dicho, y adicionalmente, se mencionan las ventajas asociadas al proceso de educción de dicho conocimiento. Luego, se realiza una breve introducción al área de Explotación de Información. A continuación, se describe en forma detallada cada una de las tres metodologías principales que se utilizan para proyectos de Explotación de Información: CRISP-DM, $\mathrm{P}^{3} \mathrm{TQ}$ y SEMMA, y se realiza una comparación entre todas ellas. Posteriormente, se exponen algunos lineamientos generales sobre la comprensión del negocio y los proyectos Explotación de Información. También, se introduce una protofase que articula un conjunto de técnicas y herramientas asociadas para lograr la 
comprensión del negocio desarrollada en [8], efectuando un estudio descriptivo de la misma, la cual constituye la base para la construcción del modelo propuesto.

En la sección III (Descripción del Problema), se plantea la problemática identificada, razón por la cual se lleva a cabo este trabajo de investigación. También, se describe la utilidad de lograr un adecuado entendimiento del negocio para el responsable del proyecto y otros miembros del equipo lo cual permite inferir la importancia de resolver el problema planteado, y finalmente se formulan las preguntas de investigación del proyecto.

En la sección IV (Solución), se desarrolla la solución propuesta y planteada para la problemática descripta. En primer lugar, se describe la propuesta, y luego se realiza la descripción de la solución planteada basada en la propuesta enunciada.

En la sección V (Prueba de Concepto), se presenta un caso de prueba donde se aplica la solución desarrollada en el presente trabajo de investigación.

En la sección VI (Conclusiones), se documentan las conclusiones más importantes de este trabajo en cuanto a la valoración sobre la investigación documental, valoración del problema, valoración de la solución, valoración del caso de estudio y la respuesta a los interrogantes planteados, que constituyen el balance final de esta investigación. Asimismo, se sugieren futuras líneas de investigación.

En la sección VII (Referencias Bibliográficas), se listan las referencias bibliográficas utilizadas en el presente trabajo.

\section{ESTADO DE LA CUESTIÓN}

En esta sección, se abordan diversas cuestiones referidas al tratamiento del conocimiento denominado "Entendimiento del Negocio" $[9 ; 8]$, con el fin de obtener un panorama claro y preciso acerca del tema en cuestión (sección II.A), tales como son: la etimología de la palabra negocio (sección II.A.1), la conceptualización del negocio (sección II.A.2), los procesos de negocio (sección II.A.3), el modelado de procesos de negocio (sección II.A.4), el entendimiento del negocio propiamente dicho (sección II.A.5), y adicionalmente, se mencionan las ventajas asociadas al proceso de educción de dicho conocimiento (sección II.A.6). Luego, se realiza una breve introducción al área de Explotación de Información (sección II.B). A continuación, se describen las principales metodologías que se utilizan para este tipo de proyectos: CRISP-DM (sección II.B.1), $\mathrm{P}^{3}$ TQ (sección II.B.2) y SEMMA (sección II.B.3), realizando un estudio comparativo entre todas ellas (sección II.B.4). Posteriormente, se exponen algunos lineamientos generales sobre la comprensión del negocio y los proyectos Explotación de Información (sección II.C). Por último, se efectúa un análisis descriptivo de una protofase metodológica que articula un conjunto de técnicas y herramientas asociadas para lograr la comprensión del negocio desarrollada en [8], la cual constituye la base para la construcción del modelo propuesto en este trabajo de investigación (sección II.D).

\section{A. Entendimiento del negocio}

\section{1) Etimología de la Palabra Negocio}

El término negocio proviene de las palabras en latín nec y otium, es decir lo que no es ocio, e implica acción o movimiento, y constituye el elemento central a gestionar, si se persigue el éxito de cualquier organización [10].

Para los romanos, la palabra otium era lo que se realizaba en el tiempo libre, sin ningún tipo de recompensa; por consiguiente, negocio para ellos era lo que se hacía por dinero [11].

\section{2) ¿Qué es el Negocio?}

El negocio es un sistema complejo, está compuesto por una organización en la cual generalmente se diferencian elementos tangibles e intangibles, tales como son los equipos de trabajo formales y las funciones que estos desempeñan. Algunas de las funciones que se distinguen, sólo se llevan a cabo en un sólo departamento o sección de la organización respectiva, mientras que otras tantas son comunes a diversos departamentos de la misma [1].

Las empresas son estructuras formales, que se construyen para llevar adelante un negocio determinado, pudiendo ser creadas para perdurar en el tiempo o bien, por el contrario, para explotar un negocio por un período de tiempo determinado [12].

Por otra parte, se considera que un negocio es mucho más que un simple producto o un servicio determinado, añadiendo que el negocio se define en base a su misión, sus objetivos, las estrategias a implementar para alcanzar los mismos, sus competidores, sus clientes y los productos o servicios que ofrece [8].

\section{3) Proceso de Negocio}

Para alcanzar sus objetivos, una empresa organiza sus actividades por medio de un conjunto de procesos denominados "Procesos de Negocios". Cada uno de ellos involucra un conjunto de datos que son producidos $\mathrm{y}$ procesados mediante una serie de tareas específicas, en la que intervienen determinados agentes (como pueden ser los empleados o departamentos de la propia organización), de acuerdo a un flujo de trabajo determinado. Asimismo, todos estos procesos se hallan regulados por un conjunto de reglas de negocio, que determinan la estructura de la información y las políticas respectivas de la propia empresa $[13 ; 14]$.

En la actualidad, las empresas y la comunidad científica están centrado su atención a los procesos de negocio, ya que reconocen que ellos constituyen un recurso fundamental para el desempeño y la obtención de ventajas competitivas en el mercado [15].

De acuerdo con [16], los procesos de negocio están centrados en el mercado. Por consiguiente, se deben revisar y ajustar los mismos de manera constante para incorporar posibles mejoras que permitan: mejorar la calidad de los productos o servicios, aumentar la satisfacción del cliente, reducir costos, optimizar la eficiencia en las operaciones del negocio, encontrar nuevos negocios $u$ oportunidades para reemplazar servicios o productos existentes o bien introducir nuevos [15].

A pesar de la importancia que tienen los procesos de negocios, la gran mayoría de las organizaciones no representa esquemáticamente cómo son sus procesos. Es decir, no es una práctica habitual que los mismos sean representados mediante modelos, y en tal sentido, que sirvan para la confección de una base que facilite la toma de decisiones. Asimismo, la gran mayoría de los modelos no consideran los sistemas informáticos que apoyan las actividades de sus procesos de negocio, a pesar de ser un aspecto fundamental de cómo se realiza el trabajo en el ámbito empresarial. Por el contrario, aquellos modelos que sí lo hacen, sólo consideran este aspecto implícitamente o bien de una manera insuficiente [17].

\section{4) Modelado de Procesos de Negocio}

Básicamente, el método tradicional utilizado para representar un negocio es dibujar un mapa de la organización, dividiendo la empresa en un número definido de secciones o 
departamentos, como por ejemplo: ventas, compras, manufactura, producción, investigación y desarrollo, etc., de acuerdo a la estructura organizacional que se necesita documentar. Sin embargo, pese a la simplicidad de dicha técnica, la misma no facilita una visión integral de la organización correspondiente, y con frecuencia, la documentación generada es incompatible, repetida o nula [1].

Según la Object Management Group, Inc. (OMG), el Modelado de Procesos de Negocio describe las actividades esenciales de la organización y cómo estas se relacionan e interactúan con los recursos específicos del negocio para alcanzar la meta establecida para el proceso respectivo [18].

De acuerdo con [19], el modelo de negocio debe focalizarse principalmente en las tareas y mecanismos claves del negocio [1].

Siguiendo con la misma línea de trabajo, en [1] se menciona que existen varios argumentos que justifican la construcción de modelos de negocio, los cuales se detallan a continuación:

\section{Sirven como base para el desarrollo de sistemas de} información.

Las descripciones del negocio son utilizadas como base para crear los sistemas de información que son necesarios para soportar los procesos de la organización. Asimismo, a partir de la información relevada, se especifican los requerimientos clave de estos sistemas para el normal funcionamiento de los mismos.

Permiten una mejor comprensión de los mecanismos principales del negocio existente.

Los modelos de negocio pueden usarse para llevar adelante programas de capacitación al personal de la propia organización. Es importante definir correctamente los roles y las tareas en la organización global para evitar inconvenientes que impidan lograr el cumplimiento efectivo de los objetivos del negocio.

Posibilitan experimentar con un nuevo concepto de negocio.

A un modelo determinado se le puede aplicar ciertas pruebas con el objetivo de validar su operación, convirtiendo el mismo en un medio oportuno para la adopción de buenas prácticas inspiradas por otros modelos de negocio exitosos. También permite aplicar nuevas tecnologías, lo cual representa una clara ventaja (por ejemplo, las relacionadas con Internet).

\section{Permiten identificar nuevos negocios.}

Aquellos elementos que no se consideran parte de la estructura central del negocio, son delegados a otros proveedores externos. En este sentido, los modelos de procesos son utilizados como base para la especificación para dichos proveedores. Esta situación, facilita la identificación de nuevas oportunidades, tales como son los proyectos de Outsourcing.

Facilitan la identificación de ideas para optimizar la estructura actual del negocio y sus operaciones.

Los modelos de negocio permiten identificar escenarios que pueden ser mejorados, de manera tal que pueden concebirse cambios en el negocio actual, los cuales son necesarios para llevar a cabo el desarrollo y la implementación del nuevo modelo de negocio mejorado, con el propósito de optimizar los procesos involucrados. La creación de un modelo implica entender por qué se hacen las cosas como se hacen.

\section{Muestran la estructura del negocio mejorado.}

Los modelos sirven para mostrar ante la gerencia la nueva solución, de manera concreta. A partir de este punto, es posible precisar nuevas acciones para llevar a cabo la propuesta presentada; por consiguiente, los modelos constituyen la base para los futuros planes de acción que apoyarán la transformación del negocio.

Un modelo global de negocio puede ser utilizado para definir qué sistemas de información son necesarios, cómo deben ser construidos y qué funcionalidad deben poseer. Existe una altísima probabilidad de que el sistema de información soporte adecuadamente las operaciones del negocio, si la especificación de requerimientos se realizó en base a un buen modelo de negocio [1].

Adicionalmente, en [1] se mencionan una serie de ventajas para desarrollar todos los sistemas de información a partir de un mismo modelo básico de negocio, a saber:

- Los sistemas informáticos permiten soportar las operaciones del negocio de manera adecuada, mejorando el trabajo y los resultados obtenidos. Estos se vuelven una parte integral del negocio global.

- Se facilita la actualización de los sistemas de información, de acuerdo a los cambios que experimenta el modelo de negocio. Esto disminuye el costo de mantenimiento de los mismos.

- Se pueden reducir costos y el esfuerzo de desarrollo en otros sistemas a partir de la reutilización de la lógica del negocio identificada.

- Los sistemas pueden compartir o intercambiar información, ya que se facilita la integración entre ellos.

- De acuerdo con [20], el desarrollo de cualquier modelo permite incrementar el conocimiento que se tiene del negocio en cuestión, y a su vez, facilita la comunicación entre las partes involucradas. En este sentido, un modelo visual permite ser comprendido y discutido con mayor facilidad que una descripción netamente textual. Este tipo de modelos constituye una fotografía actual de cómo se percibe el negocio. En términos generales, un modelo sirve de base para desarrollar las herramientas tecnológicas que soportan a los distintos procesos de negocio, y por ende, contribuye al éxito de los proyectos. Asimismo, los modelos pueden ser utilizados para realizar programas de capacitación al personal correspondiente sobre la temática en cuestión [1].

5) Entender el Negocio

Existe un tipo especial de conocimiento llamado "Entendimiento del Negocio" al cual hacen referencia las metodologías de desarrollo de sistemas de información. A pesar que en algunas de ellas se expone dicho conocimiento, se hace evidente la falta de información acerca de las herramientas que integran el soporte específico del proceso de educción y los parámetros involucrados en el proceso respectivo para alcanzar la comprensión del negocio. Asimismo, se desconoce la información relevante a manejar para lograr una comprensión adecuada del negocio ya que estas metodologías no describen dicha información. Por el contrario, todas las metodologías de desarrollo de proyectos de software dan por garantizado el conocimiento que se tiene del dominio del negocio, sin facilitar al ingeniero los instrumentos necesarios para abordar de manera precisa el entendimiento del entorno de trabajo $[9 ; 8]$.

Siguiendo con la misma línea de trabajo, en [8] se presenta una protofase que articula un conjunto de técnicas y herramientas asociadas para lograr la educción del entendimiento del negocio, independientemente del sistema de información a desarrollar, ya sea que se trate de un sistema basado en conocimiento, un sistema de gestión tradicional o bien, un sistema de Explotación de Información.

De acuerdo con [21], la tecnología de información es una parte integral de las operaciones diarias de un gran número de 
empresas. Asimismo, se menciona que actualmente, la mayoría de los negocios utilizan algún tipo particular de sistemas de información; sin embargo, muchas compañías no están conformes con la calidad de los mismos, aduciendo que son difíciles de manejar, son poco confiables, ofrecen un soporte de negocio incompleto $\mathrm{u}$ obsoleto, y no se complementan con otros sistemas adicionales. En la mayoría de los casos, esto es consecuencia de un entendimiento incorrecto del negocio al momento de llevar a cabo el desarrollo de estos sistemas. Esto es común en aquellas empresas que usan numerosos sistemas informáticos pequeños, que aunque soportan ciertos procesos del negocio, funcionan de manera autónoma, de manera tal que es usual que la información generada por dichos sistemas sea inconsistente [1].

Por tanto, en base a lo expresado en el párrafo anterior, se concluye que un entendimiento adecuado del negocio contribuye al desarrollo de estos sistemas de información.

\section{6) Ventajas Asociadas al Entendimiento del Negocio}

La comprensión adecuada del negocio aporta una serie de ventajas a la hora de llevar adelante el desarrollo de un proyecto, facilitando el cumplimiento efectivo de los objetivos propuestos. Por el contrario, un entendimiento insuficiente o inapropiado del dominio del negocio puede ocasionar una serie de trastornos durante el ejercicio del mismo.

El entendimiento correcto del negocio ayuda a la construcción e implementación de la solución a desarrollar, y a su vez, condiciona el desarrollo del proyecto en cuestión. Cualquier proyecto de software puede no ser exitoso como consecuencia de una mala comprensión del negocio por parte de aquellas personas encargadas del manejo de dicha información. En tal sentido, la comprensión del negocio constituye el punto de inicio para lograr una adecuada organización del proyecto que permita llevar a cabo su propia gestión y administración [22].

Se debe descartar toda aquella información que resulte redundante u equívoca. En este sentido, disponer de la información apropiada permite realizar estimaciones efectivas y es esencial en el proceso de toma de decisiones. En [23] se informa que diversas estimaciones pueden ser realizadas por parte del responsable del proyecto teniendo en cuenta el mapa de actividades establecido, tales como son:

- Tiempo de ejecución del mismo.

- Costo económico.

- Cantidad de recursos necesarios.

- Perfiles de RRHH.

- Habilidades para realizar determinadas tareas.

- sfuerzo demandado.

Asimismo, se debe evitar la ejecución de actividades innecesarias, seleccionando aquellas que permitan satisfacer las necesidades del proyecto en cuestión [23]. De acuerdo con [24; $25]$, en función de las características propias del proyecto, las actividades se seleccionan o descartan [26].

En tal sentido, resulta muy importante lograr un adecuado entendimiento del negocio, para definir correctamente las fases, tareas y actividades necesarias para cumplir con los objetivos establecidos.

Un entendimiento apropiado del negocio permite alcanzar los objetivos trazados, logrando la satisfacción del cliente; por consiguiente, se obtiene confianza y aceptación por parte de los miembros de la organización, lo cual permite lograr un mejor posicionamiento frente a potenciales competidores para obtener la renovación de los contratos existentes, o bien para adjudicarse futuras licitaciones de nuevos proyectos (por ejemplo, en proyectos de Outsourcing).
De acuerdo con [27], a partir del relevamiento y la documentación apropiada de la información del negocio, tales como son: los objetivos, las entradas, las salidas, los recursos necesarios, las actividades a desarrollar, etc., se pueden definir los parámetros necesarios para especificar los requerimientos de un sistema de información determinado que apoye al proceso respectivo para la correcta toma de decisiones en un negocio [1]

\section{B. Explotación de Información}

Los proyectos de Explotación de Información difieren de forma sustancial de los proyectos de desarrollo de software tradicionales, encontrándose características muy distintas entre ambos tipos de proyectos. Por consiguiente, las herramientas utilizadas en los procesos de Ingeniería de Software tradicional, tales como son: los modelos de procesos, la ingeniería de requerimientos, los ciclos de vida y los mapas de actividades, no son aplicables a este tipo de proyectos [28; 29].

De acuerdo con $[30 ; 31 ; 32]$, la diferencia entre los proyectos de Explotación de Información y los proyectos de desarrollo de software tradicional se presenta en los procesos respectivos de desarrollo y mantenimiento, en los cuales las etapas o fases clásicas de inicio, requisitos, análisis y diseño, construcción, integración y pruebas no resultan naturales en los proyectos de Explotación de Información [29].

Un proceso de Explotación de Información permite la extracción de conocimiento no-trivial que reside de manera implícita en los datos disponibles en diversas fuentes de información a partir de la ejecución de un conjunto de tareas que se relacionan lógicamente [33]. La entrada a dicho proceso está constituida generalmente por registros procedentes de bases de datos operacionales o bien almacenes de datos (Datawarehouse) [3; 4]. Normalmente, no son los datos en sí lo más importante para el responsable de un sistema, o para un especialista, sino el conocimiento que se encuentra contenido en sus fluctuaciones, dependencias y relaciones [7].

La Explotación de Información se basa en la búsqueda de patrones relevantes en un conjunto de datos mediante la utilización de técnicas informáticas (Redes Neuronales, Inteligencia Artificial, Algoritmos Genéricos, Sistemas Expertos, etc.), como estadísticas (Regresión, Análisis de Varianza, Análisis de Agrupamiento o Clustering, Prueba ChiCuadrado, Series de Tiempo, Análisis Discriminante, etc.) [34].

En [7] se menciona que se han ido desarrollando diversas metodologías que permiten gestionar de una manera uniforme la complejidad de proyectos de Explotación de Información. La comunidad científica considera validadas las metodologías SEMMA, CRISP-DM y $\mathrm{P}^{3} \mathrm{TQ}$.

\section{1) Metodología CRISP-DM}

La metodología CRISP-DM fue creada por el grupo de empresas SPSS, NCR y Daimler Chrysler en el año 2000. Esta metodología constituye la guía de referencia más utilizada en el desarrollo de proyectos de Explotación de Datos [3; 4]. La metodología CRISP-DM consiste en un modelo jerárquico de procesos, constituido por un conjunto de tareas organizadas en cuatro niveles de abstracción, que van desde el nivel más general hasta los casos más específicos (figura 1) [35].

A nivel más general, CRISP-DM organiza el desarrollo de un proyecto de Explotación de Datos, en una serie de 6 fases, que constituyen el primer nivel de abstracción (ver figura 3). Cada una de las fases se encuentra organizada en varias tareas genéricas de segundo nivel o sub-fases. A partir de estas tareas genéricas, se desarrolla el tercer nivel, en el cual se proyectan las tareas especializadas, donde se describen cómo las acciones 
de las tareas genéricas deben llevarse a cabo en situaciones específicas.

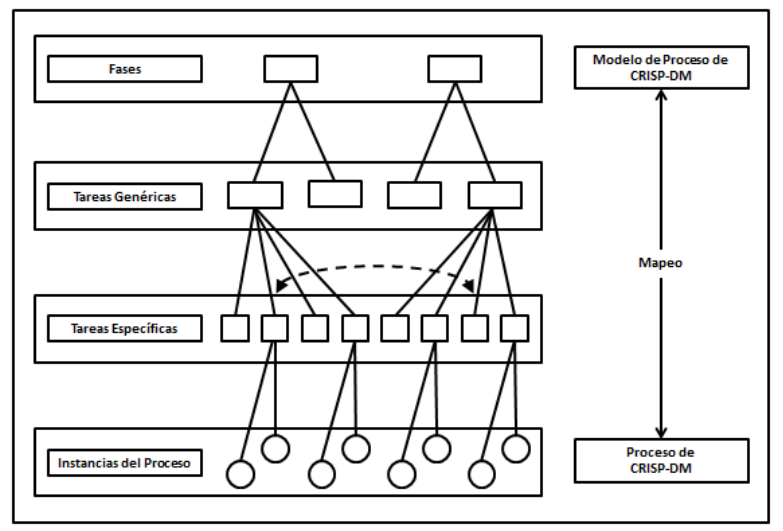

Fig. 1. Niveles de abstracción de la metodología CRISP-DM [35].

El cuarto y último nivel, agrupa el conjunto de acciones, decisiones y resultados sobre el proyecto de Explotación de Información en cuestión [35].

La metodología CRISP-DM aporta al usuario documentación adicional que será utilizada como herramienta de ayuda en el desarrollo del proyecto de Explotación de Información: el modelo de referencia y la guía del usuario [35].

El documento del modelo de referencia proporciona información acerca de las fases, tareas generales y salidas de un proyecto de Explotación de Información en general. Por tanto, la guía del usuario brinda información detallada sobre cada fase, proporcionando consejos y listas de comprobación sobre las tareas correspondientes a cada fase. De hecho, describe cómo realizar un proyecto de Explotación de Datos [35].

Como se puede observar en la figura 2, la metodología CRISP-DM estructura el ciclo de vida de un proyecto en seis fases; las flechas indican las relaciones más usuales e importantes entre ellas, aunque se pueden establecer distintas relaciones entre las distintas fases componentes. El círculo exterior simboliza la naturaleza cíclica del modelo de proceso de Explotación de Datos propiamente dicho. La secuenciación de fases no es rígida. Las fases definidas para un proyecto de desarrollo de software clásico (inicio, requerimientos, análisis $\mathrm{y}$ diseño, construcción, integración y pruebas y cierre) claramente difieren de las fases propias de esta metodología [35].

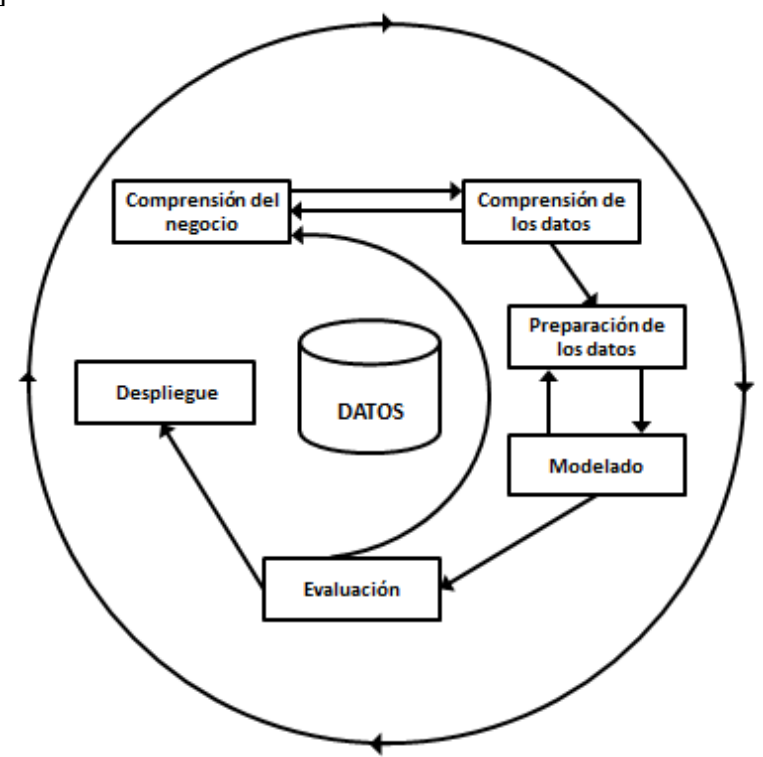

Fig. 2. Fases del modelo de proceso de la metodología CRISP-DM [35].
En [35] se hace referencia a las fases de la metodología CRISP-DM:

\section{Fase I - "Comprensión del negocio"}

Esta primera fase inicial, se basa en el entendimiento de los objetivos del proyecto y la comprensión de los requerimientos del mismo desde el punto de vista del negocio, a fin de definir el problema a resolver y diseñar una planificación preliminar para el cumplimiento efectivo de los objetivos en cuestión.

\section{Fase II - "Comprensión de los datos"}

La segunda fase de análisis, comienza con la recolección inicial de los datos con el propósito de familiarizarse con los mismos, identificando problemas de calidad asociados a ellos e información adicional relevante para la formulación de las primeras hipótesis.

\section{Fase III - "Preparación de los datos"}

La fase de preparación de los datos, abarca todas aquellas actividades destinadas a la construcción del conjunto de datos finales. Las tareas de esta fase pueden ser ejecutadas varias veces, sin un orden predefinido. Las mismas incluyen la selección de tablas, registros y atributos, así como también la transformación y limpieza de datos para que puedan ser tratados por las herramientas de modelado.

\section{Fase IV - "Modelado"}

En esta fase, se seleccionan y aplican las técnicas de modelado más apropiadas para el proyecto en cuestión, calibrando sus parámetros a valores óptimos. Básicamente, existen varias técnicas para un mismo tipo de problemas en proyectos de Explotación de Datos. Algunas de ellas, demandan requerimientos específicos sobre los datos que se van a procesar, por tal motivo muchas veces es necesario volver a la fase de preparación de los datos antes de avanzar con el modelado de los mismos.

\section{Fase V - "Evaluación"}

Esta fase, involucra la evaluación del modelo y revisión de los pasos ejecutados en relación a los objetivos del negocio, $\mathrm{y}$ busca determinar si hay alguna razón de negocio para el cual el modelo es deficiente, asegurándonos de esta forma, alcanzar los objetivos inicialmente propuestos. Al final de esta fase, se debe tener una decisión sobre el uso de los resultados alcanzados.

\section{Fase VI - "Implementación"}

La fase de despliegue o implementación, dependiendo de los requisitos del proyecto, puede ser tan sencilla como la generación de un simple reporte o tan compleja como la implementación de un proceso de Explotación de Datos repetible en toda la empresa.

En determinadas ocasiones, el propio cliente es quien lleva a cabo los pasos concretos de la implementación y no el propio analista de datos; lo cual permite al cliente conocer de manera anticipada qué acciones son requeridas con el fin de hacer uso del modelo creado.

En la figura 3, se detallan las fases componentes de la metodología CRISP-DM [7]:

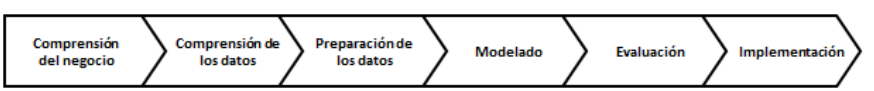

Fig. 3. Fases componentes de la metodología CRISP-DM [7].

En la tabla I, se especifican las tareas componentes y las actividades de cada fase de la metodología CRISP-DM [7]: 
TABLA I. FASES, TAREAS Y ACTIVIDADES DE LA METODOLOGÍA CRISP-DM [7].

\begin{tabular}{|c|c|c|}
\hline Fase & $\begin{array}{c}\text { Tareas } \\
\text { Componentes } \\
\end{array}$ & Actividades Asociadas \\
\hline \multirow{4}{*}{$\begin{array}{l}\text { Comprensión } \\
\text { del negocio }\end{array}$} & $\begin{array}{l}\text { Determinar los } \\
\text { objetivos del } \\
\text { negocio. }\end{array}$ & $\begin{array}{l}\text { - Background. } \\
\text { - Objetivos del negocio. } \\
\text { - Criterios de éxito del } \\
\text { negocio. }\end{array}$ \\
\hline & $\begin{array}{l}\text { Evaluar la } \\
\text { situación. }\end{array}$ & $\begin{array}{l}\text { - Inventarios de recursos. } \\
\text { - Requisitos, supuestos y } \\
\text { requerimientos. } \\
\text { - Riesgos y contingencias. } \\
\text { - Terminología. } \\
\text { - Costos y beneficios. } \\
\end{array}$ \\
\hline & $\begin{array}{l}\text { Determinar } \\
\text { objetivos del } \\
\text { Proyecto de } \\
\text { Explotación de } \\
\text { Información. }\end{array}$ & $\begin{array}{l}\text { - Las metas del Proyecto de } \\
\text { Explotación de } \\
\text { Información. } \\
\text { - Criterios de éxito del } \\
\text { Proyecto de Explotación } \\
\text { de Información. }\end{array}$ \\
\hline & $\begin{array}{l}\text { Realizar el Plan del } \\
\text { Proyecto. }\end{array}$ & $\begin{array}{l}\text { - Plan de Proyecto. } \\
\text { - Valoración inicial de } \\
\text { herramientas. }\end{array}$ \\
\hline \multirow{4}{*}{$\begin{array}{l}\text { Comprensión de } \\
\text { los datos }\end{array}$} & $\begin{array}{l}\text { Recolectar los datos } \\
\text { iniciales. }\end{array}$ & $\begin{array}{l}\text { - Reporte de recolección de } \\
\text { datos iniciales. }\end{array}$ \\
\hline & Descubrir datos. & $\begin{array}{l}\text { - Reporte de descripción de } \\
\text { los datos. }\end{array}$ \\
\hline & Explorar los datos. & $\begin{array}{l}\text { - Reporte de exploración de } \\
\text { datos. }\end{array}$ \\
\hline & $\begin{array}{l}\text { Verificar la calidad } \\
\text { de datos. }\end{array}$ & $\begin{array}{l}\text { - Reporte de calidad de } \\
\text { datos. }\end{array}$ \\
\hline \multirow{6}{*}{$\begin{array}{l}\text { Preparación de } \\
\text { los datos }\end{array}$} & $\begin{array}{l}\text { Caracterizar el } \\
\text { conjunto de datos. }\end{array}$ & $\begin{array}{l}\text { - Conjunto de datos. } \\
\text { - Descripción del conjunto } \\
\text { de datos. }\end{array}$ \\
\hline & $\begin{array}{l}\text { Seleccionar los } \\
\text { datos. }\end{array}$ & $\begin{array}{l}\text { - Inclusión/Exclusión de } \\
\text { datos. }\end{array}$ \\
\hline & Limpiar los datos. & $\begin{array}{l}\text { - Reporte de calidad de } \\
\text { datos limpios. }\end{array}$ \\
\hline & $\begin{array}{l}\text { Estructurar los } \\
\text { datos. }\end{array}$ & $\begin{array}{l}\text { - Derivación de atributos. } \\
\text { - Generación de registros. }\end{array}$ \\
\hline & Integrar los datos. & - Unificación de datos. \\
\hline & $\begin{array}{l}\text { Caracterizar el } \\
\text { formato de los } \\
\text { datos. }\end{array}$ & $\begin{array}{l}\text { - Reporte de calidad de los } \\
\text { datos. }\end{array}$ \\
\hline \multirow{4}{*}{ Modelado } & $\begin{array}{l}\text { Seleccionar una } \\
\text { técnica de } \\
\text { modelado. }\end{array}$ & $\begin{array}{l}\text { - La técnica modelada. } \\
\text { - Supuestos del modelo. }\end{array}$ \\
\hline & $\begin{array}{l}\text { Generar el plan de } \\
\text { pruebas. }\end{array}$ & - Plan de pruebas. \\
\hline & $\begin{array}{l}\text { Construir el } \\
\text { modelo. }\end{array}$ & $\begin{array}{l}\text { - Configuración de } \\
\text { parámetros. } \\
\text { - Modelo. } \\
\text { - Descripción del modelo. }\end{array}$ \\
\hline & Evaluar el modelo. & $\begin{array}{l}\text { - Evaluar el modelo. } \\
\text { - Revisación de la } \\
\text { configuración de } \\
\text { parámetros. }\end{array}$ \\
\hline \multirow[t]{3}{*}{ Evaluación } & Evaluar resultado. & $\begin{array}{l}\text { - Valoración de resultados } \\
\text { mineros con respecto al } \\
\text { éxito del negocio. } \\
\text { - Modelos aprobados. }\end{array}$ \\
\hline & Revisar. & - Revisión del proceso. \\
\hline & $\begin{array}{l}\text { Determinar } \\
\text { próximos pasos. }\end{array}$ & - Listar posibles acciones. \\
\hline \multirow{4}{*}{ Implementación } & $\begin{array}{l}\text { Realizar el plan de } \\
\text { implementación. }\end{array}$ & - Plan de Implementación. \\
\hline & $\begin{array}{l}\text { Realizar el plan de } \\
\text { monitoreo y } \\
\text { mantenimiento. }\end{array}$ & $\begin{array}{l}\text { - Plan de monitoreo y } \\
\text { mantenimiento. }\end{array}$ \\
\hline & $\begin{array}{l}\text { Realizar el informe } \\
\text { final. }\end{array}$ & $\begin{array}{l}\text { - Informe final. } \\
\text { - Presentación final. } \\
\end{array}$ \\
\hline & $\begin{array}{l}\text { Realizar la revisión } \\
\text { del proyecto. }\end{array}$ & $\begin{array}{l}\text { - Documentación de la } \\
\text { experiencia. }\end{array}$ \\
\hline
\end{tabular}

\section{2) Metodología $P T^{3} Q$ (Catalyst)}

La metodología Catalyst [36], conocida como $\mathrm{P}^{3} \mathrm{TQ}$ : Producto (Product), Lugar (Place), Precio (Price), Tiempo
(Time) y Cantidad (Quantity), fue propuesta por Dorian Pyle en el año 2003. Esta metodología básicamente propone dos modelos: el "Modelo de Negocio (MII)" y el "Modelo de Explotación de Información (MIII)" [3; 4].

\section{Modelo de Negocio (MII)}

El Modelo de Negocio (MII) aporta una guía de pasos para el desarrollo y la realización de un modelo que permite la identificación de un problema en particular de negocio (o la oportunidad de llevar a cabo la realización del mismo), y los requerimientos reales de la organización en cuestión [3; 4].

Este modelo tiene en cuenta diferentes circunstancias para el proyecto de Explotación de Datos, proponiendo acciones concretas según el contexto desde el cual se parte. En el caso de aquellos proyectos donde no existe una definición real del problema u oportunidad de negocio, se recomienda iniciar analizando las relaciones $\mathrm{P}^{3} \mathrm{TQ}$ que existen en la cadena de valor organizacional (precio/lugar/producto/tiempo/cantidad) y que son significativas para la empresa [3;4].

El modelado en MII depende del contexto en el cual está inmerso el negocio, lo que promueve el planteamiento de distintos escenarios. Ellos son: dato, oportunidad, prospectiva, definido y estratégico [7]:

\section{1er Escenario - "Dato":}

El proyecto se inicia con un conjunto de datos y la premisa es explorar este conjunto para encontrar relaciones interesantes. En este caso, se debe:

- "Determinar la procedencia y los datos a recolectar".

- "Identificar los recursos humanos para el proyecto".

- "Discutir el proyecto con los recursos humanos".

- "Caracterizar el conjunto de datos en término de las relaciones $\mathrm{P}^{3} \mathrm{TQ}$ (Product, Place, Price, Time, Quantity)".

- "Caracterizar la motivación del negocio para recolectar y almacenar los datos".

- "Descubrir quiénes o qué departamento originó el proyecto y qué se espera de él".

\section{2do Escenario - "Oportunidad":}

El proyecto se inicia con una situación de negocio (problema u oportunidad) que debe ser explorada. En este caso, se debe:

- "Identificar las características de los recursos humanos relevantes".

- "Explotar las situaciones de negocio con los recursos humanos".

- "Determinar el marco de situación del negocio".

- "Definir los objetivos de negocio relevantes".

- "Buscar los datos a utilizar".

- "Presentar el caso de negocio a los recursos humanos".

\section{3er Escenario - "Prospectiva".}

El proyecto es diseñado con el fin de descubrir dónde la Explotación de Información puede brindar un valor en el entorno de la organización. En este caso, se debe:

- "Caracterizar las claves de la organización en relación a $\mathrm{P}^{3} \mathrm{TQ}$ ".

- "Identificar los principales procesos de flujo de información de la organización".

- "Identificar los potenciales recursos humanos".

- "Hablar con los potenciales recursos humanos".

- "Descubrir cuáles de los 26 niveles de gestión son los más involucrados para cada uno de los recursos humanos".

- "Caracterizar los modelos más aplicables al negocio".

- "Explorar las fuentes de datos". 
- "Preparar los casos de negocio para cada oportunidad significante".

- "Presentar el caso de negocio a los recursos humanos".

\section{4to Escenario - "Definido"}

El proyecto comienza con la premisa de crear la especificación del modelo de Explotación de Datos con un propósito específico. En este caso, se debe:

- "Identificar los recursos humanos".

- "Discutir los requerimientos con los recursos humanos".

- "Enmarcar la situación de negocio".

- "Buscar los datos necesarios".

- "Definir los requerimientos a desarrollar".

\section{5to Escenario - "Estratégico":}

El proyecto comienza con una estrategia de análisis para brindar soporte a un escenario planeado por la organización. En este caso, se debe:

- "Identificar los recursos humanos potenciales".

- "Hablar con los recursos humanos potenciales".

- "Enmarcar la situación de negocio".

- "Si es necesario, trabajar interactivamente con los recursos humanos para crear un mapa de los escenarios estratégicos".

- "A partir del mapa, crear un modelo sistémico de la situación estratégica”.

- - "Caracterizar las claves de la organización en relación a P'TQ".

- "Relacionar el mapa con las claves de la organización en relación a $\mathrm{P}^{3} \mathrm{TQ}$ ".

- "Si es necesario, simular una situación estratégica para descubrir incertidumbres, ambigüedades, errores en la compresión intuitiva y descubrir relaciones cruciales (aquellas no entendidas, bien caracterizadas, o para las cuales los pequeños cambios tienen grandes efectos)".

- "Caracterizar las claves de las relaciones de los sistemas en término de los 26 niveles de gestión".

- "Descubrir cuáles de los 26 niveles de gestión son los más involucrados para cada recurso humano".

- "Caracterizar los modelos de los niveles de negocio más aplicados".

- "Explorar las fuentes de datos".

- "Enmarcar cada problema de negocio u oportunidad en un modelo estratégico con particular atención en las estrategias, interacciones estratégicas y los riesgos incluidos en el banco de pruebas de riesgo y las expectativas".

- "Explotar los datos para caracterizar las relaciones actuales con el sistema modelado y la simulación, tratando de que concuerden con la situación real".

- "Mostrar las relaciones descubiertas dentro de los mapas del sistema y la simulación y realizar la simulación a través del rango de escenarios requeridos".

\section{Modelo de Explotación de Información (MIII)}

El Modelo de Explotación de Información (MIII) brinda una guía de pasos para la realización y ejecución de modelos de Explotación de Información a partir del Modelo de Negocio (MII) desarrollado. Los pasos a seguir en MIII son [7]:

- Preparación de los datos". En este caso, se debe:

- "Comprobar las variables de la matriz de característica".

- "Comprobar las variables básicas para el problema".

- "Comprobar los datos básicos para el problema".

- "Comprobar las variables anacrónicas".

- "Comprobar la suficiencia de los datos".
- "Comprobar la representación de los resultados".

- "Comprobar la representación de rasgos básica".

"Selección de herramientas y modelado inicial". En este caso, se debe:

- "Definir la estructura de datos para llevar adelante la Explotación de Información".

- "Caracterizar los datos de entradas y salidas".

- "Seleccionar las herramientas de Explotación de Información".

- "Construir los valores que comprueben el modelo".

- "Si los datos no se comprenden: Crear el modelo exploratorio inicial".

- "Si se van a clasificar los datos: Descubrir el tipo apropiado de modelo de clasificación inicial".

- "Si se van a predecir los datos: Descubrir el tipo apropiado de modelo predictivo".

"Ejecución". En este caso, se debe:

- "Si es un modelo deductivo: Especificar la explicación del mismo".

- "Si el modelo de clasificación o predicción es binario: Especificar una matriz de confusión".

- "Si el modelo de clasificación o predicción es un valor continuo: Especificar una matriz de confusión, comparar la predicción con un gráfico residual, comparar la predicción con la situación actual".

- "Si el modelo de clasificación o predicción es una clase: Especificar una matriz de confusión, comparar la predicción con un gráfico residual, comparar la predicción con un argumento actual, especificar pruebas del modelo residual".

- "Si el modelo de clasificación o predicción es un valor categórico: Especificar la predicción con un gráfico residual, comparar la predicción con situaciones actuales, especificar pruebas del modelo residual, realizar histogramas residuales, comparar situaciones actuales con gráficos residuales XY, comparar la situación actual con una predicción de rangos, comparar la situación actual con curvas de predicción, comparar la situación actual con la predicción apta, especificar la varianza residual, especificar el modelo perfecto".

"Evaluación de resultados". En este caso, se debe:

- "Si es un modelo deductivo: Revisar los requerimientos descubiertos durante la ejecución, explicar en forma narrativa: a) los descubrimientos, el informe debe incluir: patrones, descubrimiento de explicaciones plausibles, clustering, conteos, contrastes y comparaciones, variables de particionamiento, generalidades de particularidades, proponer factores plausibles explícitos e implícitos latentes, identificar y explicar las relaciones entre variables (o variables grupales), crear explicaciones de cambios lógicos, creando coherencias conceptuales; y b) la verificación, el informe debe incluir: comprobación de la representatividad, comprobación de la tendencia, triangulación (usando fuentes de datos diferentes, usando métodos de modelado diferentes, utilizando teorías diferentes), considerando los límites, incorporando pruebas negativas, incorporando pruebas externas empíricas".

- "Si es un modelo de clasificación: Revisar las exigencias de la entrega desarrollada antes de la ejecución del proceso de Explotación de Información, repasar los descubrimientos realizados durante la formación, preparar una explicación de soporte, crear la calibración de los modelos, revisar los modelos requeridos para entregar".

- "Si el modelo es en tiempo real: Identificar las novedades". 
"Comunicación de resultados". En este caso, se debe:

- "Dar a las partes restantes del proyecto los resultados y sugerir como implementarlos".

La metodología $\mathrm{P}^{3} \mathrm{TQ}$, en sus dos modelos, está constituida por un conjunto de pasos denominados "cajas" (boxes). Conceptualmente, dicha metodología determina que luego de ejecutar una acción se deben evaluar los resultados obtenidos y determinar cuál es el paso que se debe ejecutar posteriormente [3; 4]. Los boxes del modelo explican en forma detallada los conceptos y/o acciones que se realizan [34]. En [7] se señala que cada uno de los modelos está estructurado en base a:

- Caja de actividades: señalan el conjunto de pasos a cumplir.

- Caja de descubrimientos: informan las acciones de Exploración de Datos necesarias para poder decidir qué hacer en el paso subsiguiente.

- Caja de técnicas: brindan información complementaria acerca de los pasos recomendados en la caja de descubrimientos o de acción.

- Caja de ejemplos: proporcionan una descripción detallada acerca de cómo usar una determinada técnica. Estas cajas son aplicables en el Modelo de Explotación de Información (MIII).

En la figura 4, se visualiza la interacción de los diferentes modelos de la metodología $\mathrm{P}^{3} \mathrm{TQ}$ y sus componentes [7]:

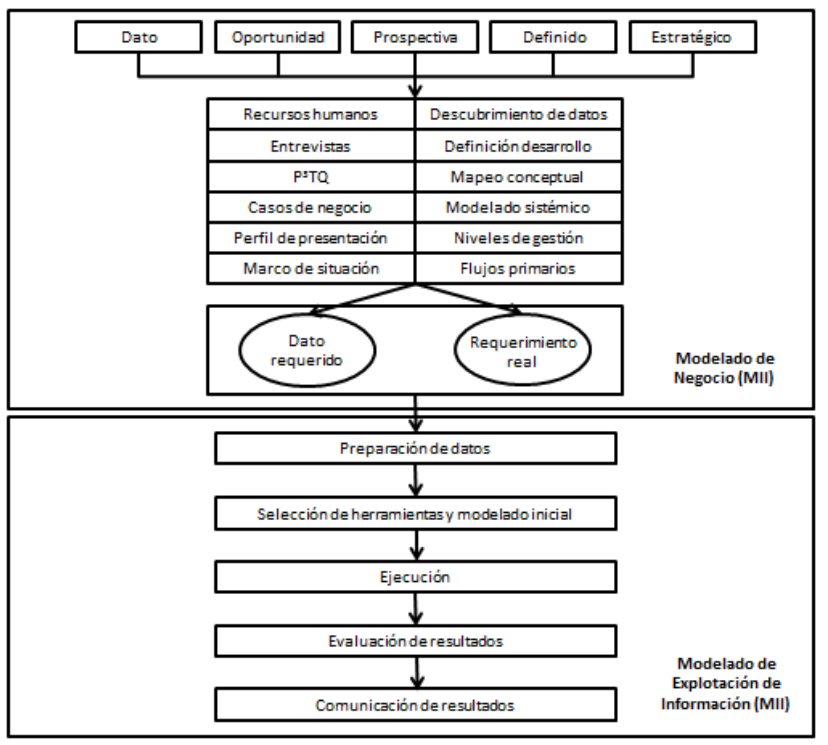

Fig. 4. Fases de la metodología $\mathrm{P}^{3} \mathrm{TQ}$ y sus componentes [7].

\section{3) Metodología SEMMA}

La metodología SEMMA, creada por el SAS Institute, se define como el proceso de selección, exploración y modelado de grandes cantidades de datos para revelar patrones de negocio desconocidos $[3 ; 4]$.

El nombre de esta terminología corresponde al acrónimo de las cinco fases básicas del proceso: Sample (Muestreo), Explore (Exploración), Modify (Modificación), Model (Modelado) y Assess (Valoración) [7; 3; 4; 37].

En la figura 5, se observan las cinco fases básicas del proceso contemplado por la metodología SEMMA [7]:

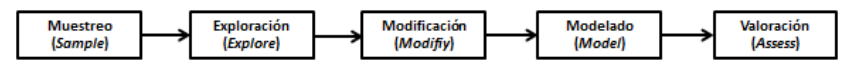

Fig. 5. Fases componentes de la metodología SEMMA [7].

En $[3 ; 4]$ se indica que las actividades de análisis y comprensión del problema abordado son excluidas de la metodología SEMMA, ya que la misma se encuentra enfocada fundamentalmente en aspectos técnicos. Dicha metodología fue propuesta inicialmente para trabajar con el software de Explotación de Datos de la compañía SAS.

En la figura 6, se visualizan las cinco fases de la metodología SEMMA y la dinámica general de la misma [7]:

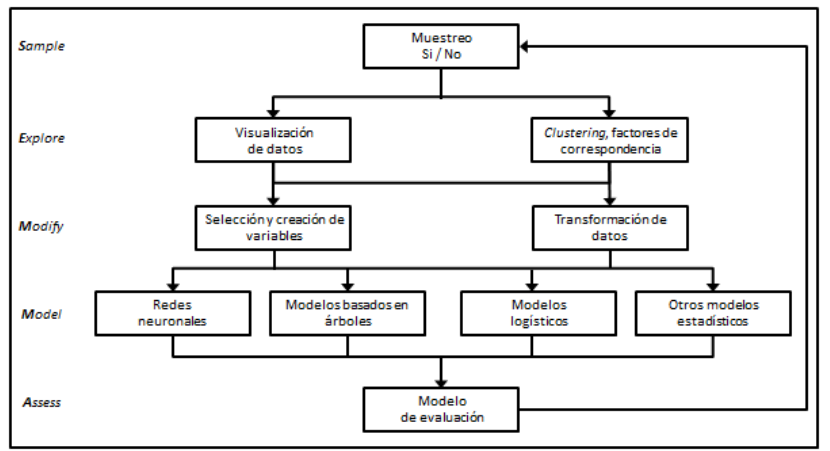

Fig. 6. Dinámica general de la metodología SEMMA [7].

En [7] se describen las fases de la metodología SEMMA:

Fase I - "Muestreo (Sample)" $\rightarrow$ Extracción de una muestra representativa.

En esta primera fase de la metodología, se realiza la extracción de un conjunto de datos (población muestral) sobre la que se va a llevar a cabo el análisis. La muestra debe ser representativa de la población, caso contrario los resultados obtenidos no son válidos para el proceso en cuestión. El método de muestreo más común se denomina "muestreo aleatorio simple", en el que cada elemento en la población tiene la misma probabilidad de ser seleccionado. En esta metodología, para cada una de las muestras escogidas se debe asociar un determinado nivel de confianza.

Fase II - "Exploración (Explore)" $\rightarrow$ Exploración de los datos de la muestra seleccionada.

En esta fase, se realiza un análisis de los datos extraídos en la muestra, para lo cual se propone el uso de herramientas de visualización o de diferentes técnicas estadísticas para la exploración de la información seleccionada, que contribuyan a poner de manifiesto relaciones entre variables. Esto permite simplificar el problema y optimizar la eficiencia del modelo, ayudando a refinar los procesos de descubrimiento de información en las fases subsiguientes del proceso en cuestión.

Fase III - "Modificación (Modifv)" $\rightarrow$ Modificación de los datos.

La tercera fase de la metodología, involucra la modificación de los datos que van a ser ingresados al modelo para que tengan el formato adecuado, mejorando la definición de los mismos.

Fase IV - "Modelado (Model)" $\rightarrow$ Modelación de los datos.

En esta fase, se procede a modelar el conjunto de datos, permitiendo al software realizar una búsqueda completa de combinaciones de datos que ayudarán a predecir los resultados esperados de manera confiable. El objetivo de esta fase es establecer una relación entre las variables objeto del estudio y las variables explicativas, de manera tal que posibiliten inferir el valor de las mismas con un nivel de confianza determinado.

Las técnicas utilizadas para el modelado de los datos incluyen técnicas adaptativas, lógica difusa, reglas de asociación, árboles de decisión, redes neuronales y computación evolutiva; como así también involucran métodos estadísticos tradicionales. 


\section{Fase V - "Valoración (Assess)" $\rightarrow$ Evaluación de los datos}

La última fase de la metodología SEMMA, consiste en la valoración de los datos obtenidos para determinar el grado de confiabilidad de los mismos y así poder evaluar el modelo, mediante la comparación con otros métodos estadísticos o con nuevas poblaciones muestrales.

4) Estudio Comparativo de las Principales Metodologías de Proyectos de Explotación de Información

Según una publicación realizada en el año 2007 por la comunidad KDnuggets (Data Mining Community's Top Resource), CRISP-DM ha sido la metodología más utilizada en el área de Explotación de Datos [4].

De acuerdo a los resultados presentados en [3], la metodología SEMMA inicia el proyecto a partir de un conjunto de datos; mientras que CRISP-DM comienza el proceso con el análisis del negocio. Por tanto, la metodología $\mathrm{P}^{3} \mathrm{TQ}$ considera cinco escenarios posibles como punto de partida (siendo más completa en este aspecto).

Teniendo en cuenta la estructura de fases del proceso de Explotación de Datos, en la tabla II se observa como SEMMA excluye la fase de análisis y comprensión del problema, y se enfoca principalmente en aspectos técnicos; mientras que CRISP-DM y $\mathrm{P}^{3} \mathrm{TQ}$ contemplan dicha fase antes de comenzar el proceso de Explotación de Datos. En las tres metodologías se contemplan la fase de la selección y preparación de los datos, la fase de modelado y la fase de evaluación de los patrones obtenidos. Sin embargo, en SEMMA el proceso de evaluación e interpretación de dichos patrones se realiza sobre el desempeño del modelo en cuestión, mientras que en las otras dos metodologías restantes la evaluación se realiza teniendo en cuenta la utilidad que se aporta al dominio de la aplicación o al problema de la organización en cuestión. En SEMMA, no se considera la fase de implementación. Por tanto, CRISP-DM adiciona además una planificación para controles futuros y un análisis de finalización del proyecto denominado 'análisis postmortem' [3].

TABLA II. FASES DEL PROCESO DE EXPLOTACIÓN DE DATOS DE LAS METODOLOGÍAS CRISP-DM, SEMMA Y P ${ }^{3}$ TQ (SÍNTESIS) [3]

\begin{tabular}{|c|c|c|c|}
\hline FASES & CRISP - DM & SEMMA & $\mathbf{P}^{3}$ TQ \\
\hline $\begin{array}{c}\text { Análisis y } \\
\text { comprensión del } \\
\text { negocio }\end{array}$ & $\begin{array}{c}\text { Comprensión } \\
\text { del negocio }\end{array}$ & $\begin{array}{c}\text { Modelado del } \\
\text { negocio }\end{array}$ \\
\hline $\begin{array}{c}\text { Selección y } \\
\text { preparación de } \\
\text { los datos }\end{array}$ & $\begin{array}{c}\text { Entendimiento } \\
\text { de los datos } \\
\text { Preparación de } \\
\text { los datos }\end{array}$ & $\begin{array}{c}\text { Muestreo } \\
\text { Comprensión }\end{array}$ & $\begin{array}{c}\text { Preparación } \\
\text { de } \\
\text { los datos }\end{array}$ \\
\hline Modelado & Modelado & Modelado & $\begin{array}{c}\text { Selección de } \\
\text { herramientas y } \\
\text { modelado } \\
\text { inicial }\end{array}$ \\
\hline Evaluación & Evaluación & Valoración & $\begin{array}{c}\text { Refinamiento } \\
\text { del modelo }\end{array}$ \\
\hline Implementación & Despliegue & & Comunicación \\
\hline
\end{tabular}

En [3] también se considera el nivel de detalle en las tareas llevadas a cabo en cada fase; SEMMA, propone sólo los pasos generales del proyecto de Explotación de Datos, sin especificar exactamente las tareas que deben llevarse a cabo en cada una de sus fases. Aquellas organizaciones que apliquen la metodología SEMMA en sus proyectos, deberán ser responsables de establecer las tareas y las actividades que se implementarán en cada etapa, ya que sólo se definen las fases generales en dicha metodología. En cambio, CRISP-DM y $\mathrm{P}^{3} \mathrm{TQ}$, especifican con mayor detalle las actividades del proceso en cuestión, inclusive la metodología $\mathrm{P}^{3} \mathrm{TQ}$ indica además 'cómo' deben realizarse las mismas.

En referencia a las actividades para la gestión del proyecto, en la tabla III se observa como las mismas no están incluidas en SEMMA. Por su parte, las metodologías $\mathrm{P}^{3} \mathrm{TQ}$ y CRISP$\mathrm{DM}$ incorporan actividades de planificación para las diferentes áreas de la gestión del proyecto, pero no proponen tareas de control y monitoreo [3].

En el caso de la metodología $\mathrm{P}^{3} \mathrm{TQ}$, las actividades de planificación se llevan a cabo en el "Modelado del Negocio (MII)". Tomando como escenario inicial un problema u oportunidad organizacional, la planificación del riesgo está presente en la tarea "Describir la situación del negocio para el proceso de Explotación”. Por tanto, la planificación del alcance, tiempo, costo y recursos humanos, se ven reflejadas en la tarea "Armar el caso de negocio" [3].

En la metodología CRISP-DM, las actividades de planificación del riego se proponen en la tarea "Evaluación de la situación", y aquellas actividades vinculadas a la planificación de alcance, tiempo, costo y recursos humanos, se presentan en la tarea "Crear un plan para el proyecto de Explotación de Datos". Si bien no se detallan tareas de monitoreo y control, el plan del proyecto debe ser examinado, y en caso de ser necesario reformado, antes del inicio de cada fase del proceso [3].

TABLA III. ACTIVIDADES PARA LA GESTIÓN DEL PROYECTO DE CRISP-DM, SEMMA Y P ${ }^{3}$ TQ (SÍNTESIS) [3].

\begin{tabular}{|c|c|c|c|}
\hline FASES & CRISP - DM & SEMMA & $\mathbf{P}^{3} \mathrm{TQ}$ \\
\hline $\begin{array}{l}\text { Gestión del } \\
\text { alcance }\end{array}$ & $\begin{array}{c}\text { Planificación } \\
\text { del } \\
\text { alcance en la } \\
\text { tarea "Crear un } \\
\text { plan de } \\
\text { proyecto de } \\
\text { Explotación de } \\
\text { Datos" }\end{array}$ & & $\begin{array}{c}\text { Planificación } \\
\text { del } \\
\text { alcance en la } \\
\text { tarea "Armar } \\
\text { el caso de } \\
\text { negocio" del } \\
\text { Modelado del } \\
\text { Negocio }\end{array}$ \\
\hline $\begin{array}{l}\text { Gestión del } \\
\text { tiempo }\end{array}$ & $\begin{array}{l}\text { Planificación } \\
\text { del tiempo en } \\
\text { la tarea "Crear } \\
\text { un plan de } \\
\text { proyectos de } \\
\text { Explotación de } \\
\text { Datos" }\end{array}$ & & $\begin{array}{c}\text { Planificación } \\
\text { del } \\
\text { tiempo en la } \\
\text { tarea "Armar } \\
\text { el caso de } \\
\text { negocio" del } \\
\text { Modelado del } \\
\text { Negocio }\end{array}$ \\
\hline $\begin{array}{l}\text { Gestión del } \\
\text { costo }\end{array}$ & $\begin{array}{c}\text { Planificación } \\
\text { del costo en la } \\
\text { tarea "Crear un } \\
\text { plan de } \\
\text { proyecto de } \\
\text { Explotación de } \\
\text { Datos" }\end{array}$ & & $\begin{array}{c}\text { Planificación } \\
\text { del } \\
\text { costo en la } \\
\text { tarea "Armar } \\
\text { el caso de } \\
\text { negocio" del } \\
\text { Modelado del } \\
\text { Negocio }\end{array}$ \\
\hline $\begin{array}{c}\text { Gestión del } \\
\text { riesgo }\end{array}$ & $\begin{array}{l}\text { Planificación } \\
\text { del riesgo en la } \\
\text { tarea } \\
\text { "Evaluación de } \\
\text { la situación" }\end{array}$ & & $\begin{array}{c}\text { Planificación } \\
\text { del riesgo en } \\
\text { la tarea } \\
\text { "Describir la } \\
\text { situación del } \\
\text { negocio para } \\
\text { el proceso de } \\
\text { Explotación" }\end{array}$ \\
\hline $\begin{array}{c}\text { Gestión de los } \\
\text { recursos } \\
\text { humanos }\end{array}$ & $\begin{array}{c}\text { Planificación } \\
\text { de los recursos } \\
\text { humanos en la } \\
\text { tarea "Crear un } \\
\text { plan de } \\
\text { proyecto de } \\
\text { Explotación de } \\
\text { Datos" }\end{array}$ & & $\begin{array}{l}\text { Planificación } \\
\text { de los recursos } \\
\text { humanos en la } \\
\text { tarea "Armar } \\
\text { el caso de } \\
\text { negocio" del } \\
\text { Modelado de } \\
\text { Negocio. }\end{array}$ \\
\hline
\end{tabular}

En $[7 ; 38]$ se indica que las tres metodologías identifican técnicas de Explotación de Información (TEI) utilizables. A 
diferencia de CRISP-DM, las metodologías $\mathrm{P}^{3}$ TQ y SEMMA no identifican problemas de inteligencia de negocio (PIN), ni realizan una caracterización abstracta de los mismos (CRISPDM hace una caracterización parcialmente abstracta de dichos problemas). $\mathrm{P}^{3} \mathrm{TQ}$ y SEMMA, tampoco identifican relaciones entre problemas de inteligencia de negocio y técnicas de Explotación de Información, ni procesos de Explotación de Información (CRISP-DM esboza parcialmente los procesos a desarrollar) (tabla IV).

TABLA IV. CONCEPTOS DE INTELIGENCIA DE NEGOCIO, TÉCNICAS Y PROCESOS DE EXPLOTACIÓN DE INFORMACIÓN ABARCADOS POR LAS METODOLOGÍAS CRISP-DM, SEMMA Y $\mathrm{P}^{3} \mathrm{TQ}$ $(\bullet=$ SI, o $=$ PARCIALMENTE, $x=$ NO) [7].

\begin{tabular}{|c|c|c|c|}
\hline METODOLOGÍA & $\frac{\sum}{\frac{2}{0}}$ & $\sum_{\substack{\mathbf{2} \\
\sqrt{2}}}^{\lessgtr}$ & $\stackrel{0}{a}$ \\
\hline $\begin{array}{l}\text { Identifica problemas de inteligencia de negocio } \\
\text { (PIN). }\end{array}$ & $\bullet$ & $\mathbf{X}$ & $\mathbf{X}$ \\
\hline Identifica una caracterización abstracta de PIN. & O & $\mathbf{X}$ & $\mathbf{X}$ \\
\hline $\begin{array}{l}\text { Identifica técnicas de Explotación de Información } \\
\text { (TEI) utilizables. }\end{array}$ & $\bullet$ & - & $\bullet$ \\
\hline Identifica relaciones entre las TEI y los PIN. & O & $\mathbf{X}$ & $\mathbf{X}$ \\
\hline $\begin{array}{l}\text { Identifica procesos de Explotación de } \\
\text { Información (proceso PIN x TEI). }\end{array}$ & O & $\mathbf{X}$ & $\mathbf{X}$ \\
\hline
\end{tabular}

Un estudio comparativo entre las principales metodologías de Explotación de Información realizado en [34] permitió concluir que la metodología $\mathrm{P}^{3} \mathrm{TQ}$ es la más completa de las tres mencionadas. Dicha metodología, analiza más profundamente un mayor número de variables con respecto a las otras dos metodologías. Si bien CRISP-DM es más abierta y completa que SEMMA, no llega a obtener el nivel de detalle de $\mathrm{P}^{3} \mathrm{TQ}$, ya que no se analizan los pasos, resultados $\mathrm{y}$ situaciones que se pueden presentar dentro de cada fase (tabla V).

De acuerdo con [32], al evaluar estas metodologías, se observa la falta de herramientas que permiten soportar de forma completa la fase de administración de proyectos [29].

TABLA V. COMPARACIÓN DE LAS PRINCIPALES METODOLOGÍAS DE EXPLOTACION DE INFORMACIÓN [34].

\begin{tabular}{|l|c|c|c|}
\hline & SEMMA & CRISP-DM & PYLE \\
\hline $\begin{array}{l}\text { Permite elección totalmente } \\
\text { libre de herramientas. }\end{array}$ & NO & SI & SI \\
\hline Cantidad de fases. & 5 & 6 & $\begin{array}{c}\text { 5 (1 MII y } 4 \\
\text { MIII) }\end{array}$ \\
\hline $\begin{array}{l}\text { Todas las fases pueden } \\
\text { relacionarse. }\end{array}$ & NO & SI & SI \\
\hline $\begin{array}{l}\text { Considera motivo del } \\
\text { proyecto. }\end{array}$ & NO & NO & SI \\
\hline $\begin{array}{l}\text { Considera naturaleza del } \\
\text { interés de las partes. }\end{array}$ & NO & SI & SI \\
\hline $\begin{array}{l}\text { Considera otros aspectos no } \\
\text { técnicos. }\end{array}$ & NO & NO & $\begin{array}{c}\text { Slace, } \\
\text { Price, Time, } \\
\text { Quantity) }\end{array}$ \\
\hline $\begin{array}{l}\text { Identifica claramente las } \\
\text { variables sobre las que el } \\
\text { proyecto tiene impacto. }\end{array}$ & & SI \\
\hline $\begin{array}{l}\text { Está detallada paso a paso } \\
\text { cada etapa del método. }\end{array}$ & & Noduct \\
\hline
\end{tabular}

\section{Lineamientos Generales sobre la Comprensión del Negocio} y los Proyectos de Explotación de Información

En particular, las metodologías de Explotación de Información subrayan la importancia de alcanzar el entendimiento del negocio y el vínculo existente entre el problema del negocio en cuestión con el patrón a descubrir a partir del proceso de Explotación de Información [39].

De acuerdo a la discusión sobre las metodologías CRISPDM, SEMMA y $\mathrm{P}^{3} \mathrm{TQ}$ presentada en [7], la fase de "Comprensión de Negocio" de la metodología CRISP-DM, se relaciona con la fase de "Modelado de Negocio (MII)" de la metodología $\mathrm{P}^{3} \mathrm{TQ}$; sin embargo, estas fases no tienen relación con ninguna fase de la metodología SEMMA.

Según el análisis comparativo de las metodologías CRISPDM, SEMMA y $\mathrm{P}^{3} \mathrm{TQ}$ realizado en [3], $\mathrm{P}^{3} \mathrm{TQ}$ es la metodología más completa en lo que respecta al análisis y comprensión del negocio, mientras que SEMMA excluye esta actividad del modelo. En la metodología $\mathrm{P}^{3} \mathrm{TQ}$, se destaca su fase de "Modelado de Negocio (MII)", la cual comprende cinco puntos iniciales para el proyecto (dato, oportunidad, prospectiva, definido y estratégico), que posteriormente contribuirán a la definición de una serie de requerimientos y a determinar una situación organizacional que será abordada desde la Explotación de Información.

A estas conclusiones pueden añadirse las obtenidas en [32], mencionando que la metodología $\mathrm{P}^{3} \mathrm{TQ}$ define una evaluación completa del negocio denominada "Modelado del Negocio".

Asimismo, para alcanzar el éxito de un proyecto de Explotación de Información, es necesario comprender lo que el cliente realmente necesita, para ello resulta sumamente importante entender los problemas de negocio que se presentan [32].

\section{Protofase Metodológica: Técnicas y Herramientas Asociadas}

La protofase metodológica para la comprensión del negocio, fue presentada por María Alejandra Ochoa en el año 2006. Dicha protofase puede ser incorporada en cualquier metodología de desarrollo de software e involucra un conjunto de técnicas $y$ herramientas asociadas que modelan la comprensión estática del negocio; la evaluación de los objetivos del negocio; los medios, las expectativas y restricciones (o limitaciones) para lograr los objetivos propuestos; y las meta técnicas que soportan a las técnicas presentadas [8].

En [8] se señala que el modelo estática del negocio se obtiene a partir de las siguientes técnicas, a saber: la descripción del escenario actual: misión, objetivos, estrategias, productos/servicios, clientes, competencia; el glosario de términos del negocio; el organigrama de la organización; la definición de requisitos estructurados y el mapa estático de negocio.

\section{Descripción del escenario actual}

De acuerdo con [40], está descripción procura reunir la información que se tiene acerca del negocio al inicio del proyecto. En tal sentido, es necesario poder definir la misión, los objetivos que se pretenden alcanzar, las estrategias a implementar, los productos o servicios que se ofrecen al mercado, las características principales de los clientes y los competidores respectivos. Todos estos elementos constituyen la base sobre la que se lleva a cabo la definición del negocio [8]. 


\section{Glosario de términos del negocio}

Considerando el trabajo de [41], en este glosario se listan todos los términos específicos del dominio del negocio que guardan relación con los objetivos propuestos, pudiendo excluirse aquellos términos que no se relacionan con el proyecto en cuestión. Resulta conveniente que los integrantes del dominio del negocio participen en la definición de los términos utilizados, o en su defecto, aprueben las definiciones formuladas [8].

\section{Organigrama de la organización}

Teniendo en cuenta el trabajo de [42], los organigramas permiten conocer diferentes aspectos de la organización, tales como son: los niveles de jerarquía organizacional, los medios o canales de comunicación, la división de funciones, los supervisores de cada grupo de empleados, las líneas de autoridad y responsabilidad, la naturaleza lineal o staff del departamento, etc. Asimismo, se añade que estos revelan las relaciones existentes entre los departamentos de la empresa a lo largo de las autoridades principales de la misma [8].

\section{Definición de requisitos estructurados (SRD)}

De acuerdo con [43], a partir de la aplicación de dicha técnica se pretende tener un panorama claro acerca de cuáles son las entidades intervinientes, tanto internas como externas, que permiten alcanzar los objetivos que la organización se plantea. Asimismo, el SRD permite completar el conjunto de entradas y salidas de un sistema de información [8].

\section{Mapa estático del negocio}

En este mapa, se visualiza toda la información que parece ser más estable dentro de la organización, a saber: el nombre de la organización, la misión, los productos o servicios, los clientes, los competidores y el glosario de términos. Si bien dicha información puede modificarse, permanece inalterable por un periodo de tiempo considerable [8]. Esta información se puede visualizar en la figura 7 :

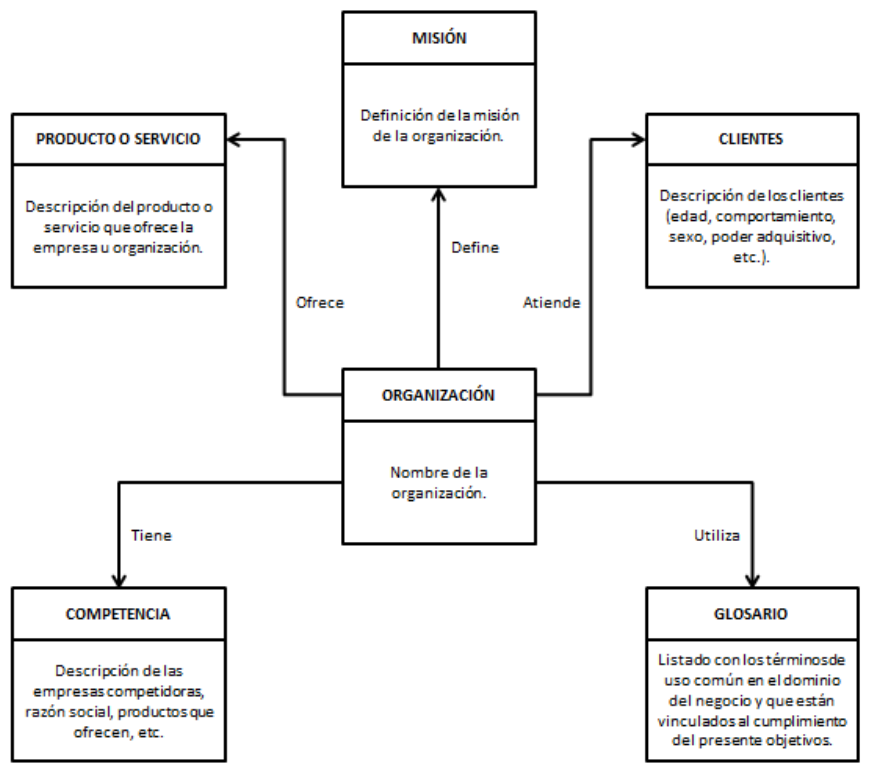

Fig. 7. Mapa estático del negocio [8].

Siguiendo con la misma línea de trabajo, en [8] se menciona que la evaluación de los objetivos del negocio involucra las siguientes técnicas, a saber: el análisis FODA; el análisis de los factores críticos del éxito; el análisis de riesgo y el mapa de condicionamientos de los objetivos.

\section{Análisis FODA}

De acuerdo con [44], la matriz o análisis FODA permite diagnosticar de manera precisa la situación actual del negocio, y por lo tanto, facilita la toma de decisiones en base a los objetivos trazados y las políticas implementadas. El término FODA es el acrónimo de las palabras Fortalezas, Oportunidades, Debilidades y Amenazas. Considerando estas cuatro variables, tanto las fortalezas como las debilidades son internas de la organización, por lo que es posible actuar directamente sobre ellas. Por el contrario, las oportunidades y las amenazas son externas a la empresa, y en consecuencia, resulta muy complicado modificar las mismas. El objetivo primordial de este análisis radica en obtener información procesada y lista para la toma de decisiones a partir de la transformación de datos iniciales percibidos [8].

\section{Análisis de los Factores Críticos De Éxito}

Teniendo en cuenta el trabajo de [45], a partir de los factores críticos de éxito (FCE) se puede llevar a cabo la planificación de las actividades a desarrollar y los recursos necesarios para la ejecución de las mismas dentro de la organización, lo cual facilita la asignación de prioridades y roles dentro del ámbito organizacional. Asimismo, se señala que el análisis de los factores críticos de éxito tiene como objetivo fundamental identificar todos aquellos factores del entorno que favorecen la implantación exitosa de una estrategia determinada [8].

\section{Análisis de Riesgos}

Considerando el trabajo de [46], el análisis de riesgos es muy importante para llevar adelante una adecuada gestión del proyecto. Este análisis puede implicar gran parte del esfuerzo destinado a la planificación del proyecto y está compuesto por un conjunto de actividades, tales como son [8]:

$$
\begin{aligned}
& \text { - "Identificación del riesgo". } \\
& \text { - "Proyección del riesgo". } \\
& \text { - "Cálculo del riesgo". } \\
& \text { - "Gestión del riesgo". }
\end{aligned}
$$

\section{Mapa de condicionamientos de los objetivos}

Este mapa tiene como eje central los objetivos que se plantea la organización en la actualidad. En él se describen las fortalezas, las oportunidades, las debilidades y las amenazas, los riesgos y los factores críticos del éxito. También se describen las estrategias a implementar para lograr los objetivos de la organización, que se determinan a partir de los elementos componentes previamente nombrados. Asimismo, se detalla el nombre de la organización. En términos generales, dicho mapa tiene un carácter más dinámico que el anterior, dada la información que contiene [8]. Esta información se puede observar en la figura 8 :

En [8] se añade que la determinación de los medios, expectativas y restricciones para alcanzar los objetivos del negocio se consigue mediante las siguientes técnicas, a saber: los recursos humanos; las fuentes de información para entender el entorno del proyecto; el análisis de los requerimientos; las expectativas que surgen de los objetivos del negocio, las restricciones o limitaciones que imponen los objetivos propios del negocio y el mapa táctico para lograr los objetivos propios del negocio.

\section{Recursos humanos}

De acuerdo con [47], en este nivel de análisis, se debe definir el perfil de los recursos humanos que se requieren para alcanzar los objetivos del negocio. En tal sentido, resulta relevante definir los tipos de profesionales necesarios, las especialidades demandadas, la posición que ocuparía cada uno de ellos, cuál sería su aporte o función, e identificar quiénes son los individuos que van a aportar el conocimiento respectivo del dominio del negocio. Asimismo, es importante especificar, 
de manera cualitativa, el tipo de asignación requerida, a saber: full-time, part-time o esporádica [8].

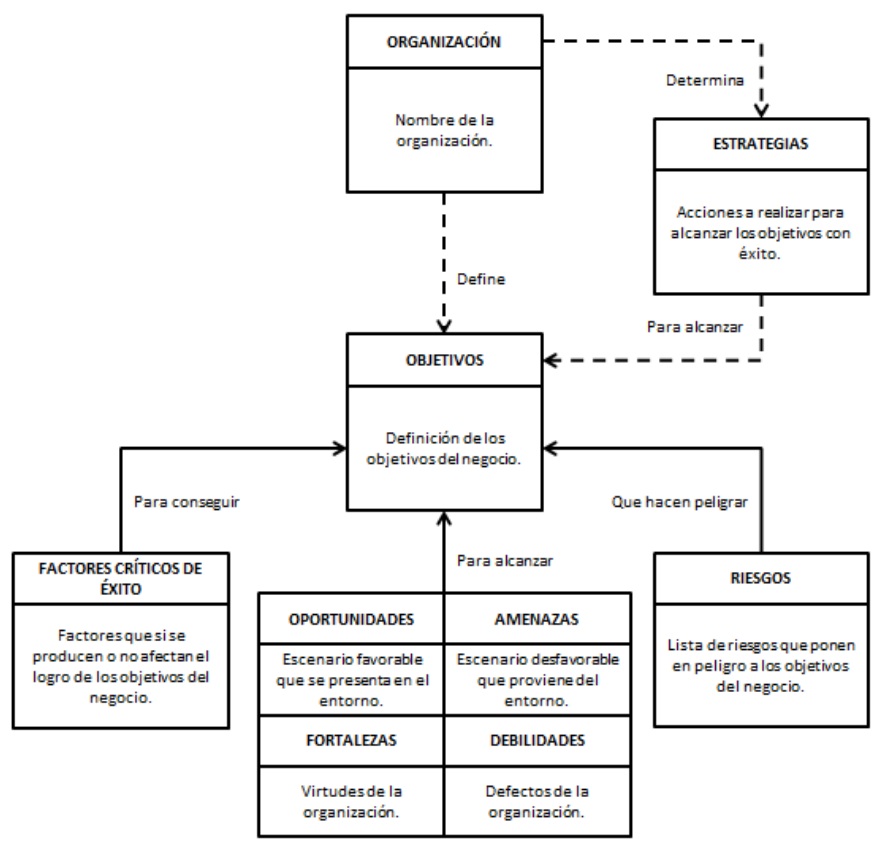

Fig. 8. Mapa de condicionamientos de los objetivos [8].

\section{Fuentes de información}

Considerando el trabajo de [41], las fuentes de información son de gran utilidad para lograr la comprensión del negocio; las mismas pueden ser tanto externas como internas. Existe información que determina el marco de referencia en el cual una organización desarrolla sus actividades, tales como son: los decretos, las leyes, las disposiciones, las normas, las publicaciones, etc., estableciendo las pautas generales de trabajo de las diferentes organizaciones. Asimismo, existe información adicional que puede ser extraída de otros tipos de documentos, tales como son: los manuales de procedimientos, las minutas internas elaboradas en las reuniones de equipos, etc. A este nivel de análisis, se considera que las fuentes externas son más apropiadas para alcanzar el entendimiento del negocio [8].

\section{Análisis de requerimientos}

Teniendo en cuenta el trabajo de [47], para poder lograr los objetivos del negocio es fundamental que se cumplan ciertos requerimientos, es decir, se deben dar ciertas condiciones necesarias para que el resultado final del proyecto se pueda lograr de manera satisfactoria. Estos requerimientos pueden ser categorizados en función de su prioridad, y pueden ser de diversa naturaleza. Asimismo, cada requerimiento posee un conjunto de características propias que lo distingue, pudiendo ser: "necesario", "conciso", "completo", "consistente" y "no ambiguo" [8].

\section{Expectativas}

En alusión a ideas y conceptos presentados en [48], es de gran importancia saber administrar correctamente las expectativas de todos los proyectos, en especial en aquellos que son de gran tamaño, tienen gran visibilidad para la organización, implican una alta criticidad y/o un profundo impacto político para el negocio. Cuando se realiza una gestión adecuada de las expectativas, se puede lograr la satisfacción de las partes involucradas, evitando así la confusión, la decepción y la frustración [8].

\section{Restricciones}

De acuerdo con [49], existen determinadas limitaciones que imposibilitan alcanzar los objetivos del negocio de manera eficaz y eficiente en función de la calidad y el tiempo. Estas barreras, que pueden ser tanto físicas como políticas, necesitan ser identificadas para su posterior tratamiento; asimismo, es necesario que la organización o sistema en cuestión, se adecue, de manera tal que estas restricciones afecten el cumplimiento de los objetivos pero en menor medida [8].

\section{Mapa táctico para alcanzar los objetivos}

Este mapa comprende todos los medios que se requieren para alcanzar los objetivos de la organización, a saber: los recursos humanos, las fuentes de información y los requerimientos. Asimismo, se incluyen en el mismo, otros elementos que se generan a partir de estos, tales como son: las expectativas y las restricciones [8]. Esta información se puede observar en la figura 9:

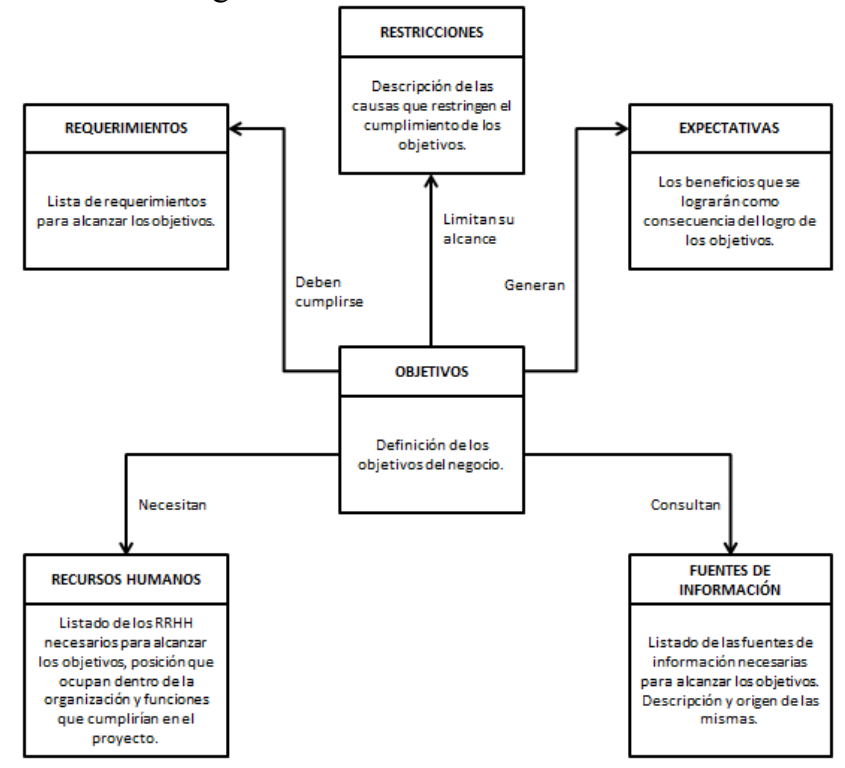

Fig. 9. Mapa táctico para alcanzar los objetivos [8]

Por último, en [8] se presenta una serie de meta técnicas asociadas a las técnicas propuestas, que resultan necesarias para poder lograr la comprensión del negocio, a saber:

- Entrevista Abierta

- Entrevista Estructurada

- JAD

- Estudio de Documentación

- Cuestionarios

- Análisis Estructural de Textos

En la tabla VI, se especifican las técnicas y meta técnicas sugeridas para cada una de ellas [8]. Se denominan técnicas a las que producen una salida esperada, mientras que las meta técnicas son aquellas que sirven de soporte para las primeras, y pueden resultar sumamente útiles para complementar la información de salida de las técnicas correspondientes, y por ende, permitir alcanzar un adecuado entendimiento del negocio [8].

\section{DESCRIPCIÓN DEL PROBLEMA}

En esta sección, se plantea la problemática de investigación del presente trabajo, a partir de la complejidad que involucra la comprensión clara del dominio del negocio en proyectos de Explotación de Información (sección III.A), y se formulan las preguntas de investigación del proyecto (sección III.B). 
TABLA VI. PLANILLA DE TÉCNICAS Y META TÉCNICAS [8].

\begin{tabular}{|c|c|c|c|c|c|c|c|}
\hline \multirow{2}{*}{\multicolumn{2}{|c|}{ TÉCNICAS }} & \multicolumn{6}{|c|}{ META TÉCNICAS } \\
\hline & & 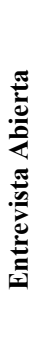 & 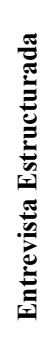 & \multirow{2}{*}{$\underset{3}{\Xi}$} & \multirow{2}{*}{ 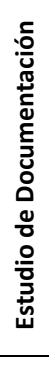 } & \multirow{2}{*}{ 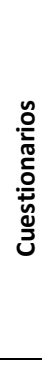 } & 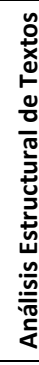 \\
\hline \multirow{6}{*}{ 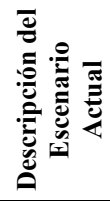 } & \multirow{6}{*}{$\begin{array}{r}\text { Misión } \\
\text { Objetivos } \\
\text { Estrategias } \\
\text { Producto/Servicio } \\
\text { Clientes } \\
\text { Competencia }\end{array}$} & $\mathbf{X}$ & $\mathbf{X}$ & & & & \\
\hline & & & $\mathbf{X}$ & $\mathbf{X}$ & & & \\
\hline & & & $\mathbf{X}$ & $\mathbf{X}$ & & & \\
\hline & & $\mathbf{X}$ & & & $\mathbf{X}$ & $\mathbf{X}$ & \\
\hline & & $\mathbf{X}$ & & & & $\mathbf{X}$ & \\
\hline & & $\mathbf{X}$ & & & & & \\
\hline \multicolumn{2}{|r|}{ Glosario de Términos } & $\mathbf{X}$ & & $\mathbf{X}$ & & & $\mathbf{X}$ \\
\hline \multicolumn{2}{|r|}{ Organigrama } & & & & $\mathbf{X}$ & $\mathbf{X}$ & \\
\hline \multicolumn{2}{|r|}{$S R D$} & & $\mathbf{X}$ & & & & $\mathbf{X}$ \\
\hline \multicolumn{2}{|r|}{ Análisis FODA } & & & $\mathbf{X}$ & & & \\
\hline \multicolumn{2}{|r|}{ Análisis de los FCE } & & & $\mathbf{X}$ & & & \\
\hline \multicolumn{2}{|r|}{ Análisis de Riesgos } & & & $\mathbf{X}$ & & & \\
\hline \multicolumn{2}{|r|}{ Requerimientos } & & $\mathbf{X}$ & $\mathbf{X}$ & & & $\mathbf{X}$ \\
\hline \multicolumn{2}{|r|}{ Expectativas } & & $\mathbf{X}$ & $\mathbf{X}$ & & & \\
\hline \multicolumn{2}{|r|}{ Restricciones } & & $\mathbf{X}$ & $\mathbf{X}$ & & & \\
\hline \multicolumn{2}{|c|}{ Recursos Humanos } & & $\mathbf{X}$ & $\mathbf{X}$ & & & \\
\hline \multicolumn{2}{|c|}{ Fuentes de Información } & & & & $\mathbf{X}$ & & \\
\hline
\end{tabular}

\section{A. Identificación del Problema de Investigación}

Como se mencionó en la sección anterior, las metodologías de desarrollo de sistemas de información hacen referencia a un tipo especial de conocimiento denominado "Entendimiento del Negocio". Si bien en algunas de ellas se explica dicho conocimiento, ninguna describe con precisión qué información debe ser relevada para lograr la comprensión del negocio ni tampoco qué técnicas pueden ser utilizadas para llevar a cabo el tratamiento de dicho conocimiento $[9 ; 8]$.

Asimismo, se sostiene que todas las metodologías de desarrollo de proyectos de software dan por asegurado el conocimiento que se tiene del negocio; sin embargo, no proveen al responsable del proyecto y a otros miembros del equipo de una etapa o fase que facilite la comprensión del entorno en el que va a llevar a cabo su trabajo $[9 ; 8]$.

Cualquier proyecto de software puede fracasar como consecuencia de una comprensión incorrecta del negocio. Por tal motivo, el entendimiento adecuado del mismo ayuda a definir el tipo de solución a desarrollar y condiciona el proyecto en cuestión. Asimismo, se informa que actualmente no se dedica tiempo para comprender la organización en la cual se va a llevar a cabo el proyecto de software; por el contrario, el conocimiento del dominio del negocio se va adquiriendo a medida que avanza el proyecto respectivo y se interactúa con la organización. Muchas iteraciones y ciertos costos asociados se podrían evitar si se pudiera obtener desde el inicio del proyecto y de manera metódica la información del dominio del problema en cuestión. Por tanto, la comprensión del negocio constituye el punto de partida para lograr una correcta organización del proyecto que permita su propia gestión [22].

De acuerdo con [50], la gestión de un proyecto de software se inicia a partir de una serie de actividades que se denominan planificación del proyecto. Antes del comienzo de un proyecto, se debe realizar una estimación: del trabajo a realizar, de los recursos necesarios y del tiempo que transcurrirá desde el inicio hasta el final de su realización [51].
Disponer de la información adecuada permite realizar estimaciones válidas y es fundamental para garantizar la correcta toma de decisiones. El responsable del proyecto debe prescindir de toda aquella información errónea u obsoleta, que impida alcanzar el entendimiento del negocio; un relevamiento de información de tales características podría provocar ciertos inconvenientes durante el desarrollo del proyecto e incluso dificultar el logro de los objetivos trazados al comienzo del mismo.

Asimismo, se debe evitar la realización de actividades innecesarias, seleccionando aquellas que permitan cubrir las necesidades y prioridades del proyecto. La selección errónea de segmentos de una metodología estándar podría provocar algunos inconvenientes durante el desarrollo del proyecto e incluso dificultar el cumplimiento efectivo de los objetivos propuestos en el mismo. Una selección acertada de los segmentos genera confianza en el equipo de proyecto para el uso de la metodología. La elección y realización de actividades que no se ajustan a las características específicas de un proyecto, pueden ocasionar una serie de trastornos durante el ejercicio del mismo [23]. En tal sentido, se puede afirmar que es fundamental la selección adecuada de actividades para lograr una adecuada comprensión del negocio.

El problema abierto que se identifica en la presente sección, consiste en la necesidad de estructurar y categorizar la masa de información que debe ser relevada para alcanzar el entendimiento del negocio para proyectos de Explotación de Información. Asimismo, se pone de manifiesto la necesidad de definir todas las fases, tareas y productos involucrados en el proceso de educción del entendimiento del negocio para obtener desde el comienzo del proyecto, de manera sistemática, la información del dominio del problema en forma organizada y coordinada. Consecuentemente, resulta necesario abordar el tratamiento del conjunto de técnicas que se utilizan para extraer o capturar el conocimiento del negocio a partir de la correcta definición de fases, tareas y productos correspondientes al proceso de respectivo.

En el presente trabajo se propone la construcción de un modelo de proceso de conceptualización del entendimiento del negocio para proyectos de Explotación de Información que posea bien diferenciadas sus fases, tareas y productos, tomando como base la protofase metodológica desarrollada en [8], y definiendo las técnicas adecuadas para el tratamiento de la información pertinente

\section{B. Preguntas de Investigación}

Teniendo en cuenta el problema planteado en la sección anterior surgen los siguientes interrogantes que se intentan responder a lo largo del desarrollo de este trabajo de investigación:

- ¿Es posible construir un modelo de proceso de conceptualización para proyectos de Explotación de Información que posea bien diferenciadas sus fases, tareas y productos para alcanzar el entendimiento del negocio?

- ¿Pueden ser adecuadas las técnicas de educción del entendimiento del negocio de las metodologías de desarrollo de software mencionadas en este trabajo para ser utilizadas en el modelo de proceso a construir? En caso afirmativo: ¿se deben realizar modificaciones en ellas?

Teniendo en cuenta la problemática descripta en esta sección, y luego de presentar los interrogantes surgidos a partir del abordaje de la misma, en los próximas secciones se 
presenta la propuesta de un modelo de proceso de conceptualización del entendimiento del negocio para proyectos de Explotación de Información que solucione el problema planteado y se lleva a cabo la prueba de concepto sobre la solución propuesta.

\section{SOLUCIÓN}

En esta sección, se desarrolla la solución planteada para la problemática descripta en la sección anterior. En primer lugar, se describe la propuesta (sección IV.A), y luego se lleva a cabo la descripción de la solución planteada basada en la propuesta enunciada (sección IV.B).

\section{A. Propuesta}

Se propone como solución a los problemas mencionados y descriptos en la sección anterior, la construcción de un modelo de proceso de conceptualización del entendimiento del negocio, que contemple todos aquellos elementos necesarios para lograr una adecuada comprensión del mismo, y que sirva, y pueda ser utilizado para los distintos proyectos de Explotación de Información llevados a cabo por diferentes tipos de organizaciones empresariales u otras entidades.

Para la construcción del modelo de proceso respectivo, se prevé utilizar como base la protofase presentada en [8], que articula un conjunto de técnicas y herramientas asociadas para lograr la comprensión del negocio.

\section{B. Solución Basada en la Propuesta}

Teniendo en cuenta la problemática descripta en la sección anterior, se lleva a cabo la presentación del nuevo modelo de proceso para alcanzar la comprensión del negocio (sección IV.B.1), estructurada en dos partes: en primer término, se describe la estructura general del proceso de conceptualización del entendimiento del negocio y su modo de funcionamiento (sección IV.B.1.a); y en segundo término, se analizan las fases, tareas y productos que conforman el soporte del proceso respectivo (sección IV.B.1.b). Posteriormente, se propone un conjunto de técnicas necesarias para implementar las correspondientes tareas que conforman el modelo de proceso para lograr una adecuada comprensión del negocio a partir del trabajo realizado en [8] (sección IV.B.2). En primer lugar, se presentan las técnicas empleadas en la fase "Conceptual/Exploratoria" del presente modelo (sección IV.B.2.a), a saber: técnica de "Descripción de la Idea $u$ Oportunidad de Negocio" (sección IV.B.2.a.i); técnica de "Descripción de la Plataforma Estratégica y Valores de la Organización" (sección IV.B.2.a.ii) y técnica de "Descripción del Escenario Real de Negocio y Glosario de Términos" (sección IV.B.2.a.iii). En segundo lugar, se presentan las técnicas utilizadas en la fase de "Análisis y Evaluación" (sección IV.B.2.b), tales como son: la técnica de "Análisis de Riesgos" (sección IV.B.2.b.i); la técnica de "Análisis de los Factores Críticos de Éxito”" (sección IV.B.2.b.ii); la técnica de "Análisis FODA" (sección IV.B.2.b.iii) y la técnica de "Análisis de Beneficios" (sección IV.B.2.b.iv). En tercer y último lugar, se presentan las técnicas aplicadas en la fase de "Planeación Operativa" (sección IV.B.2.c), a saber: técnica de "Descripción de Estrategias" (sección IV.B.2.c.i); técnica de "Análisis de Recursos Humanos" (sección IV.B.2.c.ii); técnica de "Análisis de Fuentes de Información” (sección IV.B.2.c.iii); técnica de "Análisis de Requerimientos" (sección IV.B.2.c.iv); técnica de "Análisis de Restricciones" (sección IV.B.2.c.v) y técnica de "Construcción del Mapa Integrador del Negocio" (sección IV.B.2.c.vi).

\section{1) Modelo de Proceso Propuesto}

En base a lo expuesto anteriormente, se ha tomado como base para la construcción del modelo de proceso de conceptualización del entendimiento del negocio la protofase desarrollada en [8], que presenta un conjunto de técnicas y herramientas asociadas para alcanzar la comprensión del negocio, y que puede ser incorporada en cualquier metodología utilizada para el desarrollo de software.

La solución presentada en el trabajo citado en el párrafo anterior, incluye una combinación de técnicas y herramientas que permiten llevar a cabo el modelado de la comprensión estática del negocio; la evaluación de los objetivos propios del negocio; los medios, las expectativas y las restricciones para lograr los objetivos establecidos; y las meta técnicas sugeridas para cada una de las técnicas a utilizar. Teniendo en cuenta el diseño, la arquitectura y los elementos componentes de dicha solución, se definió la estructura del nuevo modelo de proceso de conceptualización del entendimiento del negocio.

a) Estructura Organizativa General del Proceso de Conceptualización del Entendimiento del Negocio

La estructura organizativa general del nuevo modelo de proceso de conceptualización del entendimiento del negocio posee tres fases componentes, a saber:

\section{Fase I $\rightarrow$ “Conceptual/Exploratoria”}

Una primera fase, denominada "Conceptual/Exploratoria", cuyo objetivo principal consiste en conocer los componentes centrales del negocio, tomando como punto de partida el origen o motivaciones para el desarrollo de la idea u oportunidad del mismo, estableciendo su plataforma estratégica y los valores de la organización, y describiendo el escenario actual y posible de negocio, junto con la construcción del glosario de términos respectivo.

\section{Fase II $\rightarrow$ de “Análisis y Evaluación”}

Una segunda fase, llamada de “Análisis y Evaluación”, cuyo objetivo primordial se focaliza en analizar la situación actual del negocio y evaluar los objetivos del negocio propiamente dichos.

\section{Fase III $\rightarrow$ de "Planeación Operativa"}

Una tercera y última fase, nombrada de "Planeación Operativa", que tiene como objetivo fundamental definir las estrategias a implementar, describir los medios necesarios (entre ellos los recursos humanos y las fuentes de información), las limitaciones y los requerimientos necesarios para el cumplimiento de los objetivos que se intentan alcanzar. Asimismo, en esta fase, se pretende resumir toda la información obtenida durante las diferentes etapas del proceso global a partir de la construcción del mapa integrador del negocio.

Este nuevo modelo de proceso de conceptualización del entendimiento del negocio, que engloba un conjunto de fases, tareas y productos, se desarrolla a partir del planteamiento de un "Problema, Necesidad o Deseo", que constituye el producto de entrada inicial, y proporciona como producto de salida final: el "Mapa Integrador del Negocio". Este proceso se ilustra en la figura 10 que se visualiza a continuación:

El modelo de proceso de conceptualización del entendimiento del negocio propuesto posee tres fases en su estructura organizativa, y todas ellas comprenden un conjunto de tareas y productos asociados a las mismas. Cada producto puede actuar como elemento de entrada de una o más tareas; y al mismo tiempo, puede constituir el elemento de salida de una determinada tarea. 
En la figura 11, se observa la dinámica del proceso en función de la interdependencia conceptual existente entre las fases, tareas y productos definidos. Esta terminología fue utilizada en el trabajo presentado en [52]. A su vez, se visualiza la interacción que existe entre las diferentes tareas del proceso y los productos necesarios para la realización de las mismas, los cuales se procesan para proporcionar los correspondientes productos de salida.

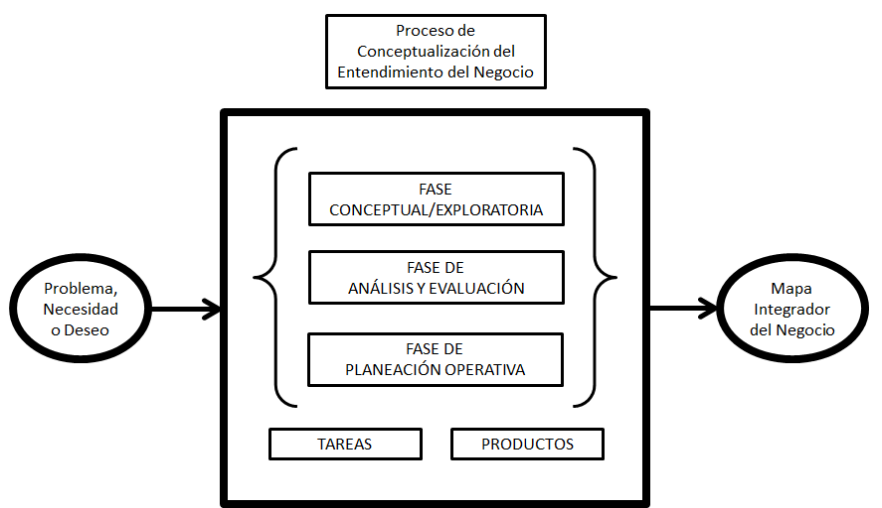

Fig. 10. Estructura organizativa general del proceso de conceptualización del entendimiento del negocio con sus fases y elementos de entrada y salida.

Siguiendo con el análisis de la figura 11, se observa la conformación funcional y estructural del modelo de proceso de conceptualización del entendimiento del negocio. En primer lugar, se lleva a cabo la realización de la fase "Conceptual/Exploratoria", que requiere el cumplimiento de tres tareas básicas que se relacionan entre sí en base a sus productos. A partir de un "Problema, Necesidad o Deseo", que constituye el producto de entrada de la primera tarea, y a su vez, el punto de partida del proceso general, se realiza la tarea de "Desarrollo de la Idea u Oportunidad de Negocio", y se obtiene como producto de salida la "Idea u Oportunidad de Negocio". Por tanto, la "Idea u Oportunidad de Negocio", constituye el producto de entrada para la realización de la tarea subsiguiente de "Formulación de la Plataforma Estratégica y Valores de la Organización”, la cual proporciona como productos de salida: la "Misión", la "Visión”, los "Objetivos" y los "Valores" propios de la organización. Estos tres primeros elementos mencionados constituyen la denominada "Plataforma Estratégica" [53]. Finalmente, con la "Misión", la "Visión", los "Objetivos" y los "Valores", como productos de entrada, se lleva a cabo la ejecución de la última tarea de dicha fase, llamada "Construcción del Escenario Existente de Negocio y Glosario de Términos", a partir de la cual se obtienen como productos de salida el llamado "Escenario Real de Negocio", que está constituido por diferentes elementos componentes, a saber: el "Sector", la "Actividad", los "Productos/Servicios", la "Cartera de Clientes", el "Mercado Relevante”, la "Estructura Organizacional (Organigrama)” y la "Definición de Requisitos Estructurados (SRD)"; y el "Glosario de Términos", también propios del negocio.

En segundo lugar, se inicia el desarrollo de la fase de “Análisis y Evaluación”, que está compuesta únicamente por una sola tarea en su estructura organizativa, denominada "Análisis del Escenario Real y Evaluación de los Objetivos de Negocio", la cual utiliza como entrada a los productos de salida obtenidos a partir de la realización de la última tarea de la fase inicial de dicho proceso, es decir, el "Escenario Real de

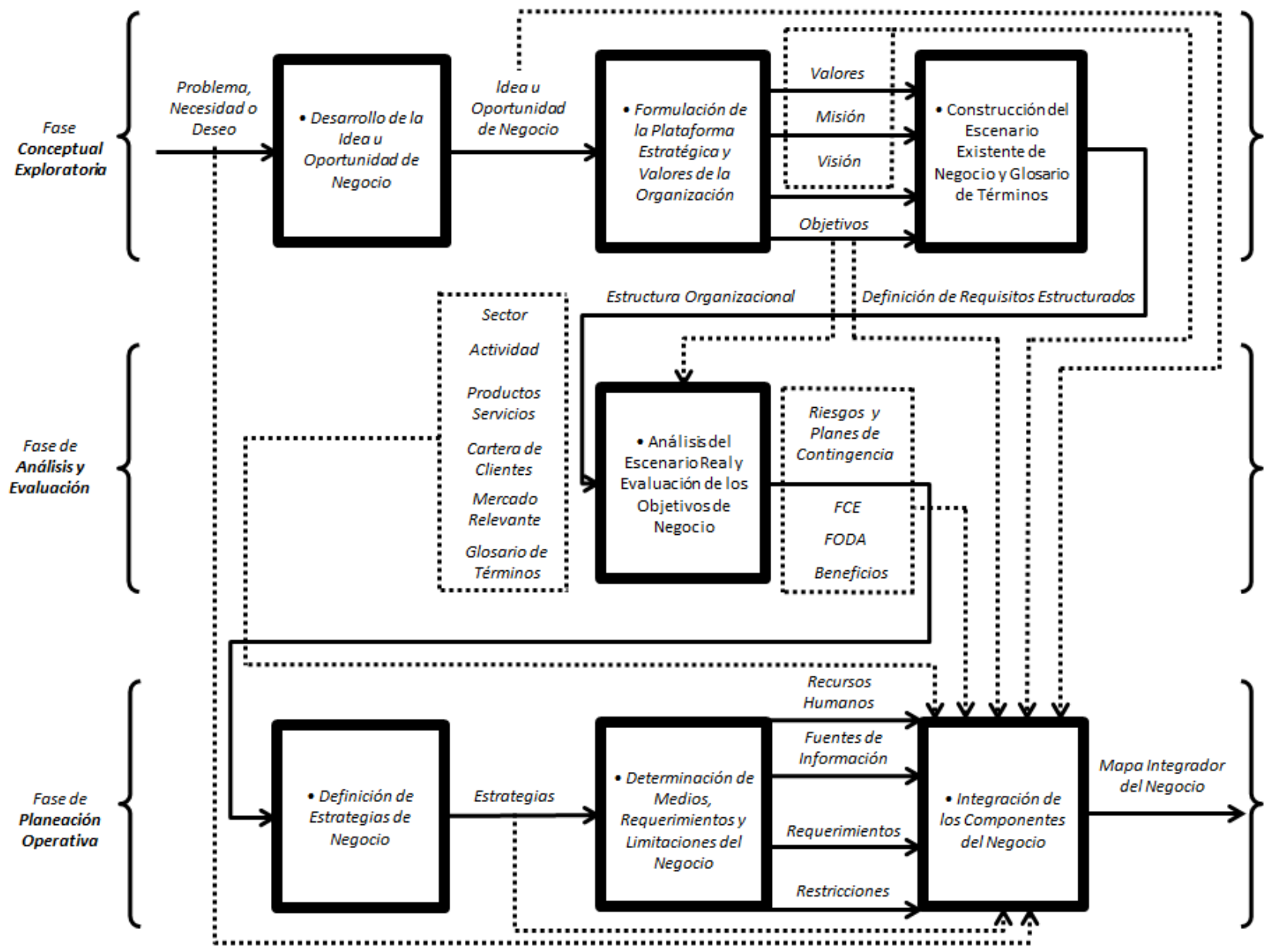

Fig. 11. Dinámica del proceso en función de la interdependencia conceptual entre las fases, tareas y productos. 
Negocio y Glosario de Términos", conjuntamente con los "Objetivos" establecidos, los cuales se procesan en el desarrollo de esta tarea, y se obtienen los respectivos productos de salida, a saber: los "Riesgos y Planes de Contingencia", los "Factores Críticos de Éxito (FCE)", las "Fortalezas", las "Oportunidades", las "Debilidades", las "Amenazas (FODA)", y los "Beneficios" que conlleva el cumplimiento efectivo de los objetivos trazados.

Por último, se lleva a cabo la realización de la tercera fase de "Planeación Operativa", que está compuesta por tres tareas principales, donde la primera tarea que se realiza es la de "Definición de Estrategias de Negocio", la cual necesita como entrada a aquellos productos obtenidos en la fase previamente descripta, es decir: los "Riesgos y Planes de Contingencia", los "Factores Críticos de Exito", las "Fortalezas", las "Oportunidades", las "Debilidades", las “Amenazas" y los "Beneficios". A partir del procesamiento de estos productos de entrada, se obtienen como productos de salida las "Estrategias" a implementar, las cuales a su vez, constituyen los productos de entrada para la realización de la próxima tarea de "Determinación de Medios, Requerimientos y Limitaciones del Negocio", la cual proporciona como productos de salida: los “Recursos Humanos", las "Fuentes de Información”, los "Requerimientos" y las "Restricciones" del negocio. Finalmente, con casi todos los productos de entrada y/o salida obtenidos hasta el momento en las distintas etapas o fases de este proceso, a saber: el "Problema, Necesidad o Deseo", la "Idea u Oportunidad de Negocio", la "Misión", la "Visión”, los "Objetivos", los "Valores", el "Escenario Real de Negocio", el "Glosario de Términos”, los "Riesgos y Planes de Contingencia”, los "Factores Críticos de Éxito", las "Fortalezas", las "Oportunidades", las "Debilidades", las "Amenazas", los "Beneficios", las "Estrategias", los "Recursos humanos", las "Fuentes de Información”, los "Requerimientos" y las "Restricciones", se lleva a cabo el desarrollo de la última tarea de esta fase, que a su vez constituye la última tarea del proceso general, denominada "Integración de los Componentes del Negocio", a partir de la cual se obtiene como producto de salida el "Mapa Integrador del Negocio”, que sintetiza la información procesada durante la ejecución de las diferentes tareas/fases, y que resulta muy importante y útil para alcanzar el entendimiento general del negocio.

\section{b) Fases, Tareas y Productos}

De acuerdo a lo expuesto en la sección IV.B.1.a, el modelo de procesos de conceptualización del entendimiento del negocio está compuesto en su estructura organizativa por tres fases componentes: la fase "Conceptual/Exploratoria", la fase de "Análisis y Evaluación" y la fase de "Planeación Operativa”. Para la implementación de dichas fases, es necesario llevar a cabo la realización de un conjunto de tareas que requieren de ciertos productos de entrada para su procesamiento, lo cual permite obtener una serie de productos de salida. Este proceso de transformación se realiza mediante la aplicación de un conjunto de técnicas, que permiten la ejecución de todas aquellas tareas definidas en el nuevo modelo de proceso; algunas de ellas presentadas en [8], readaptándolas en ciertos casos al proceso en cuestión, y otras formuladas exclusivamente en el desarrollo de este trabajo.

En el caso de la primera fase "Conceptual/Exploratoria", se emplean diferentes técnicas de transformación, a saber: para la implementación de la tarea de "Desarrollo de la Idea u
Oportunidad de Negocio", se aplica la técnica de "Descripción de la Idea u Oportunidad de Negocio"; luego, para la realización de la tarea de "Formulación de la Plataforma Estratégica y Valores de la Organización”, se emplea la técnica de "Descripción de la Plataforma Estratégica y Valores de la Organización”; y por último, para la ejecución de la última tarea de "Construcción del Escenario Existente de Negocio y Glosario de Términos" se utiliza la técnica de "Descripción del Escenario Real de Negocio y Glosario de Términos".

Para la segunda fase de "Análisis y Evaluación", se requiere la aplicación de un conjunto de técnicas para llevar a cabo únicamente la tarea de "Análisis del Escenario Real y Evaluación de los Objetivos de Negocio”, a saber: la técnica de "Análisis de Riesgos", la técnica de "Análisis de los Factores Críticos de Éxito", la técnica de "Análisis FODA" y la técnica de "Análisis de Beneficios".

Por tanto, la fase de "Planeación Operativa", al igual que las otras fases del proceso descriptas anteriormente, demanda la utilización de varias técnicas, a saber: en primer lugar, para la realización de la tarea de "Definición de Estrategias de Negocio", se aplica la técnica de "Descripción de Estrategias"; en segundo lugar, para la implementación de la tarea de "Determinación de Medios, Requerimientos y Limitaciones del Negocio", se necesitan las técnicas de "Análisis de Recursos Humanos", de "Análisis de Fuentes de Información", de "Análisis de Requerimientos" y de "Análisis de Restricciones"; y en tercer lugar, para la consumación de la última tarea de "Integración de los Componentes del Negocio", se utiliza la técnica de "Construcción del Mapa Integrador del Negocio".

En la tabla VII, se visualizan las relaciones existentes entre las fases, las tareas, los productos de entrada y/o salida y las técnicas respectivas, que permiten alcanzar el entendimiento del negocio:

2) Técnicas del Modelo de Proceso de Conceptualización

En base a lo expuesto anteriormente, y partiendo de la protofase desarrollada en [8], se definió un nuevo modelo de proceso de conceptualización del entendimiento del negocio; el mismo involucra una combinación de técnicas para implementar las correspondientes tareas del proceso respectivo. En consecuencia, en esta sección se presentan las técnicas que pueden ser aplicadas para llevar a cabo las tareas definidas en cada una de las fases componentes del presente modelo.

a) Técnicas de la Fase Conceptual/Exploratoria

En esta sección, se aborda el estudio descriptivo de las técnicas que se utilizan en la fase "Conceptual/Exploratoria", a saber:

- Técnica de "Descripción de la Idea u Oportunidad de Negocio” (sección IV.B.2.a.i).

- Técnica de "Descripción de la Plataforma Estratégica y Valores de la Organización” (sección IV.B.2.a.ii).

- Técnica de "Descripción del Escenario Real de Negocio y Glosario de Términos" (sección IV.B.2.a.iii).

b) Técnica de Descripción de la Idea u Oportunidad de Negocio

Descripción de la Idea u Oportunidad de Negocio se lleva a cabo la realización de la tarea de "Desarrollo de la Idea u Oportunidad de Negocio", en la primera fase del proceso para alcanzar el entendimiento del negocio. 
TABLA VII. FASES, TAREAS, PRODUCTOS DE ENTRADA Y/O SALIDA Y TÉCNICAS PARA ALCANZAR EL ENTENDIMIENTO DEL NEGOCIO.

\begin{tabular}{|c|c|c|c|c|c|c|}
\hline \multirow{2}{*}{ FASE } & \multirow{2}{*}{ TAREA } & \multicolumn{2}{|c|}{ PRODUCTOS DE ENTRADA } & \multirow{2}{*}{$\begin{array}{l}\text { TÉCNICA A } \\
\text { UTILIZAR }\end{array}$} & \multicolumn{2}{|c|}{ PRODUCTOS DE SALIDA } \\
\hline & & ENTRADA & $\begin{array}{l}\text { REPRESENTA } \\
\text { CIÓN }\end{array}$ & & SALIDA & $\begin{array}{l}\text { REPRESEN- } \\
\text { TACIÓN }\end{array}$ \\
\hline \multirow[b]{3}{*}{$\begin{array}{c}\text { Fase } \\
\text { Conceptual } \\
\text { Exploratoria }\end{array}$} & $\begin{array}{l}\text { Desarrollo de la } \\
\text { Idea u } \\
\text { Oportunidad de } \\
\text { Negocio } \\
\end{array}$ & $\begin{array}{l}\text { Problema, Necesidad } \\
\text { o Deseo }\end{array}$ & Tabla de Texto & $\begin{array}{l}\text { Técnica de } \\
\text { Descripción de la } \\
\text { Idea u Oportunidad } \\
\text { de Negocio }\end{array}$ & $\begin{array}{l}\text { Idea u } \\
\text { Oportunidad de Negocio }\end{array}$ & Tabla de Texto \\
\hline & $\begin{array}{l}\text { Formulación de } \\
\text { la Plataforma } \\
\text { Estratégica y } \\
\text { Valores de la } \\
\text { Organización }\end{array}$ & $\begin{array}{l}\text { Idea u } \\
\text { Oportunidad de } \\
\text { Negocio }\end{array}$ & Tabla de Texto & $\begin{array}{l}\text { Técnica de } \\
\text { Descripción de la } \\
\text { Plataforma } \\
\text { Estratégica y } \\
\text { Valores de la } \\
\text { Organización }\end{array}$ & $\begin{array}{l}\text { Plataforma Estratégica: } \\
\text { - Misión } \\
\text { - Visión } \\
\text { - Objetivos } \\
\text { Valores de la } \\
\text { Organización }\end{array}$ & Tabla de Texto \\
\hline & $\begin{array}{l}\text { Construcción } \\
\text { del Escenario } \\
\text { Existente de } \\
\text { Negocio y } \\
\text { Glosario de } \\
\text { Términos }\end{array}$ & $\begin{array}{l}\text { Plataforma } \\
\text { Estratégica: } \\
\text { - Misión } \\
\text { - Visión } \\
\text { - Objetivos } \\
\text { Valores de la } \\
\text { Organización }\end{array}$ & Tabla de Texto & $\begin{array}{l}\text { Técnica de } \\
\text { Descripción del } \\
\text { Escenario Real de } \\
\text { Negocio y Glosario } \\
\text { de Términos }\end{array}$ & $\begin{array}{l}\text { Escenario Real de } \\
\text { Negocio: } \\
\text { - Sector } \\
\text { - Actividad } \\
\text { - Productos y/o Servicios } \\
\text { - Cartera de Clientes } \\
\text { - Mercado Relevante } \\
\text { - Estructura } \\
\text { Organizacional (1) } \\
\text { - Definición de } \\
\text { Requisitos Estructurados } \\
\text { (2) } \\
\text { Glosario de Términos } \\
\end{array}$ & $\begin{array}{l}\text { Texto Plano } \\
\text { Organigrama } \\
\text { Diagrama de } \\
\text { Flujos }\end{array}$ \\
\hline $\begin{array}{c}\text { Fase de } \\
\text { Análisis y } \\
\text { Evaluación }\end{array}$ & $\begin{array}{l}\text { Análisis del } \\
\text { Escenario Real } \\
\text { y Evaluación de } \\
\text { los Objetivos de } \\
\text { Negocio }\end{array}$ & $\begin{array}{l}\text { Escenario Real de } \\
\text { Negocio: } \\
\text { - Sector } \\
\text { - Actividad } \\
\text { - Productos y/o } \\
\text { Servicios } \\
\text { - Cartera de Clientes } \\
\text { - Mercado Relevante } \\
\text { - Estructura } \\
\text { Organizacional } \\
\text { - Definición de } \\
\text { Requisitos } \\
\text { Estructurados } \\
\text { Glosario de Términos } \\
\text { Objetivos }\end{array}$ & $\begin{array}{l}\text { Texto Plano } \\
\text { Organigrama } \\
\text { Diagrama de } \\
\text { Flujos }\end{array}$ & $\begin{array}{l}\text { Técnica de Análisis } \\
\text { de Riesgos } \\
\text { Técnica de Análisis } \\
\text { de los Factores } \\
\text { Críticos de Éxito } \\
\text { Técnica de Análisis } \\
\text { FODA } \\
\text { Técnica de Análisis } \\
\text { de Beneficios }\end{array}$ & $\begin{array}{l}\text { Riesgos y Planes de } \\
\text { Contingencia } \\
\text { Factores Críticos de } \\
\text { Éxito } \\
\text { Fortalezas, } \\
\text { Oportunidades, } \\
\text { Debilidades y Amenazas } \\
\text { Beneficios }\end{array}$ & Tabla de Texto \\
\hline \multirow{3}{*}{$\begin{array}{c}\text { Fase de } \\
\text { Planeación } \\
\text { Operativa }\end{array}$} & $\begin{array}{l}\text { Definición de } \\
\text { Estrategias de } \\
\text { Negocio }\end{array}$ & $\begin{array}{l}\text { Riesgos y Planes de } \\
\text { Contingencia } \\
\text { Factores Críticos de } \\
\text { Éxito } \\
\text { Fortalezas, } \\
\text { Oportunidades, } \\
\text { Debilidades y } \\
\text { Amenazas } \\
\text { Beneficios }\end{array}$ & Tabla de Texto & $\begin{array}{l}\text { Técnica de } \\
\text { Descripción de } \\
\text { Estrategias }\end{array}$ & Estrategias & Tabla de Texto \\
\hline & $\begin{array}{l}\text { Determinación } \\
\text { de Medios, } \\
\text { Requerimientos } \\
\text { y Limitaciones } \\
\text { del Negocio }\end{array}$ & Estrategias & Tabla de Texto & $\begin{array}{l}\text { Técnica de Análisis } \\
\text { de Recursos } \\
\text { Humanos } \\
\text { Técnica de Análisis } \\
\text { de Fuentes de } \\
\text { Información } \\
\text { Técnica de Análisis } \\
\text { de Requerimientos } \\
\text { Técnica de Análisis } \\
\text { de Restricciones }\end{array}$ & $\begin{array}{l}\text { Recursos Humanos } \\
\text { Fuentes de Información } \\
\text { Requerimientos } \\
\text { Restricciones }\end{array}$ & Tabla de Texto \\
\hline & $\begin{array}{l}\text { Integración de } \\
\text { los } \\
\text { Componentes } \\
\text { del Negocio } \\
\end{array}$ & $\begin{array}{l}\text { Todos los productos } \\
\text { de entrada y/o salida } \\
\text { descriptos, con } \\
\text { excepción de (1) y (2) }\end{array}$ & Tabla de Texto & $\begin{array}{l}\text { Técnica de } \\
\text { Construcción del } \\
\text { Mapa Integrador } \\
\text { del Negocio } \\
\end{array}$ & $\begin{array}{l}\text { Mapa Integrador del } \\
\text { Negocio }\end{array}$ & Mapa \\
\hline
\end{tabular}


Para la aplicación de dicha técnica, se requiere el cumplimiento de dos pasos mandatorios: en primera instancia, se realiza un análisis del "Problema, Necesidad o Deseo" (producto de entrada); y luego, teniendo en cuenta la información procesada en el paso anterior, se describe la "Idea u Oportunidad de Negocio" (producto de salida).

TABLA VIII. TÉCNICA DE DESCRIPCIÓN DE LA IDEA U OPORTUNIDAD DE NEGOCIO.

Técnica de Descripción de la Idea u Oportunidad de Negocio

Entrada: "Problema, Necesidad o Deseo".

Salida: "Idea u Oportunidad de Negocio".

Paso 1. Análisis del "Problema, Necesidad o Deseo”.

Paso 2. Descripción de la "Idea u Oportunidad de Negocio".

i. Técnica de Descripción de la Plataforma Estratégica y Valores de la Organización

Por medio de la implementación de esta técnica, llamada Descripción de la Plataforma Estratégica y Valores de la Organización se lleva a cabo la realización de la tarea de "Formulación de la Plataforma Estratégica y Valores de la Organización”, en la primera fase del proceso para lograr la comprensión del negocio. Para la aplicación de dicha técnica, se requiere la ejecución de dos pasos obligatorios: en primer lugar, se efectúa un análisis de la "Idea u Oportunidad de Negocio" (producto de entrada); y luego, en base a la información procesada en el paso previo, se describen la "Plataforma Estratégica y Valores de la Organización" (productos de salida).

TABLA IX. TÉCNICA DE DESCRIPCIÓN DE LA PLATAFORMA ESTRATÉGICA Y VALORES DE LA ORGANIZACIÓN.

Técnica de Descripción de la Plataforma Estratégica y Valores de la Organización

Entrada: "Idea u Oportunidad de Negocio".

Salida: "Plataforma Estratégica y Valores de la Organización".

Paso 1. Análisis de la "Idea u Oportunidad de Negocio".

Paso 2. Descripción de la "Plataforma Estratégica y Valores la Organización”.

ii. Técnica de Descripción del Escenario Real de Negocio y Glosario de Términos

Partiendo de las técnicas que permiten obtener el modelo estática del negocio presentadas en [8], a saber: la descripción del escenario actual: misión, objetivos, estrategias, productos/servicios, clientes, competencia; el glosario de términos del negocio; el organigrama de la organización; la definición de requisitos estructurados y el mapa estático de negocio; se formuló una nueva técnica que incorpora elementos de las mismas, readecuándolos a las necesidades del nuevo proceso, lo cual permite lograr la descripción del escenario actual y posible de negocio y conocer la terminología relacionada con el mismo. Mediante la utilización de esta técnica, denominada Descripción del Escenario Real de Negocio y Glosario de Términos se lleva a cabo la realización de la tarea de "Construcción del Escenario Existente de Negocio y Glosario de Términos", en la primera fase del proceso para conseguir el conocimiento del negocio. Para la aplicación de dicha técnica, se requiere el cumplimiento de tres pasos mandatorios: en primera instancia, se realiza un análisis de la "Plataforma Estratégica y Valores de la Organización" (productos de entrada); luego, teniendo en cuenta la información procesada en el paso anterior, se describe el "Escenario Real de Negocio" (producto de salida), que involucra los siguientes elementos: el "Sector", la "Actividad", los "Productos/Servicios" que se ofrecen al mercado, la "Cartera de Clientes", las características generales y la delimitación del "Mercado Relevante", la "Estructura Organizacional" de la empresa y la "Definición de Requisitos Estructurados"; y finalmente, se construye un "Glosario de Términos" (producto de salida): en primer lugar, se listan los términos más usuales del negocio y luego se definen los mismos.

TABLA X. TÉCNICA DE DESCRIPCIÓN DEL ESCENARIO REAL DE NEGOCIO Y GLOSARIO DE TÉRMINOS.

Técnica de Descripción del Escenario Real de Negocio y Glosario de Términos

Entrada: "Plataforma Estratégica y Valores de la Organización".

Salida: "Escenario Real de Negocio y Glosario de Términos".

Paso 1. Análisis de la "Plataforma Estratégica y Valores de la Organización”.

Paso 2. Descripción del "Escenario Real de Negocio".

Paso 3. Construcción del "Glosario de Términos".

2.1. Listado de los términos más usuales del negocio.

2.2. Definiciones básicas de los conceptos incluidos en el mismo.

\section{c) Técnicas de la Fase de Análisis y Evaluación}

En esta sección, se aborda el estudio descriptivo de las técnicas que se emplean en la fase de "Análisis y Evaluación", a saber:

- Técnica de "Análisis de Riesgos” (sección IV.B.2.b.i).

- Técnica de "Análisis de los Factores Críticos de Exito"

(sección IV.B.2.b.ii).

- Técnica de "Análisis FODA" (sección IV.B.2.b.iii).

- Técnica de "Análisis de Beneficios" (sección IV.B.2.b.iv).

A partir de determinadas técnicas presentadas en [8], que permiten obtener la evaluación de los objetivos de negocio, a saber: el Análisis de Riesgos; el Análisis de los Factores Críticos del Éxito y el Análisis FODA; conjuntamente con el desarrollo e implementación de una nueva técnica adicional denominada Análisis de Beneficios, se lleva a cabo la realización de la tarea de "Análisis del Escenario Real y Evaluación de los Objetivos de Negocio”, en la segunda fase del proceso para alcanzar el entendimiento del negocio. 
$i$. Técnica de Análisis de Riesgos

Para la aplicación de la técnica de Análisis de Riesgos, se requiere el cumplimiento de dos pasos mandatorios: en primer lugar, se realiza un análisis de los "Objetivos" y del "Escenario Real de Negocio y Glosario de Términos" (productos de entrada); y luego, considerando la información procesada en el paso anterior, se procede a realizar un análisis de los "Riesgos" del proyecto: en primera instancia, se identifican los riesgos específicos del proyecto; posteriormente, se describen dichos riesgos; más tarde, se listan los objetivos afectados por los riesgos identificados; y finalmente, se confecciona un "Plan de Contingencia" asociado a cada riesgo (productos de salida).

TABLA XI. TÉCNICA DE ANÁLISIS DE RIESGOS.

\begin{tabular}{|l|}
\hline \multicolumn{1}{|c|}{ Técnica de Análisis de Riesgos } \\
\hline Entrada: "Objetivos"; "Escenario Real de Negocio y Glosario de \\
Sérminos". \\
Salida: "Riesgos y Planes de Contingencia". \\
Paso 1. Análisis de los "Objetivos" y del "Escenario Real de Negocio y \\
Paso 2. Análisis de "Riesgos": \\
2.1. Identificación de los riesgos específicos del proyecto. \\
2.2. Descripción de los riesgos identificados. \\
2.3. Confección de los objetivos afectados por los riesgos \\
encontrados. \\
2.4. Confección del plan de contingencia asociado a cada \\
riego.
\end{tabular}

ii. Técnica de Análisis de los Factores Críticos de Éxito.

Para la aplicación de la técnica de Análisis de los Factores Críticos de Éxito, se requiere el cumplimiento de dos pasos obligatorios: en primer instancia, se realiza un análisis de los "Objetivos" y del "Escenario Real de Negocio y Glosario de Términos" (productos de entrada); y luego, teniendo en cuenta la información procesada en el paso anterior, se procede a efectuar un análisis de los "Factores de Críticos de Éxito" propios del proyecto: en primer lugar, se identifican los factores de críticos de éxito específicos del proyecto; luego, se describen los mismos; posteriormente, se listan los objetivos afectados por los factores identificados; y por último, se enumeran las áreas impactadas por los factores de críticos de éxito definidos (productos de salida).

iii. Técnica de Análisis de Beneficios

Para la aplicación de la técnica de Análisis de Beneficios, se requiere el cumplimiento de dos pasos obligatorios: en primer instancia, se realiza un análisis de los "Objetivos" y del "Escenario Real de Negocio y Glosario de Términos" (productos de entrada); y luego, en base a la información procesada en el paso anterior, se describen los "Beneficios" exclusivos del proyecto (producto de salida).

iv. Técnica de Análisis FODA

Para la aplicación de la técnica de Análisis FODA, se requiere el cumplimiento de dos pasos mandatorios: en primer lugar, se realiza un análisis de los "Objetivos" y del "Escenario Real de Negocio y Glosario de Términos" (productos de entrada); y luego, teniendo en cuenta la información procesada en el paso anterior, se describen las "Fortalezas" y "Debilidades" propias de la organización, así como también las "Oportunidades" y "Amenazas" (productos de salida).

TABLA XII. TÉCNICA DE LOS FACTORES CRÍTICOS DE ÉXITO.

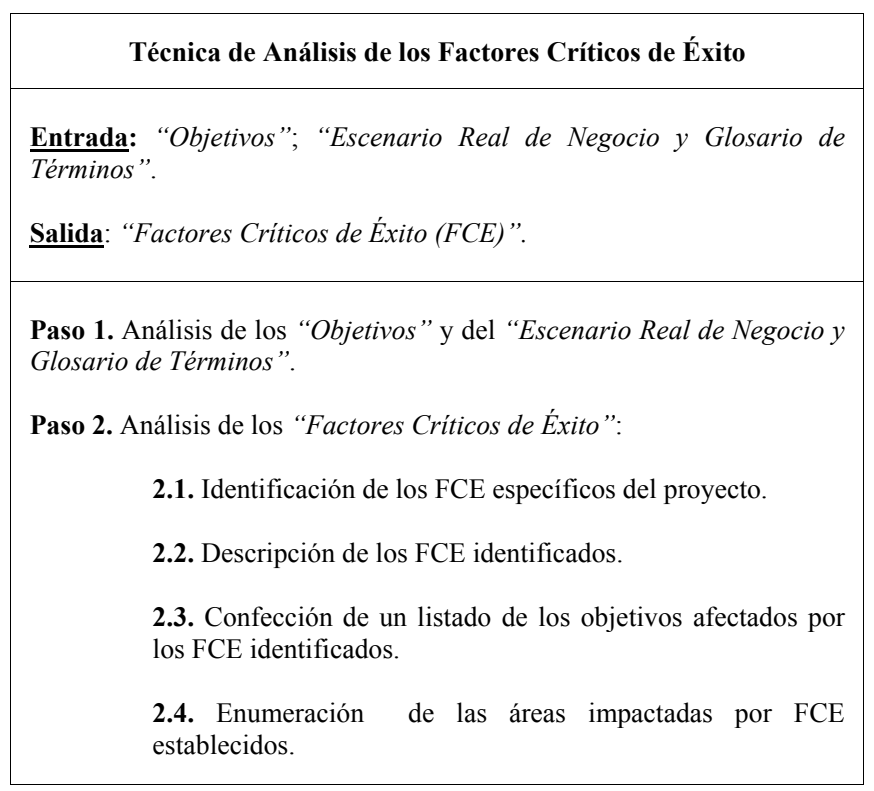

TABLA XIII. TÉCNICA DE ANÁLISIS FODA.

\begin{tabular}{|c|}
\hline Técnica de Análisis FODA \\
\hline $\begin{array}{l}\text { Entrada: "Objetivos"; "Escenario Real de Negocio y Glosario de } \\
\text { Términos". }\end{array}$ \\
\hline Salida: "Fortalezas"; "Oportunidades"; "Debilidades"; "Amenazas". \\
\hline $\begin{array}{l}\text { Paso 1. Análisis de los "Objetivos" y del "Escenario Real de Negocio y } \\
\text { Glosario de Términos". }\end{array}$ \\
\hline $\begin{array}{l}\text { Paso 2. Descripción de las "Fortalezas", las "Oportunidades", las } \\
\text { "Debilidades" y las "Amenazas". }\end{array}$ \\
\hline
\end{tabular}

TABLA XIV. TÉCNICA DE ANÁLISIS DE BENEFICIOS.

\begin{tabular}{|c|}
\hline Técnica de Análisis de Beneficios \\
\hline $\begin{array}{l}\text { Entrada: "Objetivos"; "Escenario Real de Negocio y Glosario de } \\
\text { Sérminos". } \\
\underline{\text { Salida: "Beneficios". }}\end{array}$ \\
\hline $\begin{array}{l}\text { Paso 1. Análisis de los "Objetivos" y del "Escenario Real de Negocio y } \\
\text { Glosario de Términos". } \\
\text { Paso 2. Descripción de "Beneficios". }\end{array}$ \\
\hline
\end{tabular}

\section{c) Técnicas de la Fase de Planeación Operativa}

En esta sección, se realiza el estudio descriptivo de las técnicas que se utilizan en la fase de "Planeación Operativa", a saber:

- Técnica de "Descripción de Estrategias" (sección IV.B.2.c.i).

- Técnica de "Análisis de Recursos Humanos" (sección IV.B.2.c.ii). 
- Técnica de “Análisis de Fuentes de Información” (sección IV.B.2.c.iii).

- Técnica de “Análisis de Requerimientos" (sección

IV.B.2.c.iv)

- Técnica de "Análisis de Restricciones" (sección IV.B.2.c.v).

- Técnica de "Construcción del Mapa Integrador del Negocio” (sección IV.B.2.c.vi).

Partiendo de las técnicas presentadas en [8], a saber: la descripción del escenario actual; los recursos humanos; las fuentes de información para entender el contexto del proyecto; el análisis de los requerimientos; las restricciones que imponen los objetivos del negocio; el mapa estático de la organización, el mapa de condicionamientos de los objetivos y el mapa táctico para alcanzar los objetivos de negocio, y readecuándolas a las características del proceso en cuestión, se especifica el conjunto de técnicas que permiten llevar a cabo la realización de la tareas de "Definición de Estrategias de Negocio", "Determinación de Medios, Requerimientos y Limitaciones del Negocio" e "Integración de los Componentes del Negocio", en la tercer y última fase del proceso para lograr el entendimiento del negocio.

\section{i. Técnica de Descripción de Estrategias}

Mediante la utilización de esta técnica, denominada Descripción de Estrategias se lleva a cabo la realización de la tarea de "Definición de Estrategias de Negocio", en el comienzo de la tercera fase del proceso para alcanzar el entendimiento del negocio. Para la aplicación de dicha técnica, se requiere el cumplimiento de dos pasos mandatorios: en primer lugar, se realiza un análisis de los "Riesgos y Planes de Contingencia", los "Factores Críticos de Éxito", las "Fortalezas", las "Oportunidades", las "Debilidades", las "Amenazas" y los "Beneficios" (productos de entrada); y luego, teniendo en cuenta la información procesada en el paso anterior, se describen las "Estrategias" a implementar para alcanzar los objetivos trazados (productos de salida).

\section{TABLA XV. TÉCNICA DE DESCRIPCIÓN DE ESTRATEGIAS}

\begin{tabular}{|c|}
\hline Técnica de Descripción de Estrategias \\
\hline $\begin{array}{l}\text { Entrada: "Riesgos y Planes de Contingencia"; "Factores Críticos de } \\
\text { Exito"; "Fortalezas", "Oportunidades"; "Debilidades"; "Amenazas"; } \\
\text { "Beneficios". } \\
\text { Salida: "Estrategias". }\end{array}$ \\
\hline $\begin{array}{l}\text { Paso 1. Análisis de "Riesgos y Planes de Contingencia”, "Factores } \\
\text { Críticos de Exito", "Fortalezas", "Oportunidades", "Debilidades", } \\
\text { "Amenazas" " "Beneficios". }\end{array}$ \\
\hline $\begin{array}{l}\text { Paso 2. Descripción de las "Estrategias" a implementar para alcanzar } \\
\text { los objetivos planteados. }\end{array}$ \\
\hline
\end{tabular}

En las secciones IV.B.2.c.ii, IV.B.2.c.iii, IV.B.2.c.iv y IV.B.2.c.v, se describe el conjunto de técnicas utilizadas para llevar a cabo la realización de la tarea de "Determinación de Medios, Requerimientos y Limitaciones del Negocio”, en la tercer y última fase del proceso para lograr el entendimiento del negocio.

ii. Técnica de Análisis de Recursos Humanos

Para la aplicación de la técnica de Análisis de Recursos Humanos, se requiere el cumplimiento de dos pasos mandatorios: en primera instancia, se realiza un análisis de las "Estrategias" a implementar (productos de entrada); y luego, considerando la información procesada en el paso anterior, se describe el perfil de los "Recursos Humanos" a seleccionar: en primer lugar, se define la posición que va a desempeñar el profesional dentro del equipo; posteriormente, se describen las especialidades requeridas; más tarde, se describen las tareas a desempeñar por el profesional seleccionado; y por último, se especifica el tipo de asignación durante su estadía en el proyecto actual en función del tiempo (productos de salida).

TABLA XVI. TÉCNICA DE ANÁLISIS DE RECURSOS HUMANOS.

\begin{tabular}{|l|}
\hline Técnica de Análisis de Recursos Humanos \\
\hline Entrada: "Estrategias". \\
Salida: "Recursos Humanos". \\
Paso 1. Análisis de las "Estrategias" a implementar. \\
Paso 2. Descripción del perfil de los "Recursos Humanos" a \\
seleccionar: \\
2.1. Definición de la posición que va a desempeñar el \\
profesional dentro del equipo. \\
2.2. Descripción de las especialidades requeridas. \\
2.3. Descripción de las tareas a desempeñar por el \\
profesional seleccionado. \\
2.4. Especificación del tipo de asignación durante su estadía \\
en el proyecto actual en función del tiempo (asignación full \\
time, part time u ocasional).
\end{tabular}

iii. Técnica de Análisis de Fuentes de Información

Para la aplicación de la técnica Análisis de Fuentes de Información, se requiere el cumplimiento de dos pasos mandatorios: en primer lugar, se realiza un análisis de las "Estrategias" a implementar (productos de entrada); y luego, teniendo en cuenta la información procesada en el paso previo, se describen las propiedades de las "Fuentes de Información": en primera instancia, se especifica el origen o proveedor de la información; luego, se describen las características específicas de la misma; posteriormente, se define la forma de obtención de la información respectiva; y finalmente, se describe la utilidad de la misma (productos de salida).

iv. Técnica de Análisis de Requerimientos

Para la aplicación de la técnica Análisis de Requerimientos, se requiere el cumplimiento de dos pasos mandatorios: en primera instancia, se realiza un análisis de las "Estrategias" a implementar (productos de entrada); y luego, a partir de la información procesada en el paso anterior, se describen los "Requerimientos" necesarios para alcanzar los objetivos y se clasifican los mismos en función de su prioridad (productos de salida).

v. Técnica de Análisis de Restricciones

Para la aplicación de la técnica de Análisis de Restricciones, se requiere el cumplimiento de dos pasos mandatorios: en primera lugar, se realiza un análisis de las "Estrategias" a implementar (productos de entrada); y luego, teniendo en cuenta la información procesada en el paso previo, se describen las "Restricciones" que imposibilitan lograr los objetivos propuestos y el tratamiento necesario para evitar cada limitación identificada (productos de salida). 
TABLA XVII. TÉCNICA DE ANÁLISIS DE FUENTES DE INFORMACIÓN

Técnica de Análisis de Fuentes de Información
Entrada: "Estrategias".
Salida: "Fuentes de Información".
Paso 1. Análisis de las "Estrategias" a implementar.
Paso 2. Descripción de las propiedades de las "Fuentes de
Información" a utilizar:
2.1. Especificación del origen o proveedor de información.
2.2. Describir las características específicas de la misma.
2.3. Definir la forma de obtención de la información
respectiva (periodicidad con que se consigue o accede a ella).
2.4. Descripción de la utilidad de la misma.

TABLA XVIII. TÉCNICA DE ANÁLISIS DE REQUERIMIENTOS.

\begin{tabular}{|l|}
\hline \multicolumn{1}{|c|}{ Técnica de Análisis de Requerimientos } \\
\hline Entradas: "Estrategias". \\
Salidas: "Requerimientos". \\
\hline $\begin{array}{l}\text { Paso 1. Análisis de las "Estrategias" a implementar. } \\
\text { Paso 2. Descripción de los "Requerimientos" necesarios y clasificación } \\
\text { de los mismos en función de su prioridad. }\end{array}$ \\
\hline
\end{tabular}

\section{vi. Técnica de Construcción del Mapa Integrador del Negocio}

Mediante la utilización de esta técnica, denominada Construcción del Mapa Integrador del Negocio se lleva a cabo la realización de la última la tarea del proceso general para alcanzar el entendimiento del negocio, llamada "Integración de los Componentes del Negocio". Para la aplicación de dicha técnica, se requiere el cumplimiento de dos pasos mandatorios: en primera instancia, se identifican todos los "Productos de Entrada y/o Salida" que van a conformar el nuevo mapa (productos de entrada); y luego, teniendo en cuenta la información procesada en el paso anterior, se integran todos los componentes seleccionados y se diseña el "Mapa Integrador del Negocio" respectivo (producto de salida).

El "Mapa Integrador del Negocio", permite visualizar la información obtenida durante las diferentes fases del proceso de conceptualización del entendimiento del negocio para proyectos de Explotación de Información, de ahí la importancia que involucra el correcto diseño y confección del mismo.

TABLA XIX. TÉCNICA DE ANÁLISIS DE RESTRICCIONES.

\begin{tabular}{|l|}
\hline \multicolumn{1}{|c|}{ Técnica de Análisis de Restricciones } \\
\hline$\underline{\text { Entradas: "Estrategias". }}$ \\
Salidas: "Restricciones".
\end{tabular}

Paso 1. Análisis de las “Estrategias” a implementar.

Paso 2. Descripción de las "Restricciones" que imposibilitan lograr los objetivos propuestos y el tratamiento que se lleva a cabo para evitar cada una de las limitaciones originalmente encontradas.

\section{TABLA XX. TÉCNICA DE CONSTRUCCIÓN DEL MAPA} INTEGRADOR DEL NEGOCIO.

Técnica de Construcción del Mapa Integrador del Negocio

Entradas: "Productos de Entrada y/o Salida".

Salidas: "Mapa Integrador del Negocio".

Paso 1. Identificación de los "Productos de Entrada y/o Salida" del proceso.

Paso 2. Integración de los componentes seleccionados y diseño del "Mapa Integrador del Negocio".

\section{PRUEBA DE CONCEPTO}

En esta sección, se lleva a cabo la prueba de concepto sobre la solución propuesta en la sección anterior. Para ello, se presenta un caso de prueba donde se aplica dicha solución.

\section{A. Caso de Prueba: Empresa de Marroquinería}

En esta sección, se analiza el caso de prueba correspondiente a la implementación de un posible sistema de información basado en la Explotación de Datos para una Empresa de Marroquinería dedicada al diseño, fabricación y comercialización de artículos de cuero para conocer en forma precisa qué clientes tienen una mayor probabilidad de compra de un determinado producto de la propia cartera comercial, y de esta forma poder generar e implementar en un futuro campañas de marketing conforme a las características de dichos grupos (desarrollo de un plan de marketing segmentado), con el consecuente ahorro en inversión publicitaria y aumento de efectividad de las estrategias de comunicación, optimizando la capacidad de ahorro e inversión de la empresa y entregando una mejora en los resultados. En la sección V.A.1, se lleva a cabo la realización de las tareas de la fase "Conceptual/Exploratoria" mediante la aplicación de las técnicas adecuadas; en la sección V.A.2, se ejecuta la tarea de la fase de "Análisis y Evaluación" utilizando el conjunto de técnicas definidas para la realización de la misma; y en última instancia, en la sección V.A.3, se realizan las tareas de la fase de "Planeación Operativa" a partir de la aplicación de las técnicas apropiadas.

1) Realización de las Tareas de la Fase "Conceptual/Exploratoria"

Considerando el caso de prueba propuesto en el párrafo anterior, se realizan las tareas de la fase "Conceptual/Exploratoria" mediante la ejecución de las técnicas correspondientes, a saber:

a) Realización de la Tarea de "Desarrollo de la Idea u Oportunidad de Negocio"

La tarea de "Desarrollo de la Idea u Oportunidad de Negocio" se implementa mediante la aplicación de la técnica de "Descripción de la Idea u Oportunidad de Negocio". Para la realización de este proceso, se identifica un "Problema, Necesidad o Deseo" como producto de entrada, y se obtiene como producto de salida la "Idea u Oportunidad de Negocio". 


\section{Aplicación de la Técnica de "Descripción de la Idea u Oportunidad de Negocio"}

Entrada.

TABLA XXI. DESCRIPCIÓN DE LA NECESIDAD.

\begin{tabular}{|c|c|}
\hline \multicolumn{2}{|c|}{ NECESIDAD } \\
\hline Tipo & Descripción \\
\hline $\begin{array}{l}\text { De carácter netamente económico. } \\
\text { Para satisfacer las necesidades de } \\
\text { este tipo, se precisa realizar una } \\
\text { actividad económica. }\end{array}$ & $\begin{array}{l}\text { Debido a los altos costos de } \\
\text { publicidad, difíciles de trasladar a } \\
\text { los precios de los productos de } \\
\text { cuero que comercializa la } \\
\text { empresa, surge la necesidad de } \\
\text { conocer a los consumidores que } \\
\text { tienen una mayor probabilidad de } \\
\text { compra de un determinado } \\
\text { producto, a los efectos de realizar } \\
\text { futuras campañas de marketing } \\
\text { orientadas y segmentadas a dichos } \\
\text { grupos de clientes, maximizando } \\
\text { la efectividad de las estrategias de } \\
\text { comunicación y la capacidad de } \\
\text { ahorro en inversión publicitaria; } \\
\text { de lo contrario, puede ser elevado } \\
\text { su costo, e inclusive no se podría } \\
\text { llegar a lograr los beneficios } \\
\text { esperados para la empresa. }\end{array}$ \\
\hline
\end{tabular}

Paso 1. Análisis del Problema, Necesidad o Deseo.

En este caso de estudio, se reconoce una "Necesidad" de carácter económico, que se traduce en una "Oportunidad" para desarrollar un proyecto encaminado a suplir esa "Necesidad". Para satisfacer las necesidades de este tipo, se requiere llevar a cabo una actividad económica. La identificación de esta "Necesidad" marca el comienzo de la fase inicial del ciclo de vida del presente proyecto, a partir de la cual se desarrollan las distintas etapas del mismo.

Paso 2. Descripción de la Idea u Oportunidad de Negocio.

A partir de la identificación de una "Necesidad" de carácter económico, se desarrolla una "Idea u Oportunidad de Negocio", la cual constituye la base de donde parte este proyecto empresarial. En tal sentido, se prevé implementar un posible sistema de información basado en la Explotación de Datos, con el propósito de satisfacer la "Necesidad" identificada. Este procedimiento se ilustra en la tabla XXII que se visualiza a continuación:

TABLA XXII. DESCRIPCIÓN DE LA IDEA U OPORTUNIDAD DE NEGOCIO.

\begin{tabular}{|l|}
\multicolumn{1}{|c|}{ IDEA U OPORTUNIDAD DE NEGOCIO } \\
\hline \multicolumn{1}{|c|}{ Descripción } \\
\hline $\begin{array}{l}\text { Conocer en forma precisa qué clientes tienen una mayor probabilidad de } \\
\text { compra de un determinado producto de la propia cartera comercial a } \\
\text { partir de la implementación de un sistema de información basado en la } \\
\text { Explotación de Datos, para optimizar el plan de marketing de la } \\
\text { empresa, y por ende, incrementar la efectividad de las estrategias de } \\
\text { comunicación y la capacidad de ahorro en la inversión a realizar en } \\
\text { dicha área. }\end{array}$ \\
\hline
\end{tabular}

\section{Salida.}

Tabla XXII. Descripción de la Idea u Oportunidad de Negocio.

b) Realización de la Tarea de "Formulación de la Plataforma Estratégica y Valores de la Organización”,
La tarea de "Formulación de la Plataforma Estratégica y Valores de la Organización" se implementa mediante la aplicación de la técnica de "Descripción de la Plataforma Estratégica y Valores de la Organización”. Para la realización de este proceso, se parte del conocimiento que se tiene acerca de la "Idea u Oportunidad de Negocio", que constituye el producto de entrada, y se obtienen como productos de salida la "Plataforma Estratégica y Valores de la Organización".

\section{Aplicación de la Técnica de "Descripción de la Plataforma Estratégica y Valores de la Organización"}

Entrada.

Tabla XXII. Descripción de la Idea u Oportunidad de Negocio.

\section{Paso 1. Análisis de la Idea u Oportunidad de Negocio.}

En el presente caso de estudio, se identifica una "Idea $u$ Oportunidad de Negocio" que constituye la idea fundamental detrás de la iniciativa de negocio; la misma involucra conocer en forma precisa qué clientes tienen una mayor probabilidad de compra de un determinado producto de la propia cartera comercial a partir de la implementación de un sistema de información basado en la Explotación de Datos, para mejorar el plan de marketing de la empresa, y en consecuencia, optimizar la capacidad de ahorro en inversión publicitaria y la efectividad de las estrategias de comunicación y difusión.

Paso 2. Descripción de la Plataforma Estratégica y Valores de la Organización.

A partir del análisis de la "Idea $u$ Oportunidad de Negocio", se describen los elementos constitutivos de la "Plataforma Estratégica", a saber: la "Misión", la "Visión” y los "Objetivos"; junto con los "Valores de la Organización". Este procedimiento se ilustra en la tabla XXIII que se expone a continuación:

TABLA XXIII. DESCRIPCIÓN DE LA PLATAFORMA ESTRATÉGICA Y VALORES DE LA ORGANIZACIÓN.

\begin{tabular}{|c|c|}
\hline \multicolumn{2}{|r|}{ PLATAFORMA ESTRATÉGICA } \\
\hline \multicolumn{2}{|r|}{ Descripción } \\
\hline MISIÓN & $\begin{array}{l}\text { Ofrecer productos de alta calidad y diseños } \\
\text { innovadores a los clientes; combinando lo clásico } \\
\text { con lo moderno y mostrando a las artículos de } \\
\text { cuero como objetos de arte, fruto de un proceso } \\
\text { productivo creativo. }\end{array}$ \\
\hline VISIÓN & $\begin{array}{l}\text { Ser una prestigiosa y exitosa empresa líder en el } \\
\text { diseño, fabricación y comercialización de artículos } \\
\text { de cuero. }\end{array}$ \\
\hline OBJETIVO & $\begin{array}{l}\text { Detectar clientes que tienen una mayor } \\
\text { probabilidad de compra de un determinado } \\
\text { producto de la propia cartera comercial, y poder } \\
\text { generar así futuras campañas de marketing } \\
\text { focalizadas en estos grupos de consumidores } \\
\text { (segmentación del plan de marketing). }\end{array}$ \\
\hline \multicolumn{2}{|r|}{ VALORES DE LA ORGANIZACIÓN } \\
\hline \multicolumn{2}{|r|}{ Descripción } \\
\hline Creatividad & $\begin{array}{l}\text { Confección de diseños exclusivos, innovadores y } \\
\text { únicos. }\end{array}$ \\
\hline Responsabilidad & $\begin{array}{l}\text { Cumplimiento efectivo de los compromisos } \\
\text { adquiridos. }\end{array}$ \\
\hline Excelencia & $\begin{array}{l}\text { Búsqueda de una mejora continua en los procesos } \\
\text { de negocio. }\end{array}$ \\
\hline Calidad & Altos estándares en los productos comercializados. \\
\hline Honestidad & Transparencia en la gestión. \\
\hline Aprendizaje & $\begin{array}{l}\text { De todas las técnicas y procedimientos necesarios } \\
\text { para la gestión y administración adecuada del } \\
\text { negocio. }\end{array}$ \\
\hline
\end{tabular}

Salida. 
Tabla XXIII. Descripción de la Plataforma Estratégica y Valores de la Organización.

c) Realización de la Tarea de "Construcción del Escenario Existente de Negocio y Glosario de Términos"

La tarea de "Construcción del Escenario Existente de Negocio y Glosario de Términos" se implementa mediante la aplicación de la técnica de "Descripción del Escenario Real de Negocio y Glosario de Términos". Para la realización de este proceso, se parte del conocimiento que se tiene acerca de la "Plataforma Estratégica y Valores de la Organización", que constituyen los productos de entrada, y se obtienen como productos de salida el "Escenario Real de Negocio y el Glosario de Términos".

\section{Aplicación de la Técnica de "Descripción del Escenario Real de Negocio y Glosario de Términos"}

\section{Entrada.}

Tabla XXIII. Descripción de la Plataforma Estratégica y Valores de la Organización.

Paso 1. Análisis de la Plataforma Estratégica y Valores de la Organización.

En el correspondiente caso de estudio, se formulan la "Plataforma Estratégica y Valores de la Organización", a partir de los cuales se diseña la estructura organizativa general de la compañía, ya que dicha plataforma se centra en los atributos fundamentales de la organización. En base a las formulaciones incluidas en dicha plataforma y los valores de la empresa, los cuales constituyen los pilares más importantes de cualquier organización, se obtiene un marco de referencia para la conformación estructural y funcional del negocio respectivo.

Paso 2. Descripción del Escenario Real de Negocio.

A partir del análisis de la información definida en la "Plataforma Estratégica y Valores de la Organización", se describen los elementos que constituyen el "Escenario Real de Negocio", a saber: el "Sector", la "Actividad", los "Productos", la "Cartera de Clientes", el "Mercado Relevante", la "Estructura Organizacional (Organigrama)" y la "Definición de Requisitos Estructurados (SRD)". Este procedimiento se ilustra en la tabla XXIV y en las figuras $12 \mathrm{y}$ 13 que se presentan.

\section{Paso 3. Construcción del "Glosario de Términos".}

En este paso, se confecciona un "Glosario", que comprende los términos más usuales del negocio y que es de gran utilidad para las personas que participan del proyecto en cuestión, ya que permite conocer las definiciones básicas de los conceptos incluidos en el mismo. Este procedimiento se ilustra en la tabla XXV que se observa a continuación:

TABLA XXIV. DESCRIPCIÓN DEL ESCENARIO REAL DE NEGOCIO: SECTOR, ACTIVIDAD, PRODUCTOS, CARTERA DE CLIENTES Y MERCADO RELEVANTE.

\begin{tabular}{|c|l|}
\hline \multicolumn{2}{|c|}{ ESCENARIO REAL DE NEGOCIO } \\
\hline \multicolumn{1}{|c|}{ Descripción } \\
\hline Sector & Industria Manufacturera \\
\hline Actividad & $\begin{array}{l}\text { Diseño, fabricación y comercialización de artículos de } \\
\text { cuero. }\end{array}$ \\
\hline
\end{tabular}

\begin{tabular}{|c|c|}
\hline Productos & $\begin{array}{l}\text { - Principal: } \\
\text { Carteras de cuero vacuno de excelente calidad de } \\
\text { materiales y confección. Diversidad de diseños, } \\
\text { materiales, colores y precios. Productos semi- } \\
\text { industriales de costura complementados con trabajos } \\
\text { manuales de trenzado y corte. } \\
\text { - Secundarios: } \\
\text { Zapatos, billeteras y cintos de cuero, sobre los cuales } \\
\text { se emplea el mismo concepto que para la confección } \\
\text { de carteras: productos de calidad tanto en insumos } \\
\text { como en mano de obra, y diversidad de precios, } \\
\text { colores, materiales y diseños. }\end{array}$ \\
\hline $\begin{array}{c}\text { Cartera } \\
\text { de } \\
\text { Clientes }\end{array}$ & $\begin{array}{l}\text { Se distinguen } 3 \text { grandes grupos de clientes: } \\
\text { - Consumidores Finales: } \\
\text { Este grupo está constituido por mujeres jóvenes y } \\
\text { señoras con edades entre los } 15 \text { y los } 65 \text { años, y } \\
\text { concentra el mayor porcentaje de los clientes de la } \\
\text { marca; aproximadamente el } 50 \% \text { son mujeres entre } 25 \\
\text { y } 35 \text { años de edad, un } 25 \% \text { son mayores a } 35 \text { años, y } \\
\text { el } 25 \% \text { restante, son jóvenes menores a } 25 \text { años. } \\
\text { Tienen diferentes gustos y preferencias en lo que } \\
\text { respecta a los diseños, materiales, colores, precios y } \\
\text { otras características inherentes al producto a adquirir. } \\
\text { - Revendedores Intermediarios: } \\
\text { Este grupo está constituido por vendedores } \\
\text { independientes y diversos comercios (pequeños y } \\
\text { medianos), tales como boutiques, tiendas de ropa, } \\
\text { zapaterías, etc. También manifiestan diferentes gustos } \\
\text { y preferencias a la hora de adquirir los productos a } \\
\text { comercializar. } \\
\text { Otros Clientes (No Consumidores Finales; No } \\
\text { Revendedores Intermediarios) } \\
\text { Este grupo abarca personas de ambos sexos y de todas } \\
\text { las edades, como así también pequeñas y medianas } \\
\text { empresas, etc. Generalmente, los artículos son } \\
\text { comprados para obsequiar a otras personas o } \\
\text { entidades (regalos personalizados, obsequios } \\
\text { empresariales, etc.). Al igual que los otros dos grupos } \\
\text { identificados, se interesan en las características y } \\
\text { precios de los productos a adquirir. }\end{array}$ \\
\hline $\begin{array}{l}\text { Mercado } \\
\text { Relevante }\end{array}$ & $\begin{array}{l}\text { El mercado está constituido por numerosos artesanos, } \\
\text { agrupados en pequeños talleres o cooperativas regionales, } \\
\text { que se dedican a la producción de artículos de cuero: } \\
\text { carteras, zapatos, billeteras y cintos; existen también } \\
\text { pequeñas y medianas empresas de producción que se } \\
\text { localizan principalmente en la Ciudad Autónoma de } \\
\text { Buenos Aires y la Provincia de Buenos Aires, y en menor } \\
\text { proporción en las provincias de Santa Fe y Córdoba. El } \\
\text { resto de las provincias representa una pequeña porción de } \\
\text { la totalidad del mercado de comercialización del cuero. El } \\
\text { mercado abarca diferentes sectores de nivel } \\
\text { socioeconómico, siendo muy amplio y variado en cuanto } \\
\text { a la diversidad de la cartera de productos, calidades, } \\
\text { clientes y precios. Existen productos de muy buena } \\
\text { calidad, lo cual permite competir con los productos } \\
\text { importados de primer nivel (en especial, los provenientes } \\
\text { del mercado europeo). También se encuentran artículos } \\
\text { que apuntan a segmentos de clientes con menor poder } \\
\text { adquisitivo (son carteras de cuero de menor calidad - } \\
\text { producción serial, y carteras de cuero y tela). }\end{array}$ \\
\hline
\end{tabular}

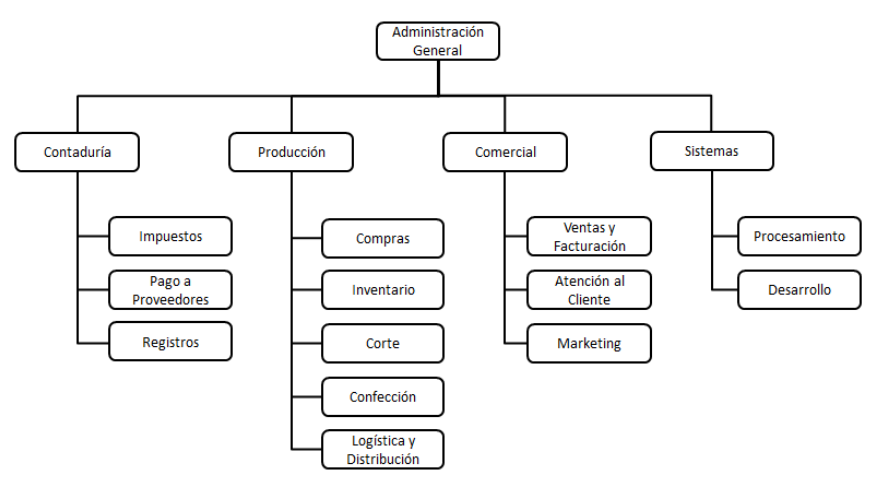

Fig. 12. Descripción del escenario real del negocio: estructura orgánica y formal de la organización. 


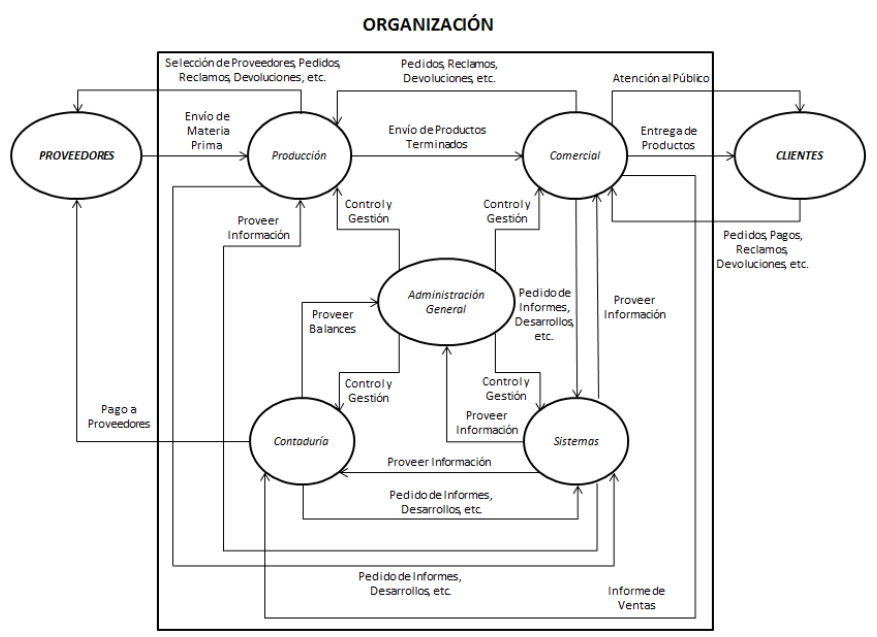

Fig. 13. Descripción del escenario real del negocio: SRD integrado de la organización.

TABLA XXV. GLOSARIO DE TÉRMINOS DEL NEGOCIO.

\begin{tabular}{|l|l|}
\hline \multicolumn{2}{|c|}{ GLOSARIO DE TÉRMINOS DE NEGOCIO } \\
\hline \multicolumn{1}{|c|}{ Término } & \multicolumn{1}{c|}{ Definición } \\
\hline Industria Manufacturera & $\begin{array}{l}\text { Es la actividad económica que transforma } \\
\text { una gran cantidad de materias primas en } \\
\text { diferentes artículos para la distribución y el } \\
\text { consumo. }\end{array}$ \\
\hline Consumidores Finales & $\begin{array}{l}\text { Son las personas que adquieren el producto } \\
\text { y hacen uso del mismo. }\end{array}$ \\
\hline $\begin{array}{l}\text { Revendedores } \\
\text { Intermediarios }\end{array}$ & $\begin{array}{l}\text { Son aquellos que compran los productos } \\
\text { terminados y los revenden a los usuarios } \\
\text { finales con el objetivo de obtener utilidades. }\end{array}$ \\
\hline $\begin{array}{l}\text { Otros Clientes (No } \\
\text { Consumidores Finales; } \\
\text { Intermediarios) }\end{array}$ & $\begin{array}{l}\text { Son aquellos que adquieren los productos } \\
\text { pero que no utilizan ni revenden los } \\
\text { mismos. }\end{array}$ \\
\hline \multirow{2}{\text{AnálisisFODA}}{} & $\begin{array}{l}\text { Es una herramienta que permite conformar } \\
\text { un cuadro de la situación existente de la } \\
\text { empresa u organización. } \\
\text { Fortalezas, Oportunidades, Debilidades y } \\
\text { Amenazas. }\end{array}$ \\
\hline
\end{tabular}

Salida.

Tabla XXIV. Descripción del Escenario Real de Negocio: Sector, Actividad, Productos, Cartera de Clientes y Mercado Relevante.

Tabla XXV. Glosario de Términos del Negocio.

Figura 12. Descripción del Escenario Real de Negocio: estructura orgánica y formal de la organización.

Figura 13. Descripción del Escenario Real de Negocio: SRD integrado de la organización.

2) Realización de la Tarea de la Fase de "Análisis y Evaluación"

Continuando con el estudio del caso de prueba propuesto, se realiza la tarea de la fase de "Análisis y Evaluación" mediante la aplicación de las técnicas correspondientes, a saber:

a) Realización de la Tarea de "Análisis del Escenario Real y Evaluación de los Objetivos de Negocio"

La tarea de "Análisis del Escenario Real y Evaluación de los Objetivos de Negocio" se implementa mediante la aplicación de un conjunto específico de técnicas, a saber: técnica de "Análisis de Riesgos"; técnica de "Análisis de los Factores Críticos de Éxito"; técnica de "Análisis FODA" y técnica de "Análisis de Beneficios". Para la realización de este proceso, se parte del conocimiento que se tiene del "Escenario Real de Negocio y Glosario de Términos" y de los "Objetivos" a alcanzar, que constituyen los productos de entrada, y se obtienen como productos de salida los "Riesgos y Planes de Contingencia”, los "Factores Críticos de Exito (FCE)”, las "Fortalezas", las "Oportunidades", las "Debilidades", las "Amenazas (FODA)" y los "Beneficios".

\section{Aplicación de la Técnica de "Análisis de Riesgos"}

Entrada.

Tabla XXIV. Descripción del Escenario Real de Negocio: Sector, Actividad, Productos, Cartera de Clientes y Mercado Relevante.

Tabla XXV. Glosario de Términos del Negocio.

Figura 12. Descripción del Escenario Real de Negocio: estructura orgánica y formal de la organización.

Figura 13. Descripción del Escenario Real de Negocio: SRD integrado de la organización.

Paso 1. Análisis de los Objetivos y del Escenario Real de Negocio y Glosario de Términos.

En este caso de estudio, se definen los “Objetivos" que se pretenden alcanzar, y luego se evalúan los mismos en función de la información referente al "Escenario Real de Negocio y Glosario de Términos" descripto previamente; los resultados de esta evaluación sirven para obtener información válida y útil sobre aspectos fundamentales asociados al cumplimiento de los objetivos definidos y a la situación actual del negocio, permitiendo establecer un marco de referencia para el desarrollo del proceso en cuestión.

Paso 2. Análisis de Riesgos

En este paso, se identifican los "Riesgos" que podrían afectar el cumplimiento efectivo de los "Objetivos" establecidos. Este procedimiento se ilustra en la tabla XXVI .

Salida.

Tabla XXVI. Análisis de Riesgos y Planes de Contingencia.

\section{Aplicación de la Técnica de "Análisis de los Factores Críticos de Éxito"}

Entrada.

Ídem técnica de "Análisis de Riesgos".

Paso 1. Análisis de los Objetivos y del Escenario Real de Negocio y Glosario de Términos.

Ídem técnica de "Análisis de Riesgos".

Paso 2. Análisis de los Factores Críticos de Éxito.

\section{TABLA XXVI. ANÁLISIS DE RIESGOS Y PLANES DE CONTINGENCIA.}

\begin{tabular}{|c|l|}
\hline \multicolumn{2}{|c|}{ ANÁLISIS DE RIESGOS } \\
\hline $\begin{array}{c}\text { Riesgo } \\
\text { Nrontificado }\end{array}$ & \multicolumn{1}{|c|}{ Ineficiente Gestión Administrativa. } \\
\hline & $\begin{array}{l}\text { Debido a que la empresa está comercializando los } \\
\text { nuevos productos en nuevos mercados y nuevas } \\
\text { regiones geográficas del país, no cuenta con los } \\
\text { conocimientos y la información correspondiente para } \\
\text { producir y comercializar dichos productos, tampoco se } \\
\text { tiene la experiencia comercial necesaria para ingresar } \\
\text { en estos nuevos mercados y en las nuevas provincias. }\end{array}$ \\
$\begin{array}{l}\text { En tal sentido, la gestión administrativa del proyecto } \\
\text { podría verse afectada negativamente como } \\
\text { consecuencia de la aplicación de estas políticas de } \\
\text { diversificación y expansión comercial y geográfica. }\end{array}$ \\
\hline Objetivo \\
Afectado & $\begin{array}{l}\text { Detectar clientes que tienen una mayor probabilidad de } \\
\text { compra de un determinado producto de la propia cartera } \\
\text { comercial, y poder generar así campañas de marketing }\end{array}$ \\
\hline
\end{tabular}




\begin{tabular}{|c|c|}
\hline & $\begin{array}{l}\text { focalizadas en estos grupos de consumidores } \\
\text { (segmentación del plan de marketing). }\end{array}$ \\
\hline $\begin{array}{c}\text { Plan de } \\
\text { Contingenci } \\
\mathbf{a}\end{array}$ & $\begin{array}{l}\text { - Implementar mecanismos eficientes de gestión } \\
\text { administrativa para optimizar la ejecución de las } \\
\text { tareas correspondientes. } \\
\text { - Programar la capacitación del personal para } \\
\text { adquirir los conocimientos y/o la información } \\
\text { necesaria para cumplir con los objetivos planteados. }\end{array}$ \\
\hline $\begin{array}{c}\text { Riesgo } \\
\text { Identificado } \\
\text { Nro. } 2\end{array}$ & Mala Calidad de los Datos. \\
\hline Descripción & $\begin{array}{l}\text { Muchos de los datos son almacenados en archivos } \\
\text { personales, cuadernos, libretas, etc., antes de ser } \\
\text { ingresados al sistema. Como consecuencia de esto, } \\
\text { durante la manipulación de los mismos, podrían } \\
\text { aparecer valores atípicos, datos duplicados, valores } \\
\text { faltantes y otros casos de anomalías que impactarían de } \\
\text { manera negativa en la calidad de los datos del negocio, } \\
\text { y por ende, en la toma de decisiones. }\end{array}$ \\
\hline $\begin{array}{l}\text { Objetivo } \\
\text { Afectado }\end{array}$ & $\begin{array}{l}\text { Detectar clientes que tienen una mayor probabilidad de } \\
\text { compra de un determinado producto de la propia cartera } \\
\text { comercial, y poder generar así campañas de marketing } \\
\text { focalizadas en estos grupos de consumidores } \\
\text { (segmentación del plan de marketing). }\end{array}$ \\
\hline $\begin{array}{c}\text { Plan de } \\
\text { Contingenci } \\
\mathbf{a}\end{array}$ & $\begin{array}{l}\text { - Metodología que permita diagnosticar la calidad de } \\
\text { los datos e implantación de un sistema que permita } \\
\text { gestionar la calidad de los mismos. } \\
\text { - Diseñar un plan de capacitación del personal } \\
\text { vinculado al procesamiento de la información. }\end{array}$ \\
\hline
\end{tabular}

En el correspondiente paso, se descubren aquellos factores que resultan fundamentales para lograr el éxito del negocio, garantizando el funcionamiento óptimo de una empresa. En caso de no identificarse correctamente estos factores, se podría retrasar e incluso impedir el cumplimiento efectivo de los "Objetivos" establecidos. Este procedimiento se ilustra en la tabla XXVII.

\section{Salida.}

Tabla XXVII. Análisis de los Factores Críticos de Éxito. Aplicación de la Técnica de "Análisis FODA"

Entrada.

Ídem técnicas de "Análisis de Riesgos" y de "Análisis de los Factores Críticos de Éxito".

Salida.

Tabla XXVIII. Análisis FODA.

Paso 1. Análisis de los Objetivos y del Escenario Real de Negocio y Glosario de Términos.

Ídem técnicas de "Análisis de Riesgos" y de "Análisis de los Factores Críticos de Éxito".

Paso 2. Descripción de Fortalezas, Oportunidades, Debilidades y Amenazas.

En este paso, se describe la situación actual de la organización en cuestión, exponiendo sus "Fortalezas", "Oportunidades", "Debilidades" y "Amenazas". Este procedimiento se ilustra en la tabla XXVIII.

\section{TABLA XXVII. ANÁLISIS DE LOS FACTORES CRÍTICOS DE} ÉXITO.

\begin{tabular}{|c|c|}
\hline \multicolumn{2}{|c|}{ ANÁLISIS DE LOS FACTORES CRÍTICOS DEL ÉXITO } \\
\hline $\begin{array}{c}\text { FCE } \\
\text { Identificado } \\
\text { Nro. 1 }\end{array}$ & Liderazgo \\
\hline Descripción & $\begin{array}{l}\text { Es importante que el líder de proyecto comunique de } \\
\text { forma precisa y transfiera su visión de liderazgo al resto } \\
\text { del equipo durante el desarrollo del proyecto. }\end{array}$ \\
\hline
\end{tabular}

\begin{tabular}{|c|l|}
\hline $\begin{array}{c}\text { Objetivo } \\
\text { Afectado }\end{array}$ & $\begin{array}{l}\text { Detectar clientes que tienen una mayor probabilidad de } \\
\text { compra de un determinado producto de la propia cartera } \\
\text { comercial, y poder generar así campañas de marketing } \\
\text { focalizadas en estos grupos de consumidores } \\
\text { (segmentación del plan de marketing). }\end{array}$ \\
\hline $\begin{array}{c}\text { Área } \\
\text { Impactada }\end{array}$ & Área de Sistemas. \\
\hline $\begin{array}{c}\text { FCE } \\
\text { Identificado } \\
\text { Nro.2 }\end{array}$ & $\begin{array}{l}\text { Información válida y correcto procesamiento de los } \\
\text { datos. }\end{array}$ \\
\hline $\begin{array}{c}\text { Descripción } \\
\text { Objetivo }\end{array}$ & $\begin{array}{l}\text { Disponer de un sistema de información que permita el } \\
\text { procesamiento de los datos de los clientes en forma } \\
\text { las transacciones realizadas. }\end{array}$ \\
\hline Afectado & $\begin{array}{l}\text { Detectar clientes que tienen una mayor probabilidad de } \\
\text { compra de un determinado producto de la propia cartera } \\
\text { comercial, y poder generar así campañas de marketing } \\
\text { focalizadas en estos grupos de consumidores } \\
\text { (segmentación del plan de marketing). }\end{array}$ \\
\hline Área & Todas las áreas del negocio. \\
\hline Impactada
\end{tabular}

TABLA XXVIII. ANÁLISIS FODA.

\begin{tabular}{|c|c|c|c|}
\hline \multicolumn{4}{|c|}{ ANÁLISIS FODA } \\
\hline \multicolumn{4}{|c|}{ Descripción } \\
\hline & Fortalezas & & Oportunidades \\
\hline & $\begin{array}{l}\text { Personal muy comprometido } \\
\text { con los objetivos del negocio. } \\
\text { Capacidad directiva. } \\
\text { Buen clima laboral. }\end{array}$ & & $\begin{array}{l}\text { Nuevas tecnologías. } \\
\text { Financiamiento de } \\
\text { inversiones de } \\
\text { actividades productivas } \\
\text { para las micro, pequeñas } \\
\text { y medianas empresas. } \\
\text { Posibilidades de } \\
\text { capacitación en el área } \\
\text { de tecnología e } \\
\text { informática a bajo costo. }\end{array}$ \\
\hline & Debilidades & & Amenazas \\
\hline$\checkmark$ & $\begin{array}{l}\text { Capacidad limitada para hacer } \\
\text { grandes inversiones en el área } \\
\text { de tecnología e informática. } \\
\text { Sistemas informáticos } \\
\text { obsoletos y falta de } \\
\text { conocimientos técnicos dentro } \\
\text { de la organización } \\
\text { (Explotación de Datos, base de } \\
\text { datos, etc.). } \\
\text { Existen limitaciones en lo que } \\
\text { respecta a la infraestructura } \\
\text { tecnológica. }\end{array}$ & & $\begin{array}{l}\text { Inflación. } \\
\text { Políticas } \\
\text { gubernamentales } \\
\text { deficientes. } \\
\text { Recesión o crisis } \\
\text { económica. }\end{array}$ \\
\hline
\end{tabular}

\section{Aplicación de la Técnica de "Análisis de Beneficios"}

Entrada.

Ídem técnicas de "Análisis de Riesgos"; de "Análisis de los Factores Críticos de Éxito" y de "Análisis FODA".

Paso 1. Análisis de los Objetivos y del Escenario Real de Negocio y Glosario de Términos.

Ídem técnicas de "Análisis de Riesgos"; de "Análisis de los Factores Críticos de Éxito" y de "Análisis FODA".

Paso 2. Descripción de Beneficios.

En este paso, se describen los "Beneficios" que se derivan del logro de los "Objetivos" establecidos. Este procedimiento se ilustra en la tabla XXIX que se observa a continuación: 
TABLA XXIX. ANÁLISIS DE BENEFICIOS.

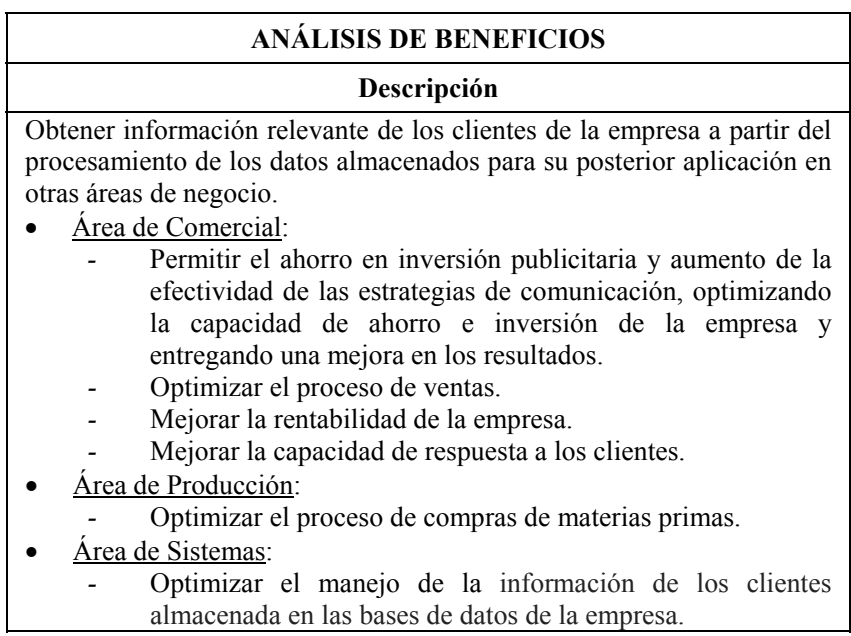

\section{Salida.}

Tabla XXIX. Análisis de Beneficios.

3) Realización de las Tareas de la Fase de "Planeación Operativa"

Concluyendo con el tratamiento del caso de prueba presentado, se realizan las tareas de la fase de "Planeación Operativa" mediante la ejecución de las técnicas correspondientes, a saber:

a) Realización de la Tarea de "Definición de Estrategias del Negocio"

La tarea de "Definición de Estrategias de Negocio" se implementa mediante la aplicación de la técnica de "Descripción de Estrategias". Para la realización de este proceso, se parte del conocimiento que se tiene acerca de los "Riesgos y Planes de Contingencias", los "Factores Críticos del Exito", las "Fortalezas", las "Oportunidades", las "Debilidades", las "Amenazas" y los "Beneficios", que constituyen los productos de entrada, y se obtienen como productos de salida las "Estrategias" para alcanzar los objetivos trazados.

\section{Aplicación de la Técnica de "Descripción de Estrategias"}

\section{Entrada.}

Tabla XXVI. Análisis de Riesgos y Planes de Contingencia.

Tabla XXVII. Análisis de Factores Críticos de Éxito.

Tabla XXVIII. Análisis FODA.

Tabla XXIX. Análisis de Beneficios.

Paso 1. Análisis de Riesgos y Planes de Contingencia, Factores Críticos de Éxito (FCE), FODA y Beneficios.

En el presente caso de estudio, se identifican los "Riesgos" asociados al proyecto en cuestión y los "Planes de Contingencia" correspondientes a los riesgos identificados, los "Factores Críticos de Éxito", las "Fortalezas", las "Oportunidades", las "Debilidades" y las "Amenazas" de la organización, como así también los "Beneficios" derivados del cumplimiento efectivo de los objetivos; lo que permite evaluar la viabilidad de dichos objetivos en función de todos estos elementos, y por ende, conocer la incidencia de dichos componentes en el desarrollo y ejecución del proyecto respectivo.

Paso 2. Descripción de las Estrategias a implementar para alcanzar los objetivos planteados.
A partir del análisis de los "Riesgos y Planes de Contingencias", los "Factores Críticos del Éxito", las "Fortalezas", las "Oportunidades", las "Debilidades", las "Amenazas" y los "Beneficios", se describen las "Estrategias" a implementar para lograr los objetivos establecidos. Este procedimiento se ilustra en la tabla XXX que se visualiza a continuación:

TABLA XXX. DESCRIPCIÓN DE ESTRATEGIAS.

\begin{tabular}{|c|c|}
\hline \multicolumn{2}{|r|}{ ESTRATEGIAS } \\
\hline & Descripción \\
\hline $\begin{array}{c}\text { - } \frac{\text { General: }}{\checkmark} \\
\text { - } \frac{\text { Específicas: }}{\checkmark} \\
\checkmark \\
\checkmark\end{array}$ & $\begin{array}{l}\text { Implementar un sistema de información basado en la } \\
\text { Explotación de Datos para conocer en forma precisa } \\
\text { qué clientes tienen una mayor probabilidad de } \\
\text { compra de un determinado producto de la propia } \\
\text { cartera comercial. } \\
\text { Controlar, dirigir y supervisar el desarrollo del } \\
\text { proyecto. } \\
\text { Definir las funciones, responsabilidades y roles del } \\
\text { personal involucrado en el proyecto. } \\
\text { Promover la participación activa y colaboración de } \\
\text { todo el personal de la empresa en el desarrollo del } \\
\text { proyecto. } \\
\text { Capacitar al personal de la empresa en las áreas } \\
\text { involucradas. } \\
\text { Confeccionar, documentar, examinar y controlar los } \\
\text { procesos administrativos y operativos asegurando la } \\
\text { calidad de los mismos. }\end{array}$ \\
\hline
\end{tabular}

\section{Salida.}

Tabla XXX. Descripción de Estrategias.

b) Realización de la Tarea de "Determinación de Medios, Requerimientos y Limitaciones del Negocio"

La tarea de "Determinación de Medios, Requerimientos y Limitaciones del Negocio" se implementa mediante la aplicación de un conjunto específico de técnicas, a saber: técnica de "Análisis de Recursos Humanos"; técnica de "Análisis de Fuentes de Información”; técnica de "Análisis de Requerimientos" y técnica de "Análisis de Restricciones". Para la realización de este proceso, se parte del conocimiento que se tiene de las "Estrategias", que constituyen los productos de entrada, y se obtienen como productos de salida los "Recursos Humanos", las "Fuentes de Información”, los "Requerimientos" y las "Restricciones".

\section{Aplicación de la Técnica de "Análisis de Recursos Humanos"}

\section{Entrada.}

Tabla XXX. Descripción de Estrategias.

Paso 1. Análisis de las Estrategias a implementar.

En este caso de estudio, se definen las "Estrategias" a utilizar para cumplir los objetivos trazados al inicio del proyecto, lo cual es clave para identificar todas aquellas acciones requeridas para alcanzar las metas establecidas y el rumbo deseado, adecuando los medios y/o las formas necesarias para lograrlo, y considerando a su vez, los requerimientos y las limitaciones propias del proyecto en cuestión, de manera tal que las mismas puedan implementarse oportuna, eficaz y eficientemente.

Paso 2. Descripción del perfil de los Recursos Humanos a seleccionar. 
En este paso, se describe el perfil de los "Recursos Humanos" a seleccionar. Este procedimiento se ilustra en la tabla XXXI que se expone a continuación:

\section{TABLA XXXI. ANÁLISIS DE RECURSOS HUMANOS.}

\begin{tabular}{|c|c|c|c|}
\hline \multicolumn{4}{|c|}{ RECURSOS HUMANOS } \\
\hline $\begin{array}{l}\text { Profesional } \\
\text { Identificado }\end{array}$ & Descripción & Función & $\begin{array}{c}\text { Asignación } \\
\text { al } \\
\text { Proyecto }\end{array}$ \\
\hline $\begin{array}{l}\text { Analista de } \\
\text { Negocio }\end{array}$ & $\begin{array}{c}\text { Es un profesional } \\
\text { especialista en } \\
\text { procesos de } \\
\text { negocio. }\end{array}$ & $\begin{array}{c}\text { Aportar sólidos } \\
\text { conocimientos y } \\
\text { experiencia en } \\
\text { los procesos de } \\
\text { negocio. }\end{array}$ & Full Time \\
\hline $\begin{array}{l}\text { Líder de } \\
\text { Proyecto } \\
\text { (Project } \\
\text { Manager) }\end{array}$ & $\begin{array}{l}\text { Es un profesional } \\
\text { especializado en el } \\
\text { campo de la } \\
\text { gestión de } \\
\text { proyectos y es } \\
\text { responsable de } \\
\text { garantizar el éxito } \\
\text { del proyecto. }\end{array}$ & $\begin{array}{c}\text { Planificar, } \\
\text { ejecutar y } \\
\text { controlar el } \\
\text { desarrollo del } \\
\text { proyecto. }\end{array}$ & Full Time \\
\hline $\begin{array}{c}\text { Técnico } \\
\text { Profesional } \\
\text { en Sistemas }\end{array}$ & $\begin{array}{l}\text { Es un profesional } \\
\text { experto en el área } \\
\text { de sistemas de } \\
\text { información. }\end{array}$ & $\begin{array}{c}\text { Desarrollar un } \\
\text { sistema } \\
\text { informático que } \\
\text { permita llevar a } \\
\text { cabo el proceso } \\
\text { de extracción de } \\
\text { patrones a partir } \\
\text { de los datos } \\
\text { obtenidos en } \\
\text { función de los } \\
\text { objetivos del } \\
\text { presente } \\
\text { proyecto. }\end{array}$ & Full Time \\
\hline $\begin{array}{c}\text { Experto o } \\
\text { Especialista } \\
\text { en } \\
\text { Explotación } \\
\text { de Datos }\end{array}$ & $\begin{array}{c}\text { Es un profesional } \\
\text { especializado en el } \\
\text { área de proyectos } \\
\text { de Explotación de } \\
\text { Datos. }\end{array}$ & $\begin{array}{c}\text { Diseñar y } \\
\text { aportar } \\
\text { soluciones al } \\
\text { problema en } \\
\text { cuestión, } \\
\text { acordes a los } \\
\text { objetivos y } \\
\text { posibilidades } \\
\text { del negocio. }\end{array}$ & Full Time \\
\hline
\end{tabular}

Salida.

Tabla XXXI. Análisis de Recursos Humanos.

\section{Aplicación de la Técnica de "Análisis de Fuentes de Información"}

Entrada.

Ídem técnica de "Análisis de Recursos Humanos".

Paso 1. Análisis de las Estrategias del Negocio.

Ídem técnica de "Análisis de Recursos Humanos".

Paso 2. Descripción de las propiedades de las Fuentes de Información a utilizar.

En este paso, se describen las características de las "Fuentes de Información”. Este procedimiento se ilustra en la tabla XXXII que se presenta a continuación:

TABLA XXXII. ANÁLISIS DE FUENTES DE INFORMACIÓN.

\begin{tabular}{|c|c|c|c|}
\hline \multicolumn{4}{|c|}{ FUENTES DE INFORMACIÓN } \\
\hline Origen & Descripción & $\begin{array}{c}\text { Periodici } \\
\text { dad }\end{array}$ & Utilidad \\
\hline $\begin{array}{c}\text { Área } \\
\text { Comercial: } \\
\text { Ventas y } \\
\text { Facturación }\end{array}$ & $\begin{array}{c}\text { Provee información } \\
\text { acerca de los atributos, } \\
\text { características de los } \\
\text { clientes, antigüedad, } \\
\text { situación geográfica, } \\
\text { etc. }\end{array}$ & $\begin{array}{c}\text { Semanal } \\
\text { mente }\end{array}$ & $\begin{array}{c}\text { Proporciona } \\
\text { datos } \\
\text { descriptivos del } \\
\text { cliente. }\end{array}$ \\
\hline
\end{tabular}

\begin{tabular}{|c|c|c|c|}
\hline $\begin{array}{c}\text { Área } \\
\text { Comercial: } \\
\text { Ventas y } \\
\text { Facturación }\end{array}$ & $\begin{array}{c}\text { Provee información } \\
\text { acerca de las } \\
\text { solicitudes de pedidos } \\
\text { de venta, órdenes de } \\
\text { venta, transacciones } \\
\text { financieras, historial de } \\
\text { pago de los clientes, } \\
\text { listado de deudores, } \\
\text { facturación, etc. }\end{array}$ & $\begin{array}{c}\text { Semanal } \\
\text { mente }\end{array}$ & $\begin{array}{c}\text { Aporta datos } \\
\text { del } \\
\text { comportamiento } \\
\text { del consumidor. }\end{array}$ \\
$\begin{array}{c}\text { Área } \\
\text { Comercial: } \\
\text { Atención al } \\
\text { Cliente }\end{array}$ & $\begin{array}{c}\text { Provee información } \\
\text { acerca de los reclamos } \\
\text { inquietudes los clientes, } \\
\text { preferencias, } \\
\text { necesidades, etc. }\end{array}$ & Semanal \\
mente. & $\begin{array}{c}\text { Brinda datos } \\
\text { actitudinales y } \\
\text { de interacción } \\
\text { de la clientela. }\end{array}$ \\
\hline
\end{tabular}

Salida.

Tabla XXXII. Análisis de Fuentes de Información.

\section{Aplicación de la Técnica de "Análisis de Requerimientos"}

\section{Entrada.}

Ídem técnicas de "Análisis de Recursos Humanos" y de "Análisis de Fuentes de Información”.

Paso 1. Análisis de las Estrategias del Negocio.

Ídem técnicas de "Análisis de Recursos Humanos" y de "Análisis de Fuentes de Información”.

Paso 2. Descripción de los Requerimientos necesarios y clasificación de los mismos en función de su prioridad.

En este paso, se describen las características de las "Requerimientos". Este procedimiento se ilustra en la tabla XXXIII que se observa a continuación:

\section{TABLA XXXIII. ANÁLISIS DE REQUERIMIENTOS.}

\begin{tabular}{|l|c|}
\hline \multicolumn{3}{|c|}{ REQUERIMIENTOS } & Clasificación \\
\hline \multicolumn{3}{|c|}{ Descripción } & Mandatorio \\
\hline $\begin{array}{l}\text { Contar con una base de datos de suficiente tamaño y } \\
\text { calidad, que pueda ser utilizada para la extracción } \\
\text { de información valiosa para cumplir con los } \\
\text { objetivos propuestos. }\end{array}$ & \\
\hline $\begin{array}{l}\text { Disponer de un experto o especialista en } \\
\text { Explotación de Datos para administrar, planificar, } \\
\text { coordinar, ejecutar y dar seguimiento y control de } \\
\text { todas las actividades relacionadas a dicho campo, }\end{array}$ & \\
aportando la solución más adecuada para el negocio. & \\
\hline $\begin{array}{l}\text { Asegurar la disponibilidad de la información } \\
\text { provista por el sistema de Explotación de }\end{array}$ & \\
Información y establecer mecanismos de \\
comunicación efectiva de los resultados para su \\
posterior uso en otras áreas del negocio.
\end{tabular}

Salida.

Tabla XXXIII. Análisis de Requerimientos.

\section{Aplicación de la Técnica de "Análisis de Restricciones"}

Entrada.

Ídem técnicas de "Análisis de Recursos Humanos"; de "Análisis de Fuentes de Información" y de "Análisis de Requerimientos".

Paso 1. Análisis de las Estrategias a implementar.

Ídem técnicas de "Análisis de Recursos Humanos"; de "Análisis de Fuentes de Información" y de "Análisis de Requerimientos".

Paso 2. Descripción de las Restricciones y tratamiento de las mismas. 
En este paso, se describen las características de las "Restricciones" y el tratamiento de las mismas. Este procedimiento se ilustra en la tabla XXXIV que se visualiza a continuación:

TABLA XXXIV. ANÁLISIS DE RESTRICCIONES.

\begin{tabular}{|c|c|}
\hline \multicolumn{2}{|c|}{ RESTRICCIONES } \\
\hline Descripción & Tratamiento \\
\hline $\begin{array}{l}\text { No todas las ventas se realizan en } \\
\text { el Showroom de la propia marca y } \\
\text { en locales comerciales, sino que } \\
\text { muchos artículos de cuero se } \\
\text { comercializan en ferias del rubro, } \\
\text { por lo cual las ventas no pueden ser } \\
\text { tratadas con el sistema } \\
\text { convencional de comercialización. }\end{array}$ & $\begin{array}{l}\checkmark \text { Implementar un sistema de } \\
\text { facturación con conexión a } \\
\text { un dispositivo móvil para } \\
\text { vender y facturar en tiempo } \\
\text { real. } \\
\checkmark \text { Capacitar al personal en el } \\
\text { uso de las nuevas } \\
\text { tecnologías de ventas y } \\
\text { facturación. }\end{array}$ \\
\hline
\end{tabular}

Salida.

Tabla XXXIV. Análisis de Restricciones.

c) Realización de la Tarea de "Integración de los Componentes del Negocio"

La tarea de "Integración de los Componentes del Negocio" se implementa mediante la aplicación de la técnica de "Construcción del Mapa Integrador del Negocio". Para la realización de este proceso, se parte del conocimiento que se tiene acerca de los "Productos de Entrada y/o Salida" obtenidos previamente y que van a conformar el nuevo mapa, los cuales constituyen los productos de entrada, y se obtiene como producto de salida el "Mapa Integrador del Negocio".

\section{Aplicación de la Técnica de “Construcción del Mapa Integrador del Negocio"}

\section{Entrada. \\ "Productos de Entrada y/o Salida" identificados.}

Paso 1. Identificación de los Productos de Entrada y/o Salida del proceso.

En el modelo de proceso propuesto para alcanzar la comprensión del negocio se definen tres fases en su estructura general, y todas ellas involucran una serie de tareas y productos asociados a las mismas. Cada producto puede actuar como componente de entrada de una o más tareas; y al mismo tiempo, puede constituir el componente de salida de una determinada tarea. A partir de los "Productos de Entrada y/o Salida” identificados, se lleva a cabo la construcción del nuevo mapa integrador.

Paso 2. Integración de los componentes seleccionados y diseño del "Mapa Integrador del Negocio".

En este paso, se produce la integración de todos los "Productos de Entrada y/o Salida" identificados previamente; y luego, se realiza el diseño del "Mapa Integrador del Negocio" que sintetiza la información obtenida a partir de los datos recolectados durante el desarrollo del proceso, reflejando los aspectos más relevantes de la organización, y en consecuencia, permite lograr un adecuado entendimiento del negocio por parte de todas las partes interesadas. Este procedimiento se ilustra en la figura 14.

Salida.

Figura 14. Mapa Integrador del Negocio.

\section{CONCLUSIONES}

En esta sección, se documentan las conclusiones más importantes de este trabajo (sección VI.A), en cuanto a la valoración sobre la investigación documental (sección VI.A.1), la valoración del problema (sección VI.A.2), la valoración de la solución (sección VI.A.3) y la valoración del caso de estudio (sección VI.A.4). Luego, se presentan las respuestas a los interrogantes planteados, que constituyen el balance final de esta investigación (sección VI.A.5). Al final de la sección, se sugieren futuras líneas de investigación (sección VI.B).

\section{A. Conclusiones}

A partir del presente trabajo de investigación se obtuvieron distintas conclusiones que se exponen a continuación.

1) Valoración sobre la Investigación Documental

En la primera parte de este trabajo, se abordó el tratamiento del conocimiento denominado "Entendimiento del Negocio" [9;8], lo cual permitió conocer los aspectos más relevantes de la temática objeto de estudio, como base para la construcción de un marco de referencia para la elaboración del nuevo modelo de proceso. Asimismo, se detallaron una serie de ventajas asociadas al proceso de educción de dicho conocimiento, justificando la creación y desarrollo de un proceso de conceptualización del entendimiento del negocio.

Posteriormente, se realizó una descripción detallada de cada una de las tres metodologías principales que se utilizan para proyectos de Explotación de Información, a saber: CRISPDM, $\mathrm{P}^{3} \mathrm{TQ}$ y SEMMA. Adicionalmente, se presentó un estudio comparativo de las metodologías expuestas, identificando semejanzas, diferencias $\mathrm{y}$ otros aspectos significativos inherentes a las mismas. El tratamiento de esta información, permitió introducirnos en el estudio de las metodologías mencionadas, lo cual constituyó una parte fundamental de nuestra base de conocimientos para la realización del presente trabajo. A su vez, se expusieron algunos lineamientos generales sobre la comprensión del negocio y los proyectos de Explotación de Información, lo cual permitió establecer la relación existente entre ambos, y por ende, conocer información relevante para el desarrollo del proceso respectivo.

Luego, se efectuó un estudio descriptivo de una protofase que articula un conjunto de técnicas y herramientas asociadas para lograr la comprensión del negocio desarrollada en [8].

El análisis realizado posibilitó obtener importantes conocimientos referentes a la protofase en cuestión, utilizada como base para la construcción del nuevo modelo desarrollado. La investigación documental realizada en el presente trabajo justificó la construcción de un modelo de proceso de conceptualización del entendimiento del negocio para proyectos de Explotación de Información.

\section{2) Valoración del Problema}

A partir de la revisión bibliográfica llevada a cabo en el presente trabajo de investigación se identificó la problemática de investigación, en base a la complejidad que involucra la comprensión clara del dominio del negocio en proyectos de Explotación de Información. La misma fue descripta en la sección III de este trabajo.

En la actualidad, debido a los grandes volúmenes de información que existen en muchas organizaciones, y teniendo en cuenta que sobre la base de esta información se toman decisiones importantes, resulta imprescindible detectar aquella que tiene un alto impacto en las operaciones del negocio. 


\begin{tabular}{|c|}
\hline FASE \\
CONCEPTUAL \\
EXPLORATORIA \\
\hline
\end{tabular}

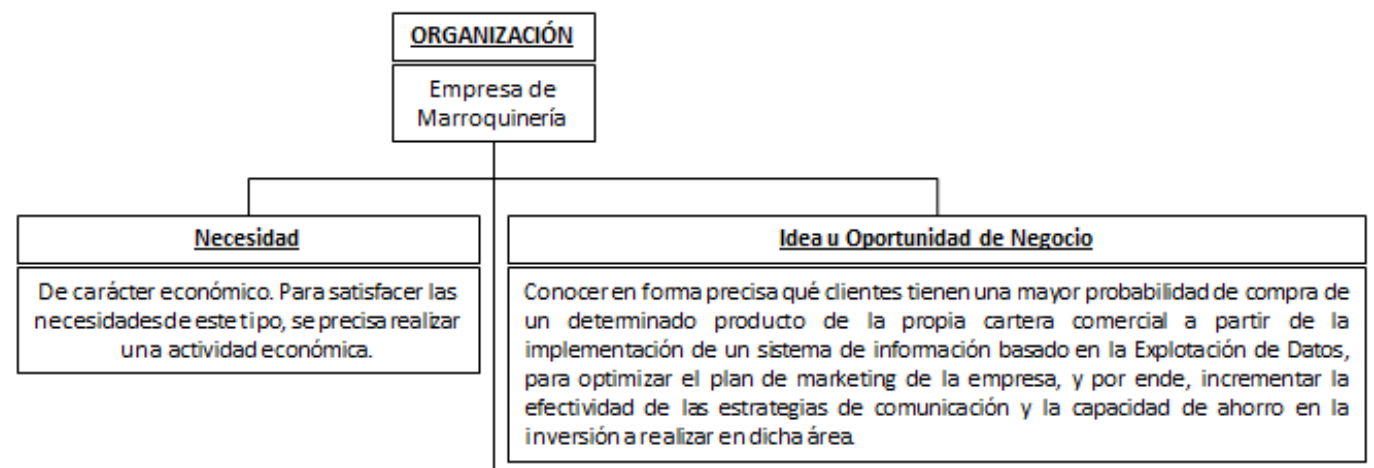

\begin{tabular}{|l|}
\hline \multicolumn{1}{|c|}{ Misión } \\
\hline \hline Ofrecer productos de alta calidad y \\
diseños innovadores a los clientes; \\
combinando lo clásico con lo modemo \\
y mostrando a las artículos de cuero \\
como objetos de arte, fruto de un \\
proceso productivo creativo. \\
\hline
\end{tabular}

\begin{tabular}{|c|}
\hline Visión \\
\hline $\begin{array}{l}\text { Ser una prestigiosa y } \\
\text { exitosa empresa líder en } \\
\text { el diseño, fabricación y } \\
\text { comercialización de } \\
\text { artículos decuero. }\end{array}$ \\
\hline
\end{tabular}

\begin{tabular}{|c|c|}
\hline Objetivos & $\underline{\text { Valores }}$ \\
\hline $\begin{array}{l}\text { Detectar clientes que tienen una mayor probabilidad } \\
\text { de compra de un determinado producto de la propia } \\
\text { cartera comercial, y poder generar así futuras } \\
\text { campañas de marketing focalizadas a estos grupos de } \\
\text { consumidores(segmentación del plande marketing). }\end{array}$ & $\begin{array}{l}\text { - Creatividad } \\
\text { - Responsabilidad } \\
\text { - Excelencia } \\
\text { - Calidad } \\
\text { - Honestidad } \\
\text { - Aprendizaje }\end{array}$ \\
\hline
\end{tabular}

\begin{tabular}{|c|c|c|c|c|c|}
\hline & & & Escenario Real de Negocio & & \\
\hline$\underline{\text { Sector }}$ & Actividad & Productos & $\underline{\text { Cartera de Clientes }}$ & Mercado Relevante & $\underline{\text { Glosario }}$ \\
\hline $\begin{array}{c}\text { Industria } \\
\text { Manufacturera }\end{array}$ & $\begin{array}{l}\text { Diseño, } \\
\text { fabricacióny } \\
\text { comercialización } \\
\text { de artículos de } \\
\text { cuero. }\end{array}$ & $\begin{array}{l}\text { - Principal: } \\
\text { Carteras de cuero. } \\
\text { - Secundarios: } \\
\text { Zapatos, billeteras } \\
\text { y cintos de cuero. }\end{array}$ & $\begin{array}{l}\text { - Consumidores Finales } \\
\text { - Revendedores Intermediarios } \\
\text { - Otros Clientes (No } \\
\text { Consumidores Finales; No } \\
\text { Revendedores Intermediarios). }\end{array}$ & \multirow{2}{*}{$\begin{array}{l}\text { Artesanos, agrupados en } \\
\text { pequeños tallereso } \\
\text { cooperativas regionales;y } \\
\text { también existen pequeñasy } \\
\text { medianas empresasde } \\
\text { producción. } \\
\text { - Diferentessectores de nivel } \\
\text { socioeconómico. } \\
\text { - Diversidad de la cartera de } \\
\text { productos, calidades, clientes } \\
\text { y precios. }\end{array}$} & \multirow{2}{*}{$\begin{array}{l}\text { Industria Manufacturera; } \\
\text { Consumidores Finales; } \\
\text { Revendedores } \\
\text { Intermediarios; Otros } \\
\text { Clientes (No } \\
\text { Consumidores Finales; } \\
\text { No Revendedores } \\
\text { Intermediarios); Análisis } \\
\text { FODA. }\end{array}$} \\
\hline & & & & & \\
\hline
\end{tabular}

FASE DE ANÁLISIS Y EVALUACIÓN

\begin{tabular}{|c|c|}
\hline \multicolumn{2}{|c|}{ Riesgos y Planes de Contingencia } \\
\hline \multicolumn{2}{|c|}{$\begin{array}{l}\text { - Ineficiente Gestión Administrativa. } \\
\text { - Implementar mecanismoseficientes de gestión administrativa (P.C.). } \\
\text { - Capacitación del personal(P.C.). } \\
\text { - Mala Calidad de los Datos } \\
\text { - Metodología para diagnosticar la calidad de los datos e implantación de } \\
\text { - un sistema que permita gestionar la calidad de losmismos(P.C.). } \\
\text { - Capacitación del personal(P.C.). }\end{array}$} \\
\hline Fortalezas & Oportunidades \\
\hline $\begin{array}{l}\text { - Personal muy } \\
\text { comprometido con } \\
\text { los objetivos del } \\
\text { Negocio. } \\
\text { - Capacidad directiva. } \\
\text { - Buenclima laboral. }\end{array}$ & $\begin{array}{l}\text { - Nuevastecnologías } \\
\text { - Financiamiento de inversiones de } \\
\text { pequeñades productivas para las micro, } \\
\text { - Posibilidades de capacitación en el área } \\
\text { de tecnología e informática a bajo } \\
\text { costo. }\end{array}$ \\
\hline
\end{tabular}

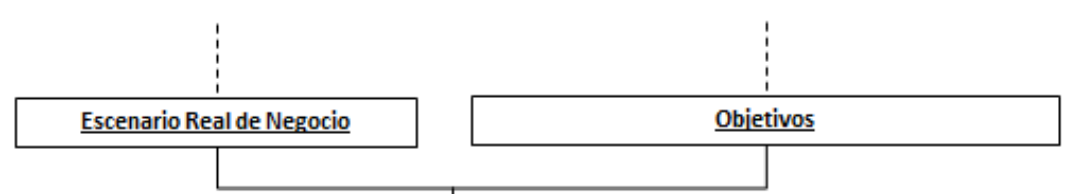

\begin{tabular}{|l|l|l|}
\hline \multicolumn{2}{|c|}{ Factores Críticos de Éxito } & \multicolumn{2}{|c|}{ Beneficios } \\
\hline \hline $\begin{array}{l}\text { - Liderazgo. } \\
\text { - Información válida y correcto } \\
\text { procesamientode los datos. }\end{array}$ & $\begin{array}{l}\text { Obtener información relevante de los } \\
\text { clientes de la empresa a partir del } \\
\text { procesamiento de los datos } \\
\text { almacenados para su posterior } \\
\text { aplicaciónenotras áreas denegocio. }\end{array}$ \\
\hline
\end{tabular}

\section{FODA}

\begin{tabular}{|c|c|}
\hline Debilidades & Amenazas \\
\hline $\begin{array}{l}\text { - Capacidad limitada para hacer grandes } \\
\text { inversiones en el área de tecnología e informática. } \\
\text { - Sistemas informáticos obsoletos y falta de } \\
\text { conocimientos técnicos dentro de la organización } \\
\text { (Explotaciónde Datos, base de datos, etc.). } \\
\text { - Existen limitaciones en lo que respecta a la }\end{array}$ & $\begin{array}{l}\text { - Inflación. } \\
\text { - Políticas } \\
\text { gubemamentales } \\
\text { deficientes. } \\
\text { - Recesión o cisis } \\
\text { económica. }\end{array}$ \\
\hline
\end{tabular}

- P. C.: Plande Contingencia

Fig. 14 a. Mapa integrador del negocio. 


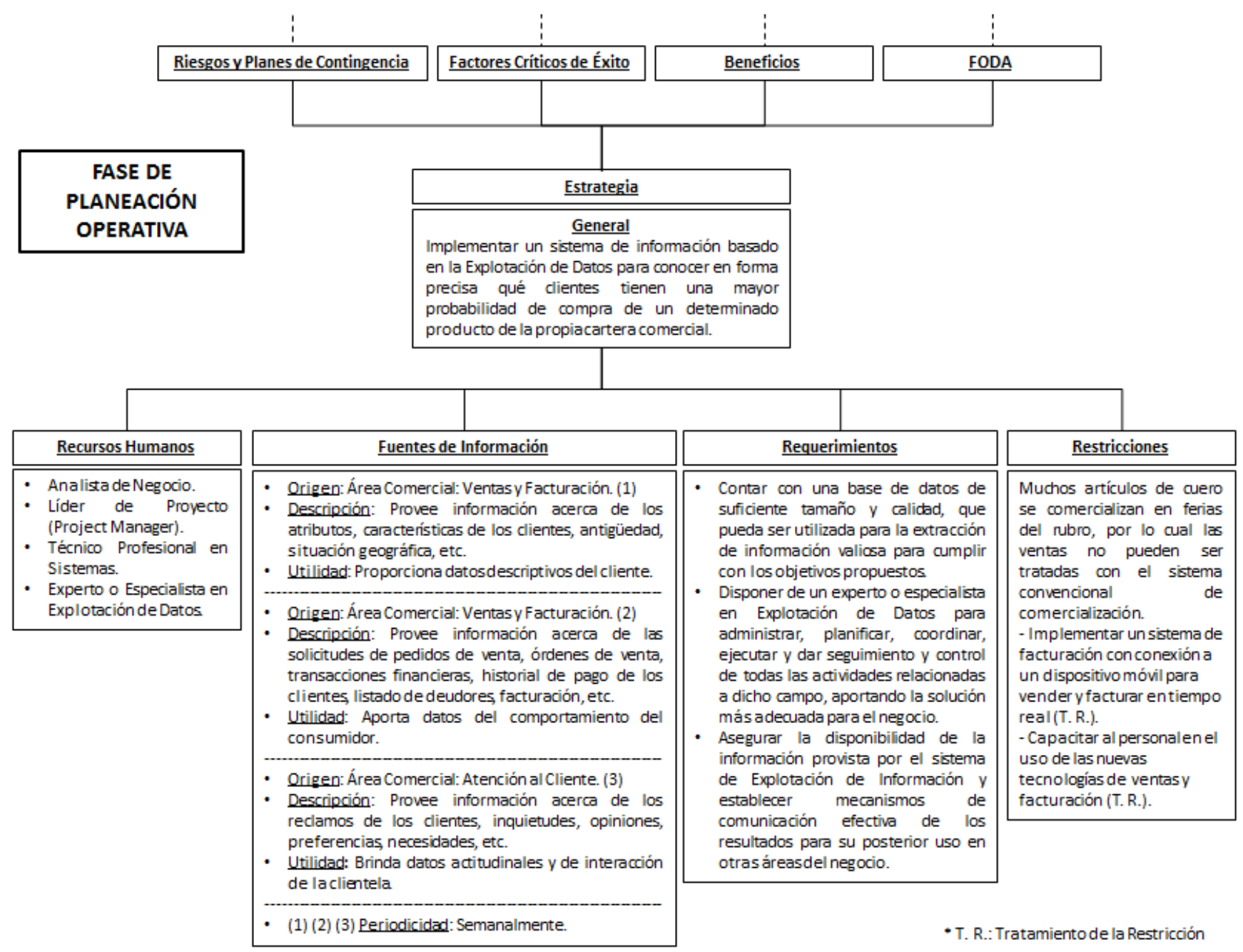

Fig. 14. b. Mapa integrador del negocio.

En tal sentido, el principal problema identificado radica en la necesidad de organizar y categorizar la masa de información que debe ser relevada y procesada para lograr una adecuada comprensión del negocio para proyectos de Explotación de Información, garantizando así la realización normal de las actividades y el cumplimiento de las tareas detalladas.

Consecuentemente, resultó necesario definir todas las fases, tareas y productos implicados en el proceso de educción del entendimiento del negocio; y luego, establecer el conjunto de técnicas asociadas a estos elementos para incorporarlas al modelo de proceso propuesto. Si bien existen técnicas utilizadas para la educción del entendimiento del negocio, fue necesario llevar a cabo un análisis detallado de las mismas para precisar de manera correcta todos los aspectos inherentes a ellas en relación al modelo creado.

Resultó muy importante dar respuesta al problema bajo consideración, teniendo en cuenta la magnitud del mismo y el gran impacto que tiene para los procesos críticos del negocio. Solucionar correctamente el problema de investigación respectivo, contribuyó a enriquecer la teoría y fue sumamente útil desde un punto de vista práctico, respondiendo a las necesidades de la práctica de la gestión del conocimiento que se tiene del negocio, lo cual contribuye a definir el tipo de solución a desarrollar y condiciona el proyecto en cuestión.

Asimismo, el problema de investigación planteado permitió formular nuevas preguntas en el campo de estudio respectivo, constituyendo una fuente de conocimiento muy importante que sirve de base para llevar adelante futuras líneas de investigación.

\section{3) Valoración de la Solución}

En la sección IV de este proyecto de investigación, se presentó una solución para la problemática identificada durante la investigación documental. El presente trabajo constituye una aproximación al estudio del conocimiento denominado "Entendimiento del Negocio", el cual fue previamente abordado por otros autores. Dicho trabajo aporta una serie de elementos que contribuyen al desarrollo de la temática objeto de estudio en el marco científico-académico.

Se construyó un modelo de proceso de conceptualización del entendimiento del negocio, el cual posee una serie de elementos necesarios para lograr una adecuada comprensión del mismo, y a su vez, puede ser utilizado para los distintos proyectos de Explotación de Información realizados por diferentes tipos de organizaciones. El mismo constituye una herramienta significativa de análisis que guía al responsable del proyecto en el tratamiento adecuado de la información pertinente, y por ende, ayuda a definir el tipo de solución a desarrollar en base a las necesidades específicas del negocio.

Asimismo, se describió la estructura general del proceso de conceptualización del entendimiento del negocio y su modo de funcionamiento, y se definieron las fases, tareas y productos que conforman el soporte del proceso respectivo. A su vez, se expuso la dinámica del proceso en función de la interdependencia conceptual existente entre las fases, tareas y 
productos previamente definidos. Por consiguiente, la definición de todos los componentes del proceso respectivo y las relaciones entre ellos, permitió la obtención desde el comienzo del proyecto, de manera ordenada, de toda la información del dominio del negocio en forma sistemática y articulada, garantizando el cumplimiento efectivo de los objetivos.

También, se revisaron un conjunto de técnicas que son utilizadas para extraer o capturar el conocimiento del negocio, con el propósito de ajustar las mismas a la estructura organizativa general del modelo de proceso creado, readaptándolas en ciertos casos al proceso en cuestión. Por otro lado, se propusieron nuevas técnicas para lograr la educción del entendimiento del negocio, las cuales fueron incorporadas al proceso respectivo.

A su vez, se describieron las ventajas que acarrea una correcta comprensión del negocio; por consiguiente, se resumió la importancia que trae aparejada la construcción del nuevo modelo de proceso de conceptualización del entendimiento del negocio.

Por último, dicho modelo aportará un valor agregado a cualquier empresa, pues a partir del mismo, existirá una mayor noción y visión de la organización y sus elementos constitutivos, a través de un enfoque integral que comprenda todos los aspectos del negocio, lo cual permitirá un mejor entendimiento del negocio respectivo.

4) Valoración del Caso de Estudio

En la sección $\mathrm{V}$ de este trabajo de investigación se llevó a cabo la prueba de concepto correspondiente a la implementación de un posible sistema de información basado en la Explotación de Datos para una Empresa de Marroquinería dedicada al diseño, fabricación y comercialización de artículos de cuero.

La información relevada permitió conocer los aspectos más importantes del negocio en cuestión, y por ende, entender en profundidad cómo opera y funciona una empresa, sus características principales y todo el entorno que la rodea, y en base a esto poder administrar correctamente el ámbito del proyecto respectivo, garantizando el éxito del mismo.

El caso de prueba presentado, permitió validar los procesos $\mathrm{y}$ conceptos definidos en el presente trabajo mediante la ejecución de un conjunto de pasos predeterminados, obteniéndose importantes conclusiones. Asimismo, posibilitó mejorar y profundizar en el conocimiento del tema analizado, y extraer ciertas lecciones aplicables al negocio en cuestión. Los resultados de la prueba realizada, sirven como referencia para la realización de nuevas experiencias que posibiliten la adquisición e incorporación de nuevos conocimientos, con el objetivo de incrementar la base de conocimiento que se tiene del negocio a partir del modelo previamente descripto.

5) Respuestas a los Interrogantes de Investigación

Las respuestas a los interrogantes planteados en la sección III.B se resumen a continuación:

- ¿Es posible construir un modelo de proceso de conceptualización para proyectos de Explotación de Información que posea bien diferenciadas sus fases, tareas y productos para alcanzar el entendimiento del negocio?

En el caso del primer interrogante planteado, se logró construir un modelo de proceso de conceptualización del entendimiento del negocio con fases, tareas y productos bien diferenciados para proyectos de Explotación de Información. El modelo construido tiene tres fases en su estructura global, y todas ellas involucran un conjunto de tareas y productos asociados a las mismas. Cada producto puede comportarse como elemento de entrada de una o más tareas; y a su vez, puede constituir el elemento de salida de una determinada tarea.

- ¿Pueden ser adecuadas las técnicas de educción del entendimiento del negocio de las metodologías de desarrollo de software mencionadas en este trabajo para ser utilizadas en el modelo de proceso a construir? En caso afirmativo: ¿se deben realizar modificaciones en ellas?

En referencia al segundo interrogante, se comprobó que las técnicas de las metodologías de desarrollo de software son adecuadas para su aplicación en el modelo de proceso construido para lograr una comprensión clara del dominio del negocio. Sin embargo, en algunos casos fue necesario llevar a cabo una readaptación de las mismas, teniendo en cuenta la conformación estructural y funcional del proceso respectivo. Asimismo, fue requerida la confección de nuevas técnicas para ser utilizadas en ciertas tareas definidas en el proceso en cuestión. En todos los casos mencionados, se especificaron todos los pasos necesarios para la correcta implementación de las técnicas involucradas.

\section{B. Futuras líneas de investigación}

Se pueden citar como futuras líneas de investigación las siguientes:

- Validar la aplicación del modelo de proceso de conceptualización del entendimiento del negocio en el desarrollo de sistemas de Explotación de Información para otros dominios del negocio que varíen en complejidad, tamaño, madurez y tipo, ya sea dentro de esta industria o en otras.

- Diseñar e implementar un sistema de variables e indicadores que permitan analizar y evaluar el comportamiento del modelo propuesto en proyectos reales.

- Analizar la posibilidad de aplicación de este modelo como apoyo al proceso de educción del entendimiento del negocio en otras metodologías de desarrollo de software no contempladas en el presente trabajo.

- Desarrollar el modelo de proceso propuesto con el propósito de obtener un estado de maduración que aumente su calidad en busca de mejorar y optimizar el proceso de educción del entendimiento del negocio.

\section{REFERENCIAS BIBLIOGRÁFICAS}

[1] León León, O., Asato España, J. (2009). La Importancia del Modelado de Procesos de Negocio como Herramienta para la Mejora e Innovación. Revista Panorama Administrativo, 4(7). http://admon.itc.mx/ojs/index.php/panorama/article/view/155/15 6. Página web vigente al 03/06/14.

[2] Amón Uribe, I., Jiménez Ramírez, C. (2009). Hacia una Metodología para la Selección de Técnicas de Depuración de Datos. Revista Avances en Sistemas e Informática. 6(1): 185190. ISSN 1657-7663.

[3] Moine, J., Gordillo, S., Haedo, A. (2011a). Análisis Comparativo de Metodologías para la Gestión de Proyectos de Minería de Datos. Proceedings VIII Workshop Bases de Datos y Minería de Datos (WBDDM). Pág. 931-938.

[4] Moine, J., Gordillo, S., Haedo, A. (2011b). Estudio Comparativo de Metodologías para Minería de Datos. Proceedings XIII Workshop de Investigadores en Ciencias de la Computación. Pág. 278-281. ISBN 978-950-673-892-1.

[5] Vilalta, J. A., Espinosa, M. (2008). Metodología para el Diagnóstico de la Calidad de los Datos. Journal Ingeniería Industrial. 29(2): 1-6. 
[6] Mariscal, G., Marbán, Ó., González, A., Segovia, J. (2007). Hacia la Ingeniería de Data Mining: Un Modelo de Proceso para el Desarrollo de Proyectos. Proceedings V Taller de Minería de Datos y Aprendizaje (TAMIDA '07). Pág. 139-148. ISBN 97884-9732-602-5.

[7] Britos, P. (2008). Procesos de Explotación de Información basados en Sistemas Inteligentes. Tesis Doctoral. Universidad Nacional de La Plata, Facultad de Informática. La Plata, Argentina.

[8] Ochoa, M. (2006). Uso de Técnicas de Educción para el Entendimiento de Negocio. Tesis de Maestría. Universidad Politécnica de Madrid.

[9] Ochoa, M. (2005). Propuesta de Técnicas de Protofase Metodológica para la Comprensión del Negocio. Reportes Técnicos en Ingeniería del Software, Vol. 7, Nro. 1. Pág. 21-25.

[10] Morales, M., Cancino, C. (2009). La RSE como Herramienta Estratégica del Negocio. Revista Economía \& Administración. Facultad de Economía y Negocios. Universidad de Chile. Nro. 158. Pág. 48-57. ISSN 076-4793.

[11] Cedeño Ruíz, T. F., Ceballos Centeno, M. C., Guevara Catagua, L. P., Vadiviezo Macías, J. L. (2010). Adecuación de un Ambiente Administrativo-Pedagógico e Implementación de un Plan de Capacitación para Administrar Pequeñas Micro Empresas Dirigido a los Integrantes del Comité de Desarrollo Comunitario "José Lívido Intriago" de la Comunidad "Las Mercedes $\mathrm{N}^{\circ} 1$ " del Cantón Santa Ana. Tesis de Grado. Universidad Técnica de Manabí, Facultad de Ciencias Administrativas y Económicas. Manabí, Ecuador.

[12] Cancino, C., Morales, M. (2010). La Racionalidad de Comprometerse con el Negocio. Revista Trend Management. Edición Especial: Management Made in Chile.

[13] García Molina, J., Ortín, M. J., Moros, B., Nicolás, J. (2007). De los Procesos del Negocio a los Casos de Uso. Técnica Administrativa, ISSN: 1666-1680 (en línea), 6(4).

[14] Ortín, M. J., García Molina, J., Moros, B., Nicolás, J. (2001). El Modelo del Negocio como base del Modelo de Requisitos. Grupo de Investigación de Ingeniería del Software. Departamento de Informática y Sistemas. Facultad de Informática. Universidad de Murcia. España.

[15] Rodríguez, A., Caro, A. (2008). Hacia la Obtención de Procesos de Negocio desde Sistemas de Información Heredados. Encuentro de Informática y Gestión (EIG). Temuco, Chile. Pág. 61-71.

[16] Jennings, N. R., Norman, T. J., Faratin, P., O'Brien, P., Odgers, B. (2000). Autonomous Agents for Business Process Management. Applied Artificial Intelligence. Vol. 14(2). Pág. 145-189.

[17] Jiménez Quintana, C., Farías Valenzuela, L., Pinto, F., Neriz Jara, L. (2003). Análisis de Modelos de Procesos de Negocios en Relación a la Dimensión Informática. Departamento de Ingeniería Informática y Ciencias de la Computación. Universidad de Concepción. No 9. ISSN 0717-4195.

[18] Object Management Group, Inc. (2008). Business Process Model and Notation, V1.1. Identificación Formal 2008-01-17.

[19] Hernández González, A. (2005). Identificación de Procesos de Negocio. Revista de Ingeniería Industrial. Vol. XXVI. Nro. 1. Facultad de Ingeniería Industrial, Instituto Superior Politécnico José Antonio Echeverría Cujae. La Habana, Cuba.

[20] Cauvet, C., Guzelian, G. (2008). Business Process Modeling: a Service-Oriented Approach. Proceedings of the 41st Hawaii International Conference on System Sciences.

[21] Laudon, K. C., Laudon, J. P. (2004). Sistemas de Información Gerencial. 6ta Edición, Prentice Hall. México.

[22] Ochoa, M., Britos, P., García-Martínez, R. (2006). Una Protofase de Entendimiento del Negocio para Metodologías de Desarrollo de Sistemas. XII Congreso Argentino de Ciencias de la Computación. San Luis. Argentina.
[23] Diez, E., Britos, P., Rossi, B., García-Martínez, R. (2003). Generación Asistida del Mapa de Actividades de Proyectos de Desarrollo de Software. Reportes Técnicos en Ingeniería del Software. (5)1:13-18. ISSN 1667-5002.

[24] Diez, E. (2003). Generador del Mapa de Actividades de un Proyecto de Desarrollo de Software. Tesis de Magister en Ingeniería de Software. Escuela de Posgrado. Instituto Tecnológico de Buenos Aires - Facultad de Informática de la Universidad Politécnica de Madrid.

[25] Juristo, N. (2003). Proceso Software. Material correspondiente a la Maestría en Ingeniería del Software del Instituto Tecnológico de Buenos Aires - Facultad de Informática de la Universidad Politécnica de Madrid.

[26] Britos, P., Fernández, E., García-Martínez, R. (2006). Propuesta Matriz de Actividades para un Ciclo de Vida de Explotación de Datos. Reportes Técnicos en Ingeniería del Software. 8(2): 3642. ISSN 1667-5002.

[27] Sparks, G. (2000). Introducción al UML, El Modelo de Procesos de Negocio Enterprise Architect. Craftware Consultores Ltda.

[28] García Martínez, R., Lelli, R., Merlino, H., Cornachia, L., Rodriguez, D., Pytel, P., Arboleya, H. (2011). Ingeniería de Proyectos de Explotación de Información para PYMES. Proceedings XIII Workshop de Investigadores en Ciencias de la Computación. Artículo 3761.

[29] García Martínez, R., Merlino, H., Diez, E., Rodriguez, D., Pytel, P., Baldizzoni, E., Arboleya, H., Martins, S. (2013). Instrumentos para la Gestión de Proyectos de Explotación de Información. Proceedings del XV Workshop de Investigadores en Ciencias de la Computación, Pág. 137-141. ISBN 978-9-87281796-1.

[30] Vanrell J., Bertone, R., García Martínez, R. (2010a). Modelo de Proceso de Operación para Proyectos de Explotación de Información. Anales del XVI Congreso Argentino de Ciencias de la Computación. Pág. 674-682. ISBN 978-950-9474-49-9.

[31] Vanrell J., Bertone, R., García Martínez, R. (2010b). Un Modelo de Proceso de Operación para Proyectos de Explotación de Información. Proceedings Workshop de Investigadores en Ciencias de la Computación. Pag. 167-171.

[32] Vanrell, J. (2012). Un Modelo de Procesos para Proyectos de Explotación de Información. Tesis de Magister en Ingeniería de Sistemas de Información. Facultad Regional Buenos Aires. Universidad Tecnológica Nacional.

[33] Rodríguez, D., Pollo-Cattaneo, F., Britos, P., García-Martínez, R. (2010). Estimación Empírica de Carga de Trabajo en Proyectos de Explotación de Información. Anales del XVI Congreso Argentino de Ciencias de la Computación. Pág. 664673. ISBN 978-950-9474-49-9.

[34] Mendez, P., Rodriguez, A. (2009). Herramienta de Estudio de Viabilidad para Proyectos que Utilizan la Metodología $\mathrm{P}^{3} \mathrm{TQ}$. Trabajo Profesional de Ingeniería en Informática. Laboratorio de Sistemas Inteligentes. Facultad de Ingeniería. Universidad de Buenos Aires.

[35] Chapman, P., Clinton, J., Keber, R., Khabaza, T., Reinartz, T., Shearer, C., Wirth, R. (2000). CRISP-DM 1.0 Step by step BIguide. Edited by SPSS.

[36] Pyle, D. (2003). Business Modeling and Data Mining. Morgan Kaufmann Publishers.

[37] SAS, (2012). SAS Enterprise Miner: SEMMA. http://www.sas.com/offices/europe/uk/technologies/ analytics/datamining/miner/semma.html. Página web vigente al 03/06/14.

[38] Pollo-Cattaneo, F., Britos, P., Pesado, P., García-Martínez, R. (2010). Ingeniería de Procesos de Explotación de Información. En Ingeniería de Software e Ingeniería del Conocimiento: Tendencias de Investigación e Innovación Tecnológica en Iberoamérica (Editores: R. Aguilar, J. Díaz, G. Gómez, ELeón). Pág. 252-263. Alfaomega Grupo Editor. ISBN 978-607707-096-2. 
[39] Martins, S. (2013). Derivación del Proceso de Explotación de Información desde el Modelado del Negocio. Trabajo Final de Licenciatura en Sistemas. Departamento de Desarrollo Productivo y Tecnológico. Universidad Nacional de Lanús.

[40] Sapag Chain, N. (1995). Criterios de Evaluación de Proyectos. Editorial McGraw-Hill.

[41] García Martínez, R., Britos, P. (2004). Ingeniería de Sistemas Expertos. Editorial Nueva Librería. ISBN 987-1104-15-4.

[42] Fernández Arena, J. A. (1986). Elementos de Administración. Editorial Diana. México.

[43] Tovar Caro, E. (1997). Educción de Requisitos y Análisis de Problemas. Módulo II: Técnicas de Ingeniería del Software. Parte A: Ingeniería del Software. Maestría en Ingeniería del Software y Universidad Politécnica de Madrid e Instituto Tecnológico de Buenos Aires.

[44] Glagovsky, H. E. (1996). ¡Esto es FODA! Facultad de Ciencias Económicas de la Universidad de Buenos Aires. http://www.monografias.com/trabajos10/foda/foda.shtml. Página web vigente al 03/06/14.

[45] Bueno, E., Morcillo, P. (1993). La Dirección Eficiente. Ediciones Pirámides, S.A. Madrid. Segunda Edición.

[46] Piattini, M., Calvo Manzano, J., Cervera, J., Fernández, L. (1996). Análisis y Diseño Detallado de Aplicaciones Informáticas de Gestión. Editorial Ra-Ma.

[47] Pressman, R. (1993). Ingeniería del Software. Un Enfoque Práctico. Editorial McGraw-Hill.

[48] TenStep, Inc. (2002). Proceso de Administración de Proyectos. http://www.tenstep1.com.mx. Página web vigente a mayo de 2002.
[49] Goldratt, E. M. (1994). La Meta. Tercera Edición. Editorial Castillo. México.

[50] Pressman, R. (2004). Software Engineering: A Practitioner's Approach. Editorial McGraw-Hill.

[51] Pytel, P. (2011). Método de Estimación de Esfuerzo para Proyectos de Explotación de Información. Herramienta Para $\mathrm{Su}$ Validación. Tesis de Magister en Ingeniería del Software. Convenio Universidad Politécnica de Madrid e Instituto Tecnológico Buenos Aires.

[52] Hossian, A. (2012). Modelo de Proceso de Conceptualización de Requisitos. Tesis Doctoral. Tesis Doctoral. Universidad Nacional de La Plata, Facultad de Informática. La Plata, Argentina.

[53] Florez, D., Gallo, G. (2008). Modelo Estándar de Control Interno - MECI. Boletín Nro. 4.

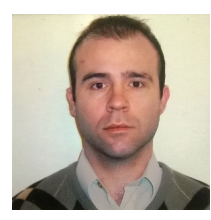

Federico Carlos Peralta. Es Candidato del Programa de Maestría en Ingeniería de Sistemas de Información por la Universidad Tecnológica Nacional (FRBA). Su investigación se centra en el "Proceso de Conceptualización del Entendimiento del Negocio para Proyectos de Explotación de Información". Es Investigador Tesista del Laboratorio de Investigación y Desarrollo en Ingeniería de Explotación de Información del Grupo de Investigación en Sistemas de Información de la Universidad Nacional de Lanús y del Laboratorio de Investigación y Desarrollo en Tecnologías de Computación Gráfica y Arte Digital de la Universidad Nacional de Río Negro. Sus áreas de interés son: Explotación de Información, Inteligencia de Negocios e Infraestructura IT. 